\title{
Experimental Measurements and Modeling of Tilting-Pad Bearing Performance and System Stability Under Reduced Oil Supply Flow Rates
}

\author{
A Dissertation \\ Presented to \\ the faculty of the School of Engineering and Applied Science \\ University of Virginia
}

In partial fulfillment

of the requirements for the degree

Doctor of Philosophy

by

Bradley Ray Nichols

December 2017 


\title{
APPROVAL SHEET
}

\author{
This Dissertation \\ is submitted in partial fulfillment of the requirements \\ for the degree of \\ Doctor of Philosophy
}

Bradley Ray Nichols

This Dissertation has been read and approved by the examining committee

Christopher P. Goyne (Advisor)

Houston G. Wood (Chairman)

\begin{tabular}{l}
\hline Roger L. Fittro \\
\hline Andres F. Clarens \\
\hline
\end{tabular}

Daniel B. Quinn

Accepted for the School of Engineering and Applied Science:

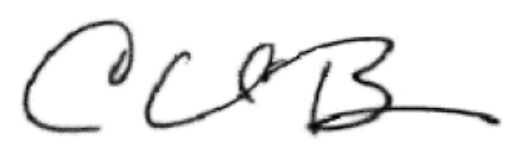

Craig H. Benson, School of Engineering and Applied Science

December 2017 


\begin{abstract}
Rotor instability is an ever present problem in the turbomachinery industry that continuously grows more important as the limits of operating speeds and pressures are pushed increasingly higher in industrial machines. Many of these high-speed, rotating machines depend on fluid-film, tilting-pad bearings to introduce stabilizing damping forces into the system through the development of a hydrodynamic film wedge. Tilting-pad bearings rely on a constant flow of fresh oil to keep bearing temperatures low while providing sufficient oil to support the shaft. Reduced oil supply flow rates in fluid-film bearings can cause cavitation, or lack of a fully-developed film layer, over one or more of the pads due to flow starvation. Partial bearing starvation has the well-documented effect of reduced power losses at the expense of increased operating temperatures. Minimizing the required oil supply flow rate provided to the bearings while safely supporting the rotor can lead to significant decreases in bearing power loss and is of great interest to the turbomachinery industry. While its effects on power loss and temperature are well known, few studies have been published which focus on the effects of oil supply flow rate on dynamic bearing performance and system stability.

A series of studies are conducted to provide a comprehensive look at the effects of oil supply flow rate on tilting-pad bearing performance through both experimental measurements and theoretical bearing model predictions. All measurements are performed on a test rig consisting of a flexible rotor supported by two tilting-pad bearings in flooded housing designs. The test rig is dynamically similar to modern, industrial machines with a high critical speed ratio and mode shapes analogous to those of a between-bearing machine. Experimental tests are performed under a number of operating speed and load conditions while systematically reducing the oil supply flow rate provided to the bearings. Steadystate bearing performance measures and subsynchronous vibration patterns are recorded for various operating conditions. Sine sweep perturbations of the rotor are performed via magnetic actuator under varying oil supply flow rates. The vibrational response is then used in a single-input, multiple-output (SIMO) system identification technique to obtain system frequency response functions (FRFs) and, in turn, modal parameters, specifically damped natural frequencies and damping ratios. The identified damping ratio provides a direct measure of system stability under varying speeds, loads, and oil supply flow rates.

All experimental results are compared to predicted results obtained from bearing models based on thermoelastohydrodynamic (TEHD) lubrication theory. These models include an oil flow starvation model meant to predict pad cavitation due to starvation in low oil flow conditions. For the conditions tested, the starvation model predicts partial pad cavitation of unloaded bearing pads under
\end{abstract}


lightly loaded conditions that increases in severity with increasing speed and decreasing oil supply flow rate. This progressive decrease in film development correlates to higher journal operating positions, increased subsynchronous vibrations, and decreased system stability observed in the experimental data. This correlation suggests that the starved model relatively accurately predicts film cavitation and bearing stiffness under reduced oil flow conditions; however, higher predicted damping ratios indicate that the bearing models over predict bearing damping. These studies provide a detailed report on the effects of oil supply flow rate on system stability and help highlight improvements that can be made to the current theoretical models. 
For my Family,

In memory of my mom, Susan Nichols. 


\section{Acknowledgements}

After nearly a decade of graduate school, I have quite the long list of people to thank, all of whom helped make this dissertation possible. I would first like to thank my long list of academic advisors. I would have never pursued an advanced degree if it hadn't been for the encouragement of Pradip Sheth. You were incredibly kind, cared greatly about your students, and saw potential in me. You are greatly missed. My sincerest thanks to Paul Allaire and Tim Dimond for serving as my academic advisors and moving on to become great colleagues and friends. Many thanks to Chris Goyne and Roger Fittro for also serving as academic advisors and ensuring that I carried this thing through to completion after moving on from the lab. Thank you to Hunter Cloud and Minhui He for their background knowledge of the test rig and software code used in this study. Thank you to all those serving on my committee and to all of the ROMAC companies who have helped fund this work.

There are many more people to thank around the Mechanical and Aerospace Department. Thanks so much to Lewis Steva and Kevin Knight in the MAE machine shop for all of the fabrication help and for lending me any tool I needed. Thanks to Karen Marshall, Lori Pedersen, and Brenda Perkins for making sure I somewhat stayed on track to graduate. Thanks to the many, many great graduate students and research scientists that shared their knowledge with me over these past nine years. The following were particularly instrumental to my graduate school experience- Pablo Yoon, Wei Jiang, Amir Younan, Jawad Chaudhry, Feng He, Jianming Cao, Simon Mushi, Matt Wagner, Jason Kaplan, Saeid Dousti, Ali Gerami, Parinya Anantachaisilp, Di Long, Michael Branagan, Zack Whitlow, Brian Weaver, Day Griffin, and Benny Schwartz. If I've left you out, please forgive me. You all were much appreciated.

I would never be where I am today if it were not for the love and support of my family. Thank you Dad and Sandra for always believing in me and for always being there for whatever I needed. Thank you to all of my aunts and uncles, Byron, Sheldon, Kathy, and Keith for treating me like a son. I'm thankful for the friendship of my cousins Brian and Wes who have acted as the brothers I never had. Thank you to my New York family, Michael, Jeanine, Jacqui, Amanda, Gram, and Grampy. You have taken me in as one of your own and I couldn't have done this without you. Finally, thank you to my best friend and love of my life, Allison. You have been by my side every step of the way and provided me with the constant love and support necessary to complete this arduous task. This work was completed in the loving memory of Paul Parsonage, Ray Nichols, and Susan Nichols who undoubtedly helped shape the person I am today and will forever be deeply missed. 


\section{Contents}

$\begin{array}{ll}\text { Abstract } & \text { iii }\end{array}$

$\begin{array}{ll}\text { Dedication } & \mathbf{v}\end{array}$

Acknowledgements vi vi vis

\begin{tabular}{ll} 
List of Figures & $\mathbf{x}$ \\
\hline
\end{tabular}

List of Tables $\quad$ Xv

1. Introduction and Motivation $\quad \mathbf{1}$

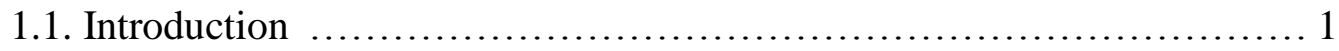

1.2. Objectives .................................................. 2

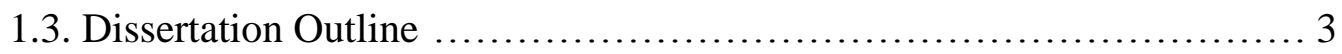

2. Steady-State Tilting-Pad Bearing Performance under Reduced Oil Supply

Flow Rates $\quad 4$

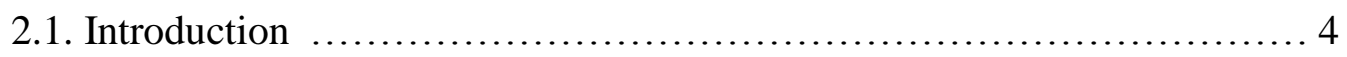

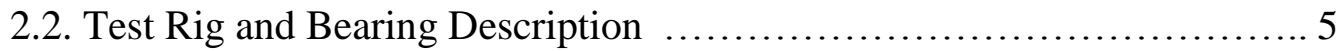

2.3. Experimental Methods .......................................... 6

2.4. Theoretical Modeling Methods .................................... 7

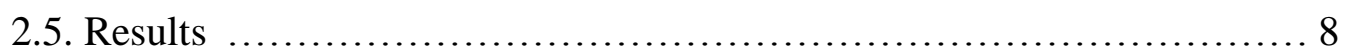

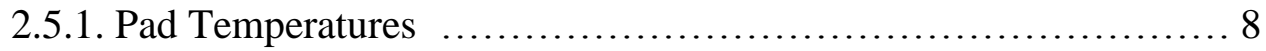

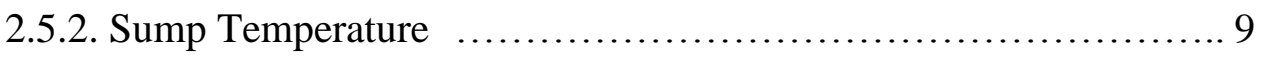

2.5.3. Steady-state Vertical Operating Position ........................10

2.5.4. Motor Input Power ........................................... 10

2.6. Discussion......................................................... 11

2.6.1. Pad Temperatures ..........................................11

2.6.2. Steady-state Vertical Operating Position ........................ 12

2.7. Conclusions ................................................ 13 


\section{Subsynchronous Vibration Patterns under Reduced Oil Supply Flow Rates}

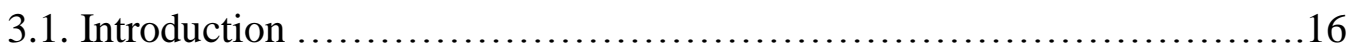

3.2. Test Rig Description .............................................. 17

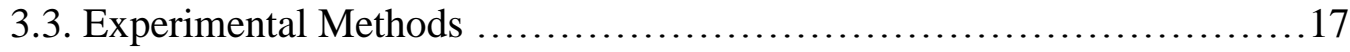

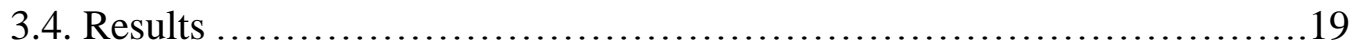

3.4.1. Ramp-up Waterfall Plot ........................................ 19

3.4.2. Subsynchronous Vibration vs. Running Speed ......................19

3.4.3. Subsynchronous Vibration vs. Oil Supply Flow Rate ................20

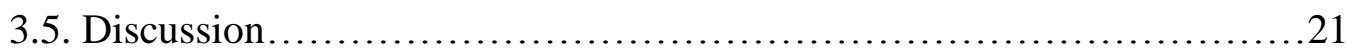

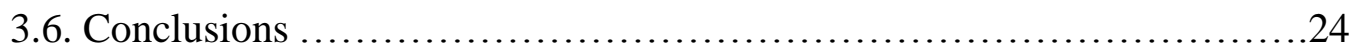

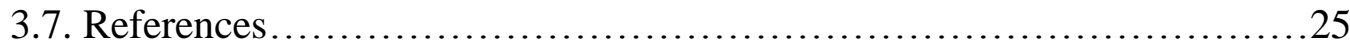

\section{Rotor Damped Natural Frequencies and Stability under Reduced Oil} Supply Flow Rates $\quad 26$

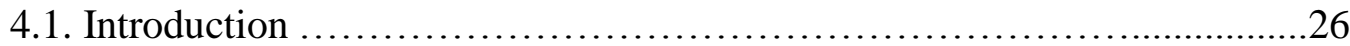

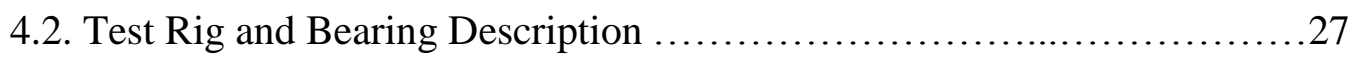

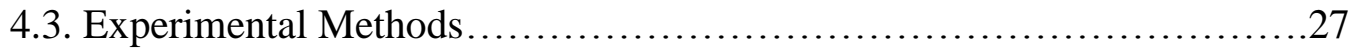

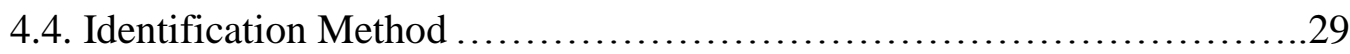

4.5. Theoretical Modeling Methods ............................................ 30

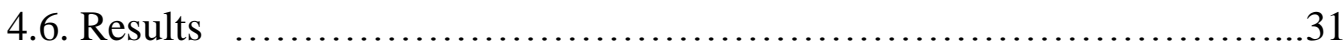

4.6.1. Damped Natural Frequency and Damping Ratio vs. Running Speed

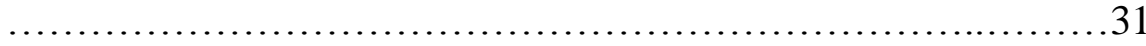

4.6.2. Effect of Bearing Load on System Dynamics .......................32

4.6.3. Effect of Oil Supply Flow Rate on System Dynamics ................33

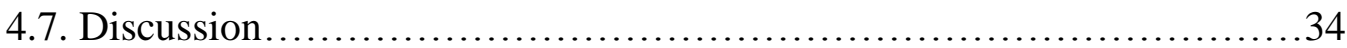

4.7.1. Damped Natural Frequency and Damping Ratio vs. Running Speed

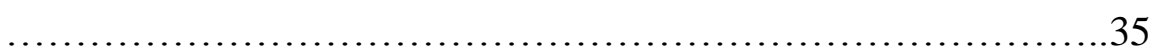

4.7.2. Effect of Bearing Load on System Dynamics ........................35

4.7.3. Effect of Oil Supply Flow Rate on System Dynamics ...............36

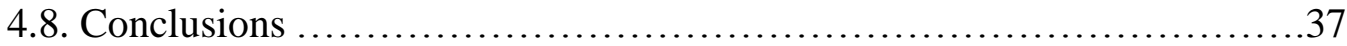

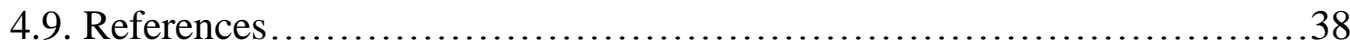

5. Conclusion $\quad 40$

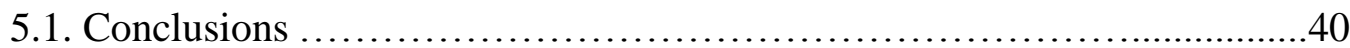

5.2. Recommended TEHD Modeling Guidelines.............................41

5.3. Contributions to the Field of Turbomachinery.......................... 42

5.4. Future Work....................................................... 42 


\section{Appendix A: Supplementary Temperatures and Vertical Shaft Operating}

Positions under Increased Load for Chapter 2

A.1. Pad Temperatures under High Load Condition, $365 \mathrm{kPa} \ldots \ldots \ldots \ldots \ldots \ldots \ldots \ldots \ldots \ldots . . . .43$

A.2. Sump Temperatures under High Load Condition, $365 \mathrm{kPa} \ldots \ldots \ldots \ldots \ldots . . . .44$

A.3. Steady-State Vertical Operating Position, $365 \mathrm{kPa} . . . \ldots \ldots \ldots \ldots \ldots \ldots \ldots . . . . . . . . . . .44$

Appendix B: Supplementary Vibration Spectra and Predicted Pressure Profiles Pertaining to Chapter $3 \quad 45$

B.1. Low Load, $124 \mathrm{kPa}$, Vibration Spectra.........................................45

B.2. Mid Load, $241 \mathrm{kPa}$, Vibration Spectra ................................46

B.3. High Load, $365 \mathrm{kPa}$, Vibration Spectra ............................. 47

B.4. Low Load, 124 kPa, Starved Model Predicted Pressure Profiles............ 48

B.5. Mid Load, $241 \mathrm{kPa}$, Starved Model Predicted Pressure Profiles............. 48

B.6. High Load, 365 kPa, Starved Model Predicted Pressure Profiles.......... 49

B.7. Pre-averaged Frequency Response vs. Speed.............................50

\section{Appendix C: Supplementary Predicted Dynamic Coefficients and Detailed} System Identification Example for Chapter 4

C.1. Predicted Synchronously Reduced Horizontal Dynamic Coefficients.......51

C.2. Graphical Representation of System Identification Procedure...............52

C.3. Identified damping ratios vs oil supply flow rate, $124 \mathrm{kPa}$, high speed....55

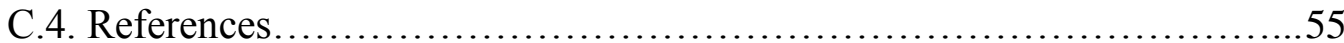




\section{List of Figures}

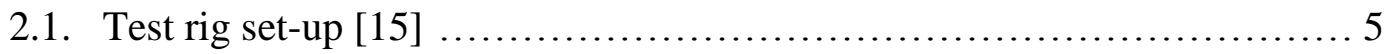

2.2. Test bearing in flooded, pressurized housing [15] .................... 5

2.3. Flooded, pressurized housing oil flow path feautures $[11] \ldots \ldots \ldots \ldots \ldots \ldots 6$

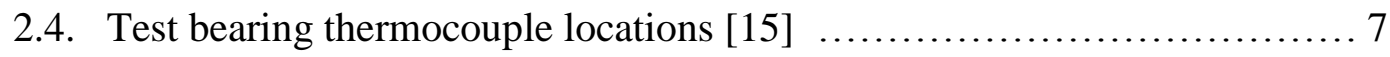

2.5. Groove mixing and hot-oil carryover concepts $[11] \ldots \ldots \ldots \ldots \ldots \ldots \ldots . \ldots$

2.6. TC 5L measured and predicted temperatures ........................ 9

2.7. TC 5T measured and predicted temperatures ......................... 9

2.8. TC 4T measured and predicted temperatures ........................ 9

2.9. TC $1 \mathrm{~L}$ measured and predicted temperatures ........................... 9

2.10. Measured and predicted sump temperatures .......................... 10

2.11. Measured and predicted vertical operating positions ( $2000 \mathrm{rpm}, 0.3$

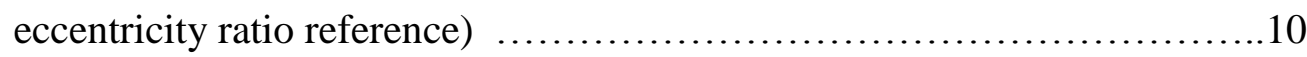

2.12. Percentage power change with oil supply flow rate $\ldots \ldots \ldots \ldots \ldots \ldots \ldots \ldots \ldots 11$

2.13. Predicted pressure profiles vs. speed, nominal flow rate, flooded model (710

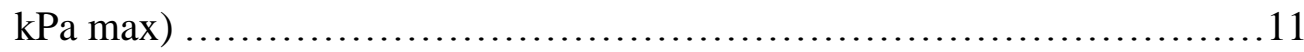

2.14. Predicted pressure profiles vs. speed, nominal flow rate, starved model (581

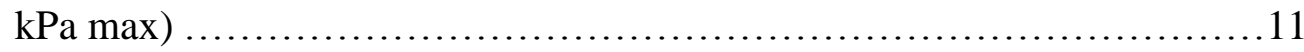

2.15. TC 4T hot-oil carryover sensitivity (flooded model, $3.79 \mathrm{lpm}$ ) .............12

2.16. Predicted pressure profiles vs. flow rate, 10,000 rpm, flooded model (696

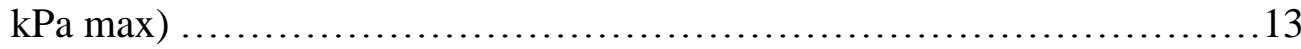

2.17. Predicted pressure profiles vs. flow rate, $10,000 \mathrm{rpm}$, starved model (627

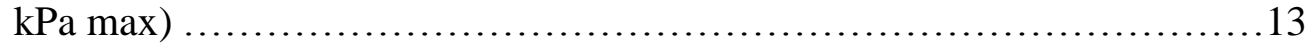

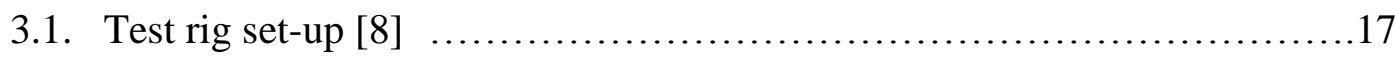

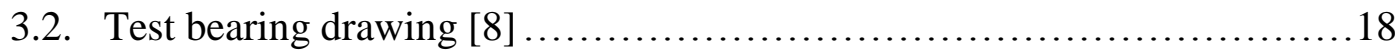

3.3. Ramp-up waterfall plot 1,000-12,000 rpm, nominal flow rate, low load .....19

3.4. Frequency response vs. running speed $0-200 \mathrm{~Hz}$, nominal flow rate, low

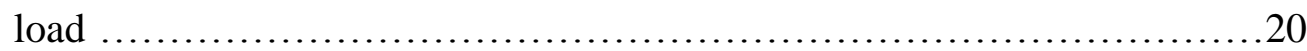

3.5. Frequency response vs. running speed $0-100 \mathrm{~Hz}$, nominal flow rate, low

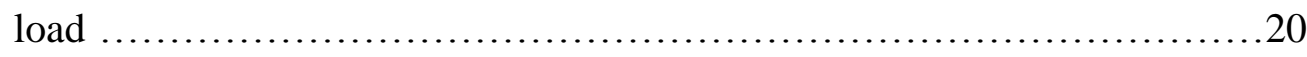


3.6. Frequency response vs. running speed 0-200 Hz, nominal flow rate, high load

3.7. Maximum subsynchronous vibration displacement vs. speed, nominal flow rate

3.8. Frequency response vs. oil supply flow rate $0-200 \mathrm{~Hz}, 9,000 \mathrm{rpm}$, low load ............................................................21

3.9. Frequency response vs. oil supply flow rate $0-200 \mathrm{~Hz}, 11,000 \mathrm{rpm}$, low load

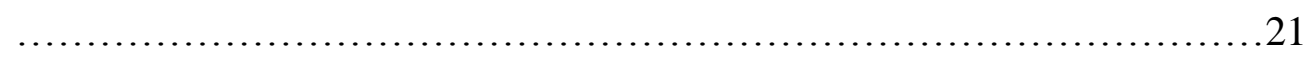

3.10. Maximum subsynchronous vibration displacement vs. flow rate, low load .........................................................22

3.11. Maximum subsynchronous vibration displacement vs. flow rate, medium load .22

3.12. Frequency response vs. oil supply flow rate $0-200 \mathrm{~Hz}, 11,000 \mathrm{rpm}$, high

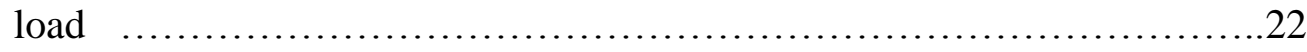

3.13. Maximum subsynchronous vibration displacement vs. flow rate, high load .22

3.14. Predicted pressure profiles vs. speed, nominal flow rate, low load (581 kPa $\max )$

3.15. Predicted pressure profiles vs. flow rate, $11,000 \mathrm{rpm}$, low load $(627 \mathrm{kPa}$ $\max )$

3.16. Predicted pressure profiles vs. speed, nominal flow rate, high load $(1,089$

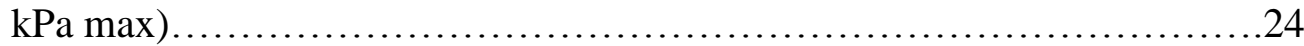

3.17. Predicted pressure profiles vs. flow rate, $11,000 \mathrm{rpm}$, high load $(1,034 \mathrm{kPa}$

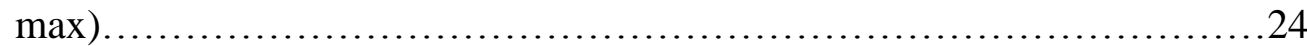

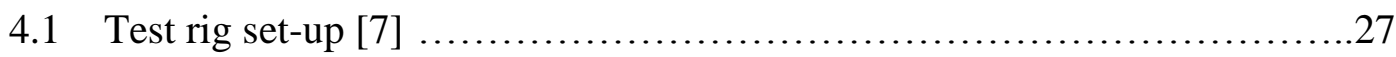

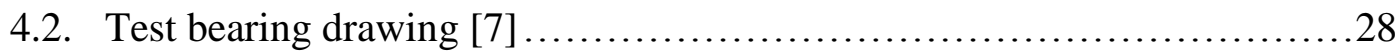

4.3. Flooded, pressurized housing oil flow path features $[8] \ldots \ldots \ldots \ldots \ldots \ldots .28$

4.4. Damped natural frequency vs. speed, $124 \mathrm{kPa}$ specific load ................ 31

4.5. Damping ratio vs. speed, $124 \mathrm{kPa}$, specific load ............................ 31

4.6. Identified frequency response functions vs. speed, forward mode

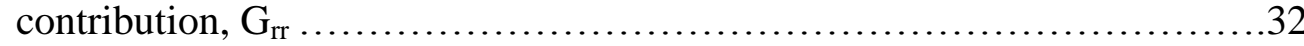

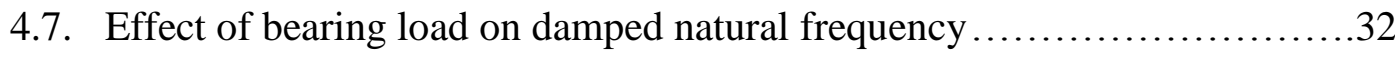

4.8. Effect of bearing load on damping ratio ............................. 32

4.9. Effect of oil supply flow rate on damping ratio, $124 \mathrm{kPa}$ specific load ......33

4.10. Effect of oil supply flow rate on damping ratio, $365 \mathrm{kPa}$ specific load ......33

4.11. Vertical stiffness and damping coefficients, $124 \mathrm{kPa}$ specific load, $100 \%$ flow rate...........................................................

4.12. Pressure profiles vs. operating speed, $124 \mathrm{kPa}$ specific load, $100 \%$ flow rate

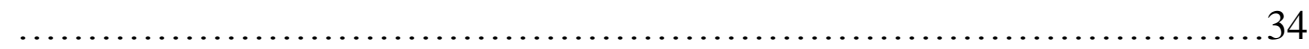

4.13. Vertical stiffness coefficients vs. load, $100 \%$ flow rate .................... 35 
4.14. Vertical damping coefficients vs. load, $100 \%$ flow rate ................... 35

4.15. Pressure profiles vs. bearing load, $12,000 \mathrm{rpm}, 100 \%$ flow rate .............36

4.16. Vertical stiffness coefficients vs. oil supply flow rate, $124 \mathrm{kPa}$ specific load

4.17. Vertical damping coefficients vs. oil supply flow rate, $124 \mathrm{kPs}$ specific load ........................................................ 36

4.18. Pressure profiles vs. oil supply flow rate, $10,000 \mathrm{rpm}, 124 \mathrm{kPa}$ specific load

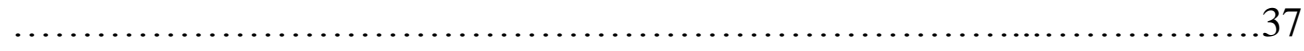

4.19. Pressure profiles vs. oil supply flow rate, $10,000 \mathrm{rpm}, 365 \mathrm{kPa}$ specific load ............................................................ 37

A.1. TC 5L measured and predicted temperatures, $365 \mathrm{kPa} \ldots \ldots \ldots \ldots \ldots \ldots . . \ldots 43$

A.2. TC 5T measured and predicted temperatures, $365 \mathrm{kPa} \ldots \ldots \ldots \ldots \ldots \ldots . . \ldots 43$

A.3. TC 4T measured and predicted temperatures, $365 \mathrm{kPa} \ldots \ldots \ldots \ldots \ldots \ldots . . . \ldots 43$

A.4. TC 1L measured and predicted temperatures, $365 \mathrm{kPa} . \ldots \ldots \ldots \ldots \ldots \ldots . . \ldots 44$

A.5. Measured and predicted sump temperatures, $365 \mathrm{kPa} . \ldots \ldots \ldots \ldots \ldots \ldots . . . . . .44$

A.6. Predicted vertical operating position, $365 \mathrm{kPa}$ (2000 rpm, 0.55 eccentricity ratio reference...................................................44

B.1. Frequency response vs. oil supply flow rate $0-200 \mathrm{~Hz}, 8,000 \mathrm{rpm}$, low

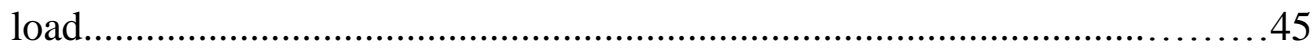

B.2. Frequency response vs. oil supply flow rate $0-200 \mathrm{~Hz}, 10,000 \mathrm{rpm}$, low

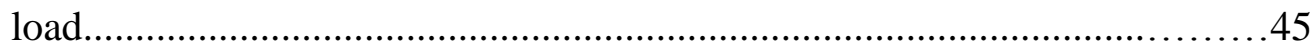

B.3. Frequency response vs. oil supply flow rate $0-200 \mathrm{~Hz}, 12,000 \mathrm{rpm}$, low

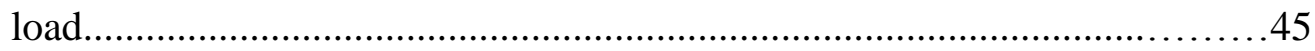

B.4. Frequency response vs. running speed $0-200 \mathrm{~Hz}$, nominal flow rate, mid

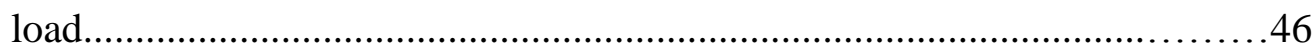

B.5. Frequency response vs. oil supply flow rate $0-200 \mathrm{~Hz}, 8,000 \mathrm{rpm}$, mid

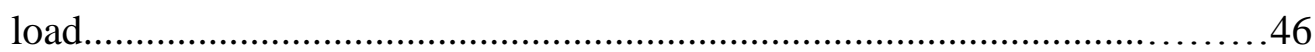

B.6. Frequency response vs. oil supply flow rate $0-200 \mathrm{~Hz}, 9,000 \mathrm{rpm}$, mid

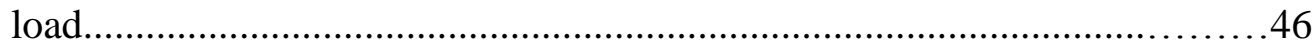

B.7. Frequency response vs. oil supply flow rate $0-200 \mathrm{~Hz}, 10,000 \mathrm{rpm}$, mid

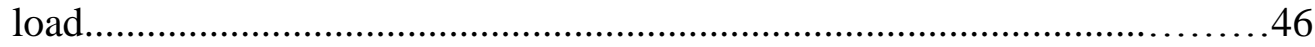

B.8. Frequency response vs. oil supply flow rate $0-200 \mathrm{~Hz}, 11,000 \mathrm{rpm}$, mid

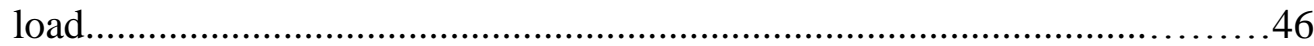

B.9. Frequency response vs. oil supply flow rate $0-200 \mathrm{~Hz}, 12,000 \mathrm{rpm}$, mid

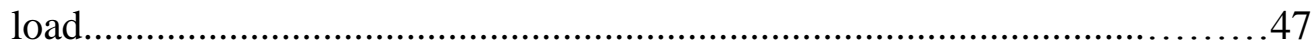

B.10. Frequency response vs. oil supply flow rate $0-200 \mathrm{~Hz}, 8,000 \mathrm{rpm}$, high

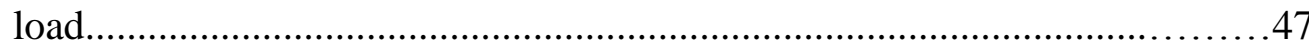

B.11. Frequency response vs. oil supply flow rate $0-200 \mathrm{~Hz}, 9,000 \mathrm{rpm}$, high load. 
B.12. Frequency response vs. oil supply flow rate $0-200 \mathrm{~Hz}, 10,000 \mathrm{rpm}$, high load.

B.13. Predicted pressure profiles vs. flow rate, $8,000 \mathrm{rpm}$, low load (581 kPa max)

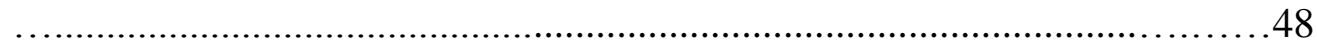

B.14. Predicted pressure profiles vs. flow rate, 9,000 rpm, low load (557 kPa max)

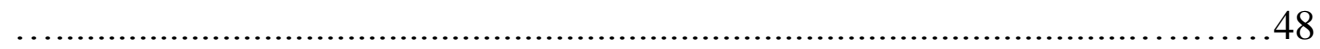

B.15. Predicted pressure profiles vs. flow rate, 10,000 rpm, low load (543 kPa $\max )$ 48

B.16. Predicted pressure profiles vs. flow rate, $12,000 \mathrm{rpm}$, low load $(717 \mathrm{kPa}$ $\max )$ .48

B.17. Predicted pressure profiles vs. flow rate, 8,000 rpm, mid load (917 kPa max)

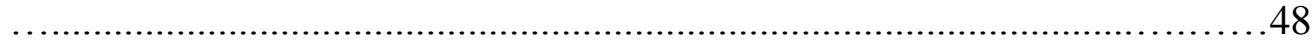

B.18. Predicted pressure profiles vs. flow rate, 9,000 rpm, mid load (876 kPa max) . .48

B.19. Predicted pressure profiles vs. flow rate, 10,000 rpm, mid load (841 kPa $\max )$

B.20. Predicted pressure profiles vs. flow rate, $11,000 \mathrm{rpm}$, mid load $(827 \mathrm{kPa}$ $\max )$

B.21. Predicted pressure profiles vs. flow rate, $12,000 \mathrm{rpm}$, mid load (876 kPa $\max )$

B.22. Predicted pressure profiles vs. flow rate, $8,000 \mathrm{rpm}$, high load $(1,089 \mathrm{kPa}$ $\max )$

B.23. Predicted pressure profiles vs. flow rate, 9,000 rpm, high load $(1,041 \mathrm{kPa}$ $\max )$

B.24. Predicted pressure profiles vs. flow rate, $10,000 \mathrm{rpm}$, high load $(1,041 \mathrm{kPa}$ $\max )$

B.25. Pre-averaged frequency response vs. running speed $0-200 \mathrm{~Hz}$, nominal flow rate, low load............................................................................50

B.26. Pre-averaged frequency response vs. running speed $0-50 \mathrm{~Hz}$, nominal flow rate, low load...........................................................................50

C.1. Horizontal stiffness and damping coefficients, $124 \mathrm{kPa}$ specific load, $100 \%$

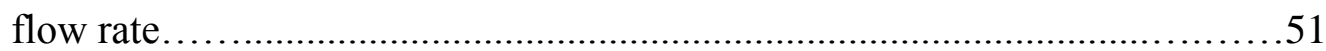

C.2. Horizontal stiffness coefficients vs. load, $100 \%$ flow rate..........................51

C.3. Horizontal damping coefficients vs. load, $100 \%$ flow rate.............................51

C.4. Horizontal stiffness coefficients vs. oil supply flow rate, $124 \mathrm{kPa}$ specific load....................................................................52

C.5. Horizontal damping coefficients vs. oil supply flow rate, $124 \mathrm{kPa}$ specific

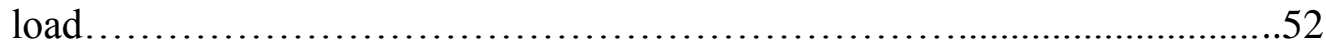

C.6. Horizontal stiffness coefficients vs. oil supply flow rate, $365 \mathrm{kPa}$ specific

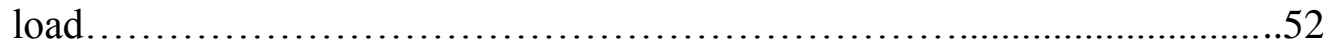


C.7. Horizontal damping coefficients vs. oil supply flow rate, $365 \mathrm{kPa}$ specific

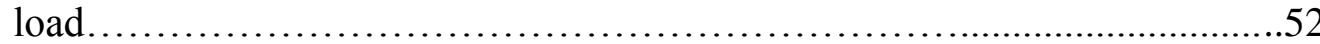

C.8. Time domain applied force raw data, $\mathrm{x}$-direction, $60 \mathrm{~Hz} \ldots \ldots \ldots \ldots \ldots \ldots \ldots \ldots \ldots \ldots \ldots . . .52$

C.9. Time domain response raw data in both directions......................................53

C.10. Averaged frequency domain spectrum of applied force, $\mathrm{x}$-direction, $60 \mathrm{~Hz} . . .53$

C.11. Averaged frequency domain spectra of shaft response.................................53

C.12. Experimentally obtained frequency response function component

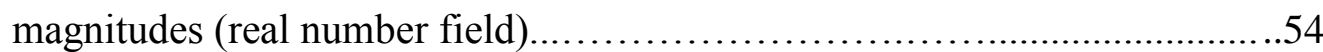

C.13. Experimentally obtained frequency response function component phases

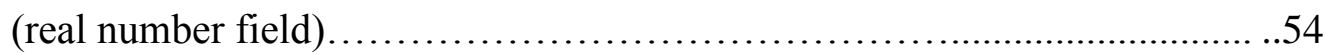

C.14.Coherence functions for frequency response function components..................54

C.15. Experimentally obtained frequency response function component magnitudes (complex number field)...............................................55

C.16. Data vs. curve fit of frequency response function component magnitudes

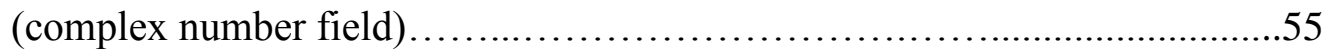

C.17. Measured damping ratio vs oil supply flow rate with error bars, $124 \mathrm{kPa}$

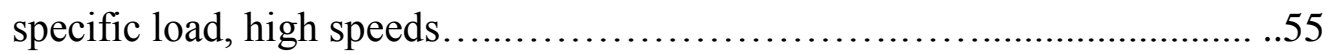




\section{List of Tables}

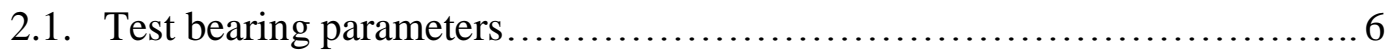

2.2. Oil supply flow rate test matrix (\% of nominal flow rate, $3.79 \mathrm{lpm}) \ldots \ldots \ldots .7$

2.3. Measurement uncertainties........................................ 7

2.4. Modeled ISO VG 32 properties.................................. 8

2.5. Modeled thermal bearing material properties......................... 8

3.1. Test bearing parameters.......................................... 18

3.2. Oil supply flow rate test matrix (\% of nominal flow rate, $3.79 \mathrm{lpm}) \ldots \ldots \ldots .18$

3.3. Operating condition and measurement uncertainties ......................19

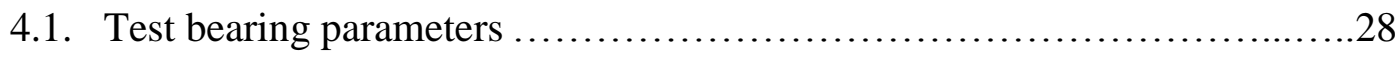

4.2. Oil supply flow rate test matrix (\% of nominal flow rate, $3.79 \mathrm{lpm}$ ) .......29

4.3. Operating conditions and measurement uncertainties.....................29 


\section{CHAPTER 1: INTRODUCTION AND MOTIVATION}

\subsection{INTRODUCTION}

Rotor instability is an ever present problem in the turbomachinery industry that continuously grows more important as the limits of operating speeds and loads are pushed increasingly higher in industrial machines. Many of these high-speed, rotating machines depend on fluid-film, tilting-pad bearings to introduce stabilizing damping forces into the system through the development of a hydrodynamic film wedge. These damping forces are necessary to counteract destabilizing, cross-coupled forces that act to promote the shaft's orbital procession, or whirling motion, most often in the direction of shaft rotation. As speeds and loads increase, these forces become larger, and greater care must be taken to ensure machine stability. Oil whirl and shaft whip are two common self-excited bearing instability phenomena. Oil whirl is characterized by subsynchronous vibration that tracks the running speed at a frequency ratio of approximately $0.5 \mathrm{X}$ during subcritical operation. It is most commonly experienced in lightly loaded, fixed geometry bearings where the shaft eccentricity is nearly centered. Tilting-pad bearing were invented, in large part, to attenuate the underlying causes of oil whirl. Shaft whip occurs when any destabilizing mechanisms in the system are greater than the bearing damping forces. It is characterized by subsynchronous vibration at the first forward damped natural frequency of the shaft and typically occurs in the approximately $0.45-0.55 \mathrm{x}$ running speed range during supercritical operation. During any system instability, the shaft whirl grows without bound until a non-linear limit cycle is met, potentially resulting in machine damage or failure. It is imperative that the supporting bearings provide enough damping to avoid such conditions. Engineers rely heavily on both experimental data and theoretical modeling of bearings to predict bearing performance and system stability.

Tilting-pad bearings depend on a constant flow of fresh oil to keep bearing temperatures low while providing sufficient oil to support the shaft. Traditionally, oil is supplied at an adequate flow rate to flood the bearing pads, producing a fullydeveloped hydrodynamic film layer over all pad surfaces. Reduction of the oil supply flow rate can cause cavitation, or lack of a fully-developed film layer, over one or more of the pads. This condition is commonly referred to as starved. Cavitation due to starvation typically begins at the leading edges of more lightly loaded pads and progresses in nature with increased starvation. In cavitated pad regions, some oil is pulled along the surface of the shaft, mixing with air and entering the pad in the form of two-phase streamlets. In the case of partially starved pads, a full film eventually develops at some circumferential location along the pad, effectively reducing the acting arc length of the pad. The extent of bearing starvation is highly dependent on a number of factors including the oil delivery method, bearing housing design, oil supply flow rate, operating speed, and bearing load. Partial bearing starvation has the well-documented effect of reduced operational power losses at the expense of increased bearing temperatures. Minimizing the required oil supply flow rate to safely support the rotor can lead to significant decreases in bearing power loss and is of great interest to the turbomachinery industry. While its effects on power loss and 
temperature are widely known, few studies have been published which focus on the effects of oil supply flow rate on dynamic bearing performance or system stability.

A series of studies are presented here that provide a thorough look at the effects of oil supply flow rate on tiltingpad bearing performance through both experimental measurements and theoretical modeling predictions. All experimental measurements are obtained from a test rig consisting of a flexible shaft supported by two tilting-pad bearings in traditional, flooded bearing housings with oil supply nozzles. The test rig design is dynamically similar to modern, industrial rotating machines with a high critical speed ratio and mode shapes analogous to those of a between-bearing machine. Under a number of operating speeds and bearing load conditions, the oil supply flow rate to the two supporting bearings is systematically reduced while collecting both steady-state and dynamic bearing performance data. Steadystate bearing performance measures are first investigated by measuring pad Babbitt temperatures, sump temperature, journal operating position, and power loss. Next, the effects of oil supply flow rate on the subsynchronous vibration signatures of the rotor are explored. Finally, system modal properties, specifically damped natural frequency and damping ratio, are obtained through shaft perturbations and system identification procedures to determine the effects of oil supply flow on system stability.

All experimental results are compared to the theoretical predictions of sophisticated bearing models based on modern thermoelastohydrodynamic (TEHD) lubrication theory. The algorithm behind these models uses numerical methods to solve finite element formulations of the 2D Reynolds and 2D energy equations for the pad pressure and temperature fields, respectively. Pad and pivot mechanical deformations, as well as pad, shaft, and shell thermal deformations are also included. All models contain advanced turbulence and groove mixing models as well as an oil flow starvation model meant to more accurately capture bearing dynamics and performance under low oil supply flow rate conditions. Both fully-flooded and starved oil flow assumptions are considered in this study. While the flooded model assumes sufficient flow for full film development over all pads, the starved model predicts partial or full pad cavitation due to starvation by comparing a prescribed oil supply flow rate to flow rates derived from the calculated pad pressure fields. Full dynamic coefficients explicitly including pad degrees of freedom are calculated by the models and added to a 2D beam-element rotordynamic shaft model to obtain predicted damped natural frequencies and damping ratios. Predictions from both models are compared to the experimental data in an effort to validate the starvation model under reduced flow rate conditions. Understanding how the oil flow assumptions ultimately affect damping ratio predictions under various operating conditions is paramount for obtaining the most accurate estimations of system stability.

\subsection{OBJECTIVES}

The extensive investigation of the effects of oil supply flow rate on tilting-pad bearing performance presented in this work is motivated by the following primary objectives.

- Conduct the first study of its kind that looks at the effects of oil supply flow rate on dynamic tilting-pad bearing performance and system stability through both measured experimental data and theoretical modeling predictions under systematically reduced flow rates for a number of operating speeds and bearing load conditions.

- Compare theoretical predictions from both flooded and starved oil flow TEHD bearing models to experimental data to help validate the starved oil flow model under reduced flow rate conditions.

- Provide insight into which bearing model most accurately predicts bearing performance under various operating conditions and recommend guidelines for using these models to ultimately predict system stability.

- Add to the limited body of available data currently found in the literature pertaining to tilting-pad bearing performance, specifically dynamic performance, under reduced oil supply flow rate conditions by systematically reducing flow rates under a number of speed and load conditions.

The most meaningful and interesting results of these investigations are presented in the form of three distinct studies- each of which helps complete the above objectives by focusing on a unique set of specific research questions. These studies, along with the research questions they address, are as follows:

\section{Study 1: Steady-state tilting-pad bearing performance under reduced oil supply flow rate conditions}

- What effects do oil supply flow rate have on steady-state bearing performance measures, specifically pad temperature, sump temperature, journal operating position, and power loss?

- Does the starved bearing flow model produce more accurate predictions of steady-state bearing performance than the flooded bearing flow model under reduced oil supply flow rate conditions? 


\section{Study 2: Subsynchronous vibration patterns under reduced oil supply flow rates}

- What effects do oil supply flow rate have on subsynchronous vibration patterns under various operating speeds and bearing load conditions?

- Can the starved bearing model be used to predict the onset of subsynchronous vibrations due to a decrease in system damping ratio caused by pad cavitation?

\section{Study 3: Rotor damped natural frequency and stability under reduced bearing oil supply flow rates}

- What effects do reduced oil supply flow rates have on system modal properties, specifically damped natural frequency and damping ratio, under various operating speeds and bearing load conditions?

- Can reduced oil supply flow rates be implemented under any operating conditions to reduce operational power losses while maintaining safe machine operation?

- Does the starved bearing flow model produce more accurate predictions of system damped natural frequency and damping ratio than the flooded bearing flow model under various speed, load, and oil supply flow rate conditions?

\subsection{DISSERTATION OUTLINE}

The motivation, objectives, and research questions of this dissertation have been presented here in Chapter 1. Chapters 2 4 each present one of the individual studies outlined above. Each of these chapters generally contains the following subsections- Introduction, Test Rig Description, Experimental Methods, Theoretical Modeling Methods, Results, Discussion, and Conclusions. Previous literature pertaining to each study is presented in that chapter's introduction. Chapter 2, which focuses on steady-state bearing performance measures, provides the most comprehensive description of the theoretical bearing models. Chapter 4 , which focuses on system damped natural frequency and damping ratio, provides a detailed explanation of the system identification technique used to obtain experimental modal properties. Chapters 2-4 present all of the results and discussions of those results comprised in this dissertation. Each of these chapters includes its own list of references. Chapter 5 provides a comprehensive list of conclusions that revisits the objectives and research questions of the dissertation and highlights the importance of this work to the turbomachinery industry. This chapter also outlines recommended TEHD modeling guidelines for reduced oil supply flow rate conditions, key contributions of this work to the turbomachinery field, and suggested future work. Appendices A, B, and C provide supplementary experimental data and theoretical predictions obtained and considered during this work but not explicitly presented in Chapters 2 through 4 . 


\section{CHAPTER 2: STEADY-STATE TILTING-PAD BEARING PERFORMANCE UNDER REDUCED OIL SUPPLY FLOW RATES}

\subsection{INTRODUCTION}

High-speed rotating machines such as pumps, compressors, and turbines are used in a wide variety of industries to transfer energy between a rotating shaft and its surrounding fluid. The dynamic interactions between the fluid and structure generate cross-coupled forces that act on the rotor. These cross-coupled forces tend to be destabilizing in nature, promoting a shaft precession, or whirling motion, in the direction of shaft rotation. As the limits of operating speeds and loads of rotating machinery are pushed increasingly higher, these forces are becoming ever larger, and greater care must be taken to ensure the stability of these machines. Tilting-pad fluid-film journal bearings (TPJBs) are commonly used in turbomachinery to counteract these destabilizing forces. In addition to providing static support to the shaft, these bearings also introduce dynamic stiffness and damping forces into the system through a developed hydrodynamic film wedge. In essence, if the damping forces provided by the bearings are greater than the destabilizing cross-coupled forces in the system, the machine will remain stable.

Choosing the right tilting-pad bearing for a given rotordynamic system is paramount to the safe and reliable operation of the machine. Engineers rely heavily on both existing experimental data and theoretical models of tiltingpad bearings to predict bearing performance. Numerous experimental studies are found in the literature that seek to provide insight into the operating characteristics of tilting-pad bearings. These studies often compare steady-state bearing performance indicators such as pad temperature, shaft operating position, and power loss for varying bearing geometries (i.e. pivot location, preload, clearance ratio, etc.) [1-4] and/or design type (i.e. flooded, leading-edge groove, spray-bar blocker, etc.) [5-7]. Operating conditions are usually varied to provide performance data at different operating speeds, specific loads, etc. Good correlation between experimental data and theoretical bearing models provides greater confidence when using the models to predict machine performance measures such as stability and unbalance response.

Some studies have specifically focused on the effects of reduced oil supply flow rate on bearing performance for various tilting-pad bearing designs [8-10]. A constant flow of fresh oil is required by tilting-pad bearings to keep operating temperatures low while developing the hydrodynamic film layer required to support the shaft. Traditionally, the oil is supplied at a flow rate sufficient to flood the bearing, producing a fully developed film layer over all of the bearing pads. Reduction of the oil supply flow rate may cause cavitation, or lack of a fully-developed film layer, over one or more of the pads. This condition is commonly referred to as starvation. Reduced oil supply flow rate has the welldocumented effects of higher bearing operating temperatures and decreased power losses. A number of advancements in tilting-pad bearing design, such as leading-edge grooves and spray-bar blockers, have focused on the oil delivery system to the bearing pads $[11,12]$. These features have the potential of allowing for cooler bearing operating temperatures at lower oil supply flow rates. 
In 2003, He [13] developed a sophisticated software algorithm to model TPJB behavior based on thermoelastohydrodynamic (TEHD) lubrication theory. This algorithm uses iterative numerical techniques to solve for pad pressure profiles, temperature distributions, and elastic deformations. It contains advanced turbulence, groove mixing, and starvation models. The starvation model was developed as an improvement over the original flooded model to more accurately capture bearing dynamics and performance under low oil supply flow rate conditions. Theoretical results using the starvation model were compared with experimental data obtained by Brockwell et al. [8] for a leading-edge groove bearing [14]. The predicted results compared reasonably well with the experimental data; however, it was noted that available data under reduced oil flow rates at the time of the study was limited. The study called for further validation of the algorithm with increased experimental data.

This study looks to provide increased experimental data under varying oil supply flow rates to both observe the effects of reduced flow rate on steady-state bearing performance and to compare these results to the predictions of the starved bearing model. A test rig, supported by two tilting-pad journal bearings in a flooded, pressurized housing design with oil inlet nozzles, is used to measure pad temperatures, journal operating position, and motor input current while systematically adjusting oil supply flow rate under a number of operating speeds. Experimental measurements are compared to theoretical TEHD analysis results using both the flooded and starved bearing model assumptions. Modeling limitations and assumptions, including a sensitivity study of hot-oil carryover factor, are discussed which help explain differences between measured and predicted temperature values. Predicted pad pressure profiles are presented that help explain differences between flooded and starved bearing model predictions. Conclusions are drawn as to which model more accurately captures bearing performance in this study and implications on bearing starvation are discussed.

\subsection{TEST RIG AND BEARING DESCRIPTION}

The test rig used in this study was originally developed to measure damped natural frequencies and damping ratios of an industrial-like rotor as a function of applied, destabilizing cross-coupled forces. The results of these tests, as well as a detailed description of the test rig, can be found in Cloud [15]. Those details pertinent to this study are reproduced here. The rig, as depicted in Figure 2.1, consists of a $1.55 \mathrm{~m}$ rotor supported by two tilting-pad bearings with a nominal diameter of $70 \mathrm{~mm}$ and a between-bearing span of $1.22 \mathrm{~m}$. The rotor contains three magnetic actuators that were not utilized in the current study. A $7.5 \mathrm{~kW}$, three-phase induction motor with a maximum speed of approximately 12,000 rpm drives the shaft

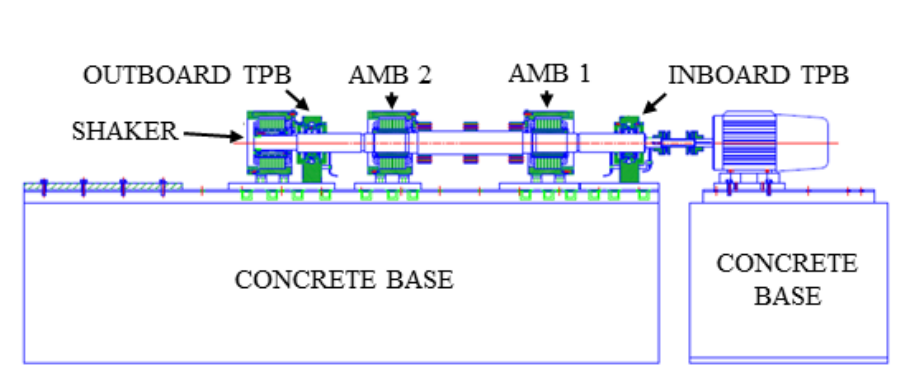

FIGURE 2.1. TEST RIG SET-UP [15].

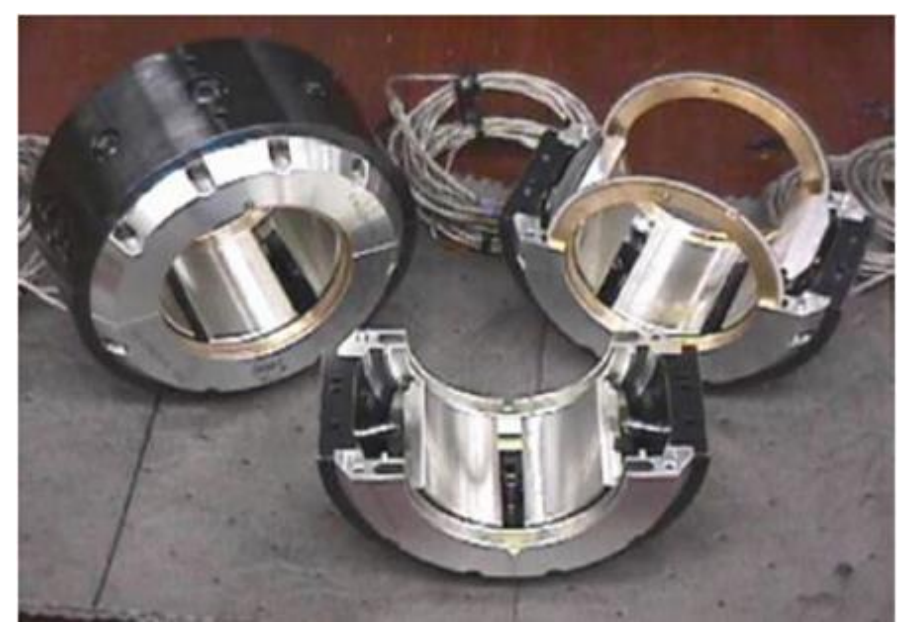

FIGURE 2.2. TEST BEARING IN FLOODED, PRESSURIZED HOUSING [15].

through a flexible coupling and is controlled with a variable frequency drive (VFD).

The bearings tested in this study, pictured in Figure 2.2, have a nominal diameter of $70 \mathrm{~mm}$ and an axial length of 52 $\mathrm{mm}$, giving them a length to diameter ratio (L/D) of 0.75 . The bearings have a machined diametral clearance of $173 \mu \mathrm{m}$, producing a clearance ratio of $2.47 \mu \mathrm{m} / \mathrm{mm}$. Each bearing consists of five pads of 55 degree arc length positioned in a load-between-pad (LBP) configuration. Each pad is centrally positioned on a ball-in-socket, spherical pivot where the ball is constructed of steel and the pivot is constructed of brass. The pads have a preload of 0.3 . A summary of the test bearing parameters can be found in Table 2.1. ISO VG 32 oil is supplied to the bearings at $43.3^{\circ} \mathrm{C}$.

As the study pertains to the effects of oil supply flow rate on bearing performance, it is important to discuss in detail the design of the tilting-pad bearings and specifically, how oil is supplied and discharged from the bearing cavity. The bearings are positioned in a pair of axially split bearing housings. Oil is supplied to each housing through a single supply orifice. Upon 
TABLE 2.1. TEST BEARING PARAMETERS.

\begin{tabular}{cc}
\hline Journal Diameter $(\mathrm{mm})$ & 70 \\
Pad Length $(\mathrm{mm})$ & 52 \\
Pad Arc Length $(\mathrm{deg})$ & 55 \\
Diametral Clearance $(\mu \mathrm{m})$ & 173 \\
Pad Offset Factor & 0.5 \\
Preload & 0.3 \\
Pad Configuration & LBP \\
Length/Diameter & 0.75 \\
Clearance Ratio $(\mu \mathrm{m} / \mathrm{mm})$ & 2.47 \\
Pad Thickness $(\mathrm{mm})$ & 15.5 \\
\hline
\end{tabular}

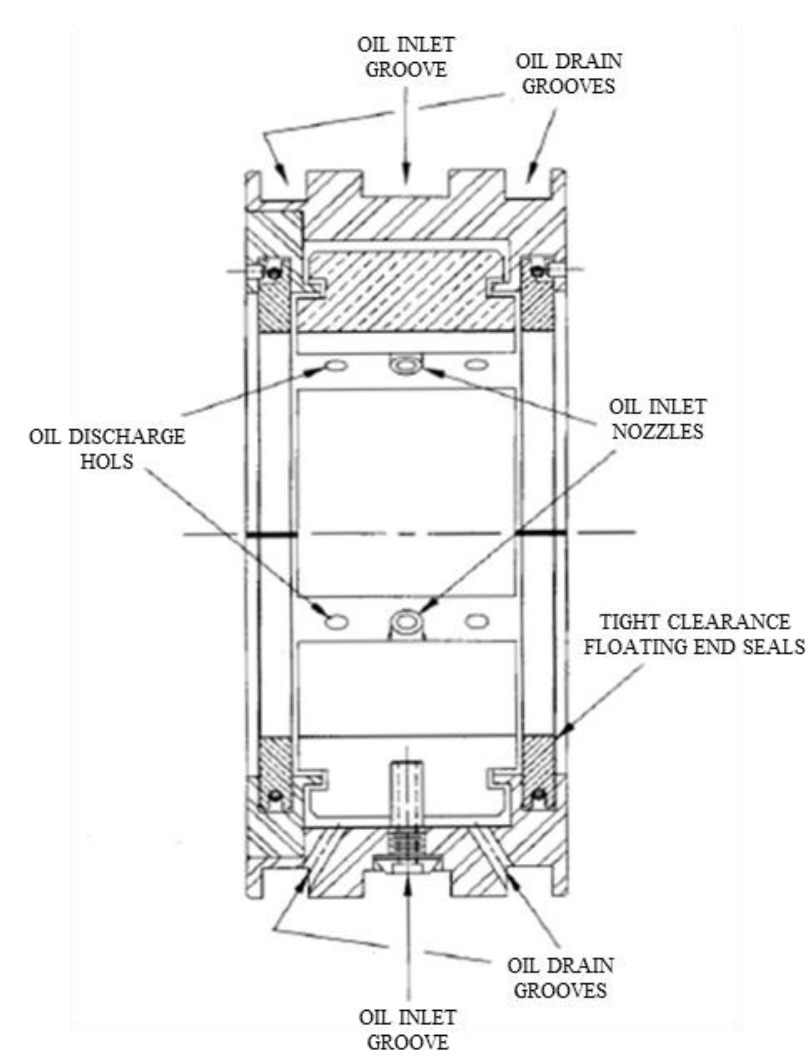

FIGURE 2.3. FLOODED, PRESSURIZED HOUSING OIL FLOW PATH FEATURES [11].

entering the housing, the lubricant fills a supply annulus that wraps circumferentially around the outer diameter of the bearing. A total of five supply nozzles, one positioned between each pad, allow oil to enter the bearing cavity. Hot oil primarily exits the bearing cavity through smaller discharge holes located on either side of the supply nozzles, while some may escape axially through two tight clearance floating end seals. This arrangement, shown schematically in Figure 2.3, produces a flooded, pressurized housing [11].

\subsection{EXPERIMENTAL METHODS}

The purpose of this study was to produce a set of experimental data under various oil supply flow rate conditions to both observe the effects of oil supply flow rate on steadystate bearing performance and to compare the results to TEHD analysis modeling predictions. To this end, measurements were recorded while systematically adjusting the oil supply flow rate under various operating speeds. The bearings were tested under a number of operating speeds ranging from 2,000 to $12,000 \mathrm{rpm}$ and a specific load of $124 \mathrm{kPa}$. For most operating speeds, three different oil supply flow rates were investigated. Some studies have provided successful methods for estimating the required oil supply flow rate to prevent starvation $[8,16]$. These methods often involve adjusting the flow rate until a specified oil temperature rise or bearing temperature is met. In many cases, recommended flow rates are provided to the end-user by the bearing manufacturer. Based on the recommendation of the manufacturer of the bearings used in this study, the nominal flow rate is considered to be 3.79 liters per minute (lpm) per bearing for all speeds tested. In addition to this nominal flow rate, flow rates of 4.54 $1 \mathrm{pm}$ and $3.03 \mathrm{lpm}$ were also tested, representing an increase and decrease of $20 \%$ of the nominal rate. Testing under the lowest flow rate was not possible at the highest operating speeds due to severely high vibration levels. Table 2.2 presents the operating conditions captured by the data as a percentage of the nominal flow rate for each speed.

Pad temperature, journal position, and motor input current were measured under each speed and flow condition. Under each operating condition, the rotor was allowed to reach steady-state conditions by running for 10 minutes. This period allowed the bearings to reach thermal equilibrium and the journal to settle into its steady-state operating position. Bearing pad Babbitt temperatures were measured using T-type thermocouples at 4 different circumferential locations, as shown in Figure 2.4. Thermocouples 4T and 5T are located near the trailing edge (i.e. $88 \%$ arc length) of Pads 4 and 5, while thermocouples $5 \mathrm{~L}$ and $1 \mathrm{~L}$ are located near the leading edge (i.e. 12\% arc length) of Pads 5 and 1 . Pads 4 and 5 represent the most heavily loaded pads in this orientation. Displacement measurements in two orthogonal directions were taken at each bearing with eddy-current proximity sensors. Temperature and displacement measurements observed at the two bearings produced similar results; therefore, only data from the outboard bearing is presented in this study. The input 
TABLE 2.2. OIL SUPPLY FLOW RATE TEST MATRIX (\% OF NOMINAL FLOW RATE, 3.79 LPM).

\begin{tabular}{cc}
\hline Speed (rpm) & Flow Rate $(\%)$ \\
\hline 2000 & 80100120 \\
4000 & 80100120 \\
6000 & 80100120 \\
8000 & 80100120 \\
9000 & 80100120 \\
10000 & 80100120 \\
11000 & 100120 \\
12000 & 100120 \\
\hline
\end{tabular}

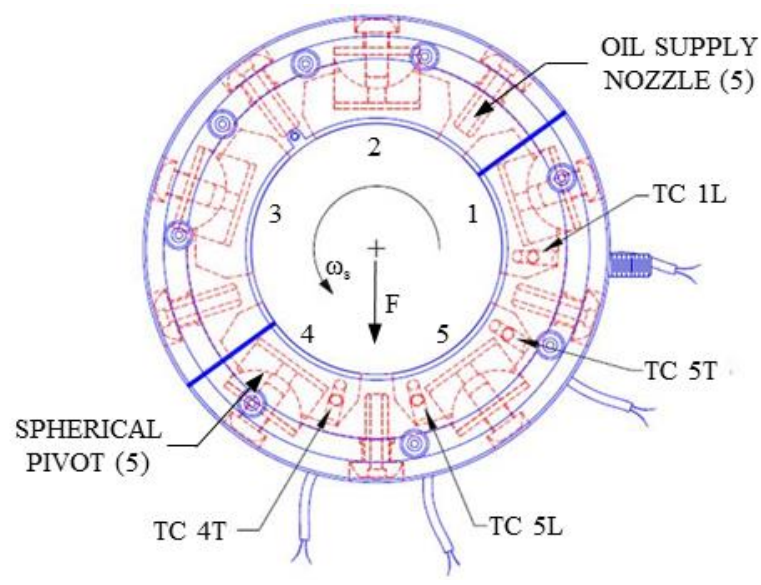

FIGURE 2.4. TEST BEARING THERMOCOUPLE LOCATIONS [15].

current to the induction motor was measured using an integrated current sensor in the motor's VFD. This current was used to estimate electrical input power for comparison across varying oil supply flow rates at each tested speed. Table 2.3 provides the uncertainties associated with the measurements presented in this study.

\subsection{THEORETICAL MODELING METHODS}

All experimentally tested operating conditions were analyzed using a sophisticated algorithm based on TEHD lubrication theory developed by He [13]. The algorithm uses numerical methods to solve a finite element formulation of the 2D Reynolds equation for the pad pressure field in the circumferential and axial directions. A finite element formulation of the generalized $2 \mathrm{D}$ energy equation is used to
TABLE 2.3. MEASUREMENT UNCERTAINTIES.

\begin{tabular}{cc}
\hline Temperature & $+/-0.75 \%$ \\
Operating Position & $+/-2 \%$ \\
Motor Input Current & $+/-2 \%$ \\
\hline
\end{tabular}

obtain the film temperature distribution in the circumferential and radial directions. Turbulence effects are included using the near-wall eddy viscosity model while cross-film viscosity variations are accounted for through exponential interpolation of the temperature dependent Reynolds model. Pad and pivot mechanical deformations, as well as pad, shaft, and shell thermal deformations, are also considered. Pivot stiffness values are calculated based on Hertzian contact stress analysis and are dependent on the resultant load developed by the oil film pressure field over each pad. Typical values ranged from $9 \mathrm{e} 8 \mathrm{~N} / \mathrm{m}$ to $2 \mathrm{e} 9 \mathrm{~N} / \mathrm{m}$ depending on operating condition and pad position and were at least one order of magnitude greater than the calculated film stiffness values. The shaft expansion is simplified as a free expansion at constant temperature equal to the average film temperature at the shaft surface. Tables 2.4 and 2.5 provide the lubricant and thermal bearing material properties, respectively, assumed in the computational analysis.

Both flooded and starved model flow assumptions are considered in this study. For both models, a total oil supply flow rate to the bearing, that of which delineates the results of the study, is prescribed. In the flooded model, it is assumed that the bearing has sufficient flow such that a continuous hydrodynamic film develops at the leading edge of all bearing pads, regardless of the prescribed flow rate. Flow rates into and out of each pad are calculated from the integrated velocity profiles at the pad boundaries. The prescribed flow rate is used in a limited fashion in the flooded flow model in the energy balance equation for calculating sump temperature. This sump temperature is then used in the bearing shell deformation calculations and ultimately affects the calculated pressure and temperature fields through the iterative solving process.

In the starved bearing model, the prescribed oil supply flow rate is divided evenly among all pads. This 'available' pad flow rate is compared to the leading edge flow rate as calculated from the integrated velocity profile at the pad inlet. If the available flow rate is less than the calculated value, the continuous film onset angle is moved circumferentially along the pad until the available and calculated flow rate values converge. In this case, the pad arc length is effectively reduced, representing the effects of pad starvation (i.e. film cavitation) at the leading edge of the pad. In these cavitated 
TABLE 2.4. MODELED ISO VG 32 PROPERTIES.

\begin{tabular}{cc}
\hline Density $\left(\mathrm{kg} / \mathrm{m}^{3}\right)$ & 865 \\
Specific Heat $\left(\mathrm{kJ} / \mathrm{kg}-{ }^{-0} \mathrm{C}\right)$ & 2.06 \\
Thermal Conductivity $\left(\mathrm{W} / \mathrm{m}^{\circ} \mathrm{C}\right)$ & 0.129 \\
Viscosity $\left(\mathrm{mm}^{2} / \mathrm{s}\right) @ 40^{\circ} \mathrm{C}$ & 29.9 \\
Viscosity $\left(\mathrm{mm}^{2} / \mathrm{s}\right) @ 100^{\circ} \mathrm{C}$ & 4.76 \\
\hline
\end{tabular}

TABLE 2.5. MODELED THERMAL BEARING MATERIAL PROPERTIES.

\begin{tabular}{cc}
\hline Pad Thermal Conductivity $\left(\mathrm{W} / \mathrm{m}^{-}{ }^{\circ} \mathrm{C}\right)$ & 50.5 \\
Pad Thermal Expansion $\left(1 /{ }^{\circ} \mathrm{C}\right)$ & $1.32 \mathrm{e}-5$ \\
Shaft Thermal Expansion $\left(1 /{ }^{\circ} \mathrm{C}\right)$ & $1.12 \mathrm{e}-5$ \\
Shell Thermal Expansion $\left(1 /{ }^{\circ} \mathrm{C}\right)$ & $1.32 \mathrm{e}-5$ \\
\hline
\end{tabular}

regions, the pressure is assumed to be ambient and a reduced axial length is assumed through the effective length method. A scaling factor is then calculated to account for these regions in the energy equation and power loss calculations. In reality, some oil is dragged along the surface of the shaft in streamlets of gas and liquid in the cavitated regions; however, these twophase flow effects are not considered in the models.

Between each pad, a complex oil mixing phenomenon occurs between the cool, fresh oil supplied by the nozzles and the hot oil exiting the trailing edge of the previous pad. Some of this hot oil is pulled by the shaft directly to the leading edge of the next pad and is known as hot-oil carryover. The remaining hot oil mixes with the cool inlet oil between the pads resulting in warm oil. This warm oil combines with the hot-oil carryover and enters the leading edge of the next pad. Figure 2.5 provides a simplified illustration of the groove mixing and hot-oil carryover concepts with example temperature values. A bulk flow energy balance model is used to approximate this groove mixing phenomenon and calculate the inlet temperature boundary condition for the leading edge of each pad. The percentage of hot oil that is carried over directly from the previous pad varies based on bearing geometry, design type, and operating condition and is not always readily known. Typical values for the hot-oil carryover factor vary between 0.7-1.0 based on industrial experience. A prescribed factor of 0.95 is assumed in all bearing models presented in this study. A sensitivity study of predicted pad temperatures to this factor is presented in the results.

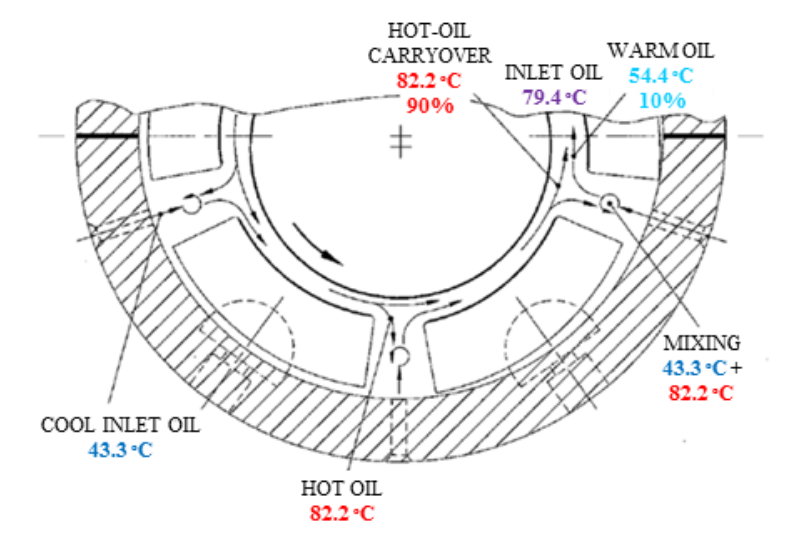

FIGURE 2.5. GROOVE MIXING AND HOT-OIL CARRYOVER CONCEPTS [11].

\subsection{RESULTS \\ 2.5.1. Pad Temperatures}

Figures 2.6 through 2.9 present both theoretical and experimental pad temperatures as a function of operating speed for all oil supply flow rates at the four thermocouple locations. Results from the fully-flooded bearing models are represented by solid lines and denoted 'FF', while results from the starved bearing models are represented by dashed lines and labeled 'S1'. Experimentally obtained data points are represented as diamonds and designated 'EX'. In general, both of the models and the experimental measurements show an increase in bearing temperature with increasing speed and decreasing oil supply flow rate. While the predicted temperatures and experimental data agree reasonably well, the measured temperatures fall below the predicted values from both models for nearly all speed and flow conditions. The differences between models and measurements generally increase with increased running speed. Potential explanations for these deviations, including model hot-oil carryover factor and thermal boundary conditions, are provided in the discussion.

Figures 2.6 and 2.7 present the temperature data for TCs $5 \mathrm{~L}$ and 5T, located near the leading and trailing edges of Pad 5 , respectively. Both models show a steady increase in temperature with speed and a slight increase in temperature with decreased oil supply flow rate, and nearly indiscernible differences in temperature predictions between the two models. The measured data show similar trends as seen in both models, but at lower overall temperatures. In general, the measured temperatures show better agreement with the models near the leading edge of the pad. For instance, at an operating speed of 12,000 rpm and an oil supply flow rate of $3.79 \mathrm{lpm}$, the measured temperature is approximately $3^{\circ} \mathrm{C}$ lower than the predicted values at TC $5 \mathrm{~L}$ and approximately $5{ }^{\circ} \mathrm{C}$ lower at TC $5 \mathrm{~T}$. 


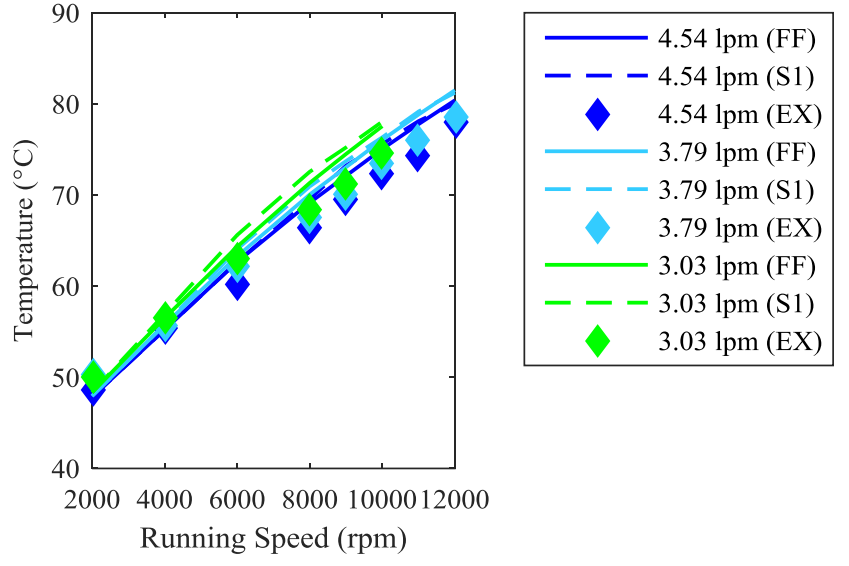

FIGURE 2.6. TC 5L MEASURED AND PREDICTED TEMPERATURES.

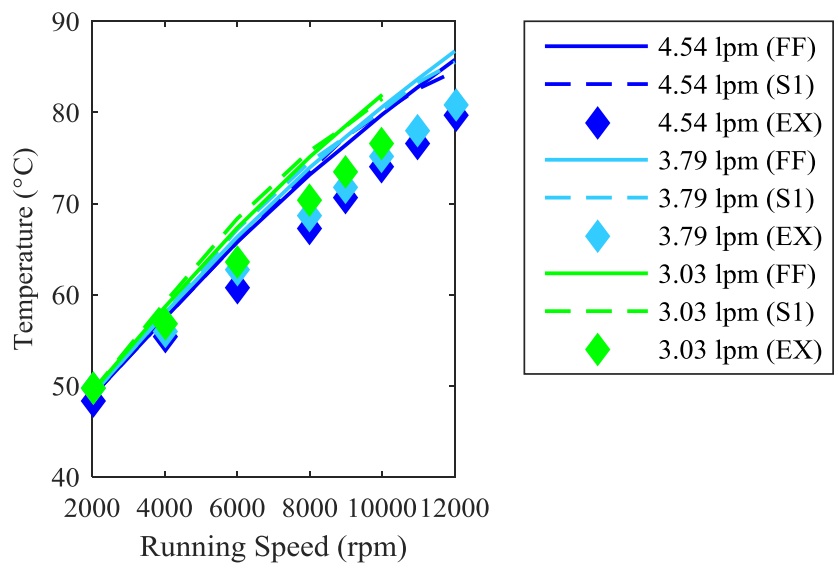

FIGURE 2.7. TC 5T MEASURED AND PREDICTED TEMPERATURES.

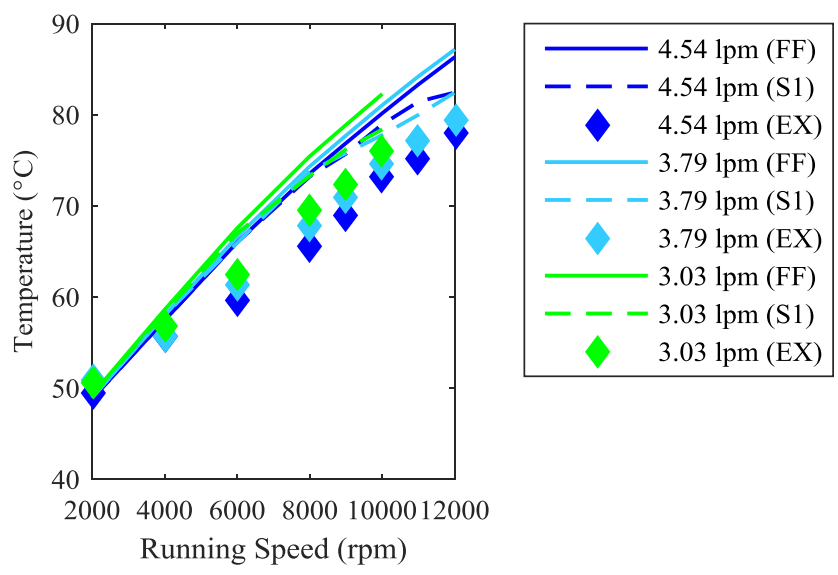

FIGURE 2.8. TC 4T MEASURED AND PREDICTED TEMPERATURES.

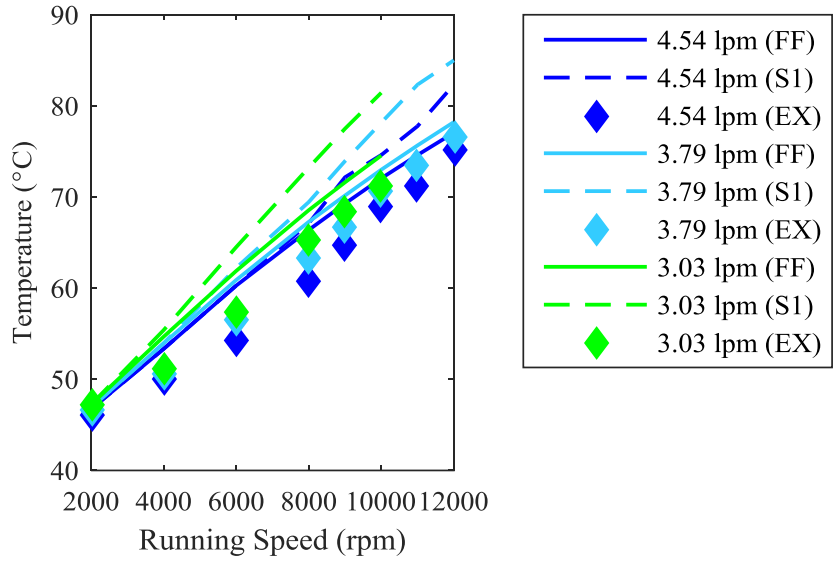

FIGURE 2.9. TC 1L MEASURED AND PREDICTED TEMPERATURES.

Figures 2.8 and 2. 9 illustrate the temperature data for TCs 4T and 1L, located near the trailing edge of Pad 4 and the leading edge of Pad 1, respectively. At these locations, the fully-flooded and starved bearing models agree with one another at lower speeds and begin to deviate at higher speeds. At the trailing edge of Pad 4, the starved model predicts lower temperatures than the flooded model at higher speeds. Conversely, at the leading edge of Pad 1, the starved model predicts higher temperatures than the flooded model at higher speeds. As the measured data is consistently lower than the predicted values at both thermocouple locations, it then follows that the data lie closer to the starved model predictions at TC 4T and closer to the flooded model predictions at TC 1L. Predicted pad pressure profiles presented in the discussion help explain the temperature deviations seen in the two models at higher speeds at these locations.

\subsubsection{Sump Temperature}

Figure 2.10 presents the theoretical and experimentally measured sump temperatures for all oil supply flow rates as a function of speed. As with the pad temperatures, both models and the data show an increase in sump temperature with increasing speed and decreasing oil supply flow rate. While the two models predict similar temperatures for all operating conditions, the flooded bearing model predicts slightly higher sump temperatures under each condition. Again, like the pad temperatures, the experimental data show similar trends as the two theoretical models but at lower overall temperatures. The data lie closer to the starved bearing model predictions due to their lower predicted temperatures; however, due to the overall trend of lower measured temperatures in both the bearing pads and sump oil, it is difficult to draw definitive conclusions from this observation. The higher predicted sump temperatures in the flooded model in comparison to the starved model are 


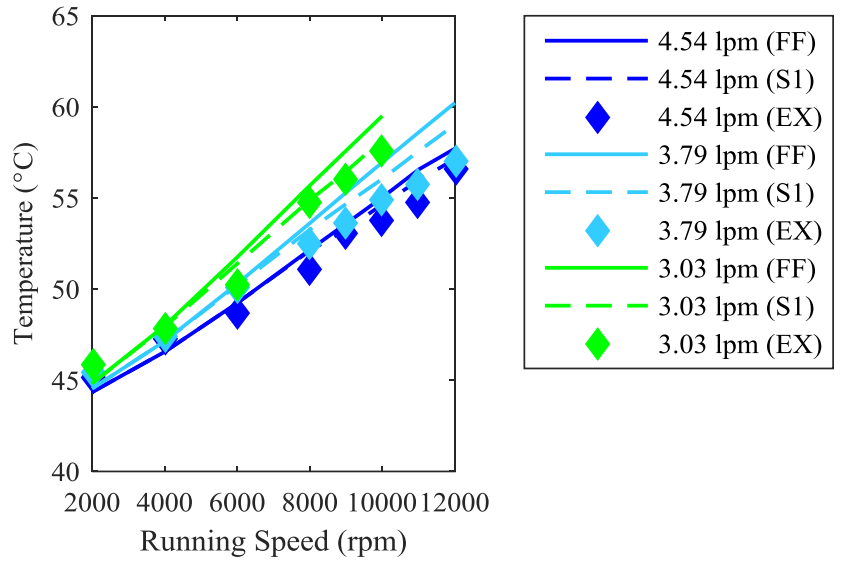

FIGURE 2.10. MEASURED AND PREDICTED SUMP TEMPERATURES.

expected as the sump temperatures are calculated from an energy balance of the whole bearing and are proportional to the predicted frictional losses in the film.

\subsubsection{Steady-state Vertical Operating Position}

Vertical journal travel with little horizontal travel is expected in tilting-pad bearings with a downward oriented load positioned between bearing pads. Indeed, the horizontal shaft motion observed during testing was negligible in comparison to the vertical motion for all tested cases. Figure 2.11 presents the theoretical and experimental changes in the vertical shaft operating position with speed for each oil supply flow rate relative to the vertical operating position at a reference speed of 2,000 rpm and operating eccentricity ratio of approximately 0.3 . Both models predict a monotonic increase in vertical operating position with speed. While the curves obtained from the flooded model flatten at higher speeds, the curves obtained from the starved model predict a more drastic and steady increase in vertical operating position with speed. For instance, at a flow rate of $3.791 \mathrm{pm}$ and a speed of $12,000 \mathrm{rpm}$, the starved bearing model predicts a vertical increase of 29 microns; nearly double the 15 micron rise predicted by the flooded model. It is interesting to note that while the starved bearing model predicts an increase in vertical operating position with decreasing oil supply flow rate, the flooded model predicts a slight drop in position with decreasing flow rate. For all operating speeds and oil supply flow rates, the measured positions agree very well with the starved model predications. Predicted pad pressure profiles presented in the discussion help explain the deviations in vertical operating position seen in the two models. Implications that these pressure profiles have on bearing starvation are also discussed.

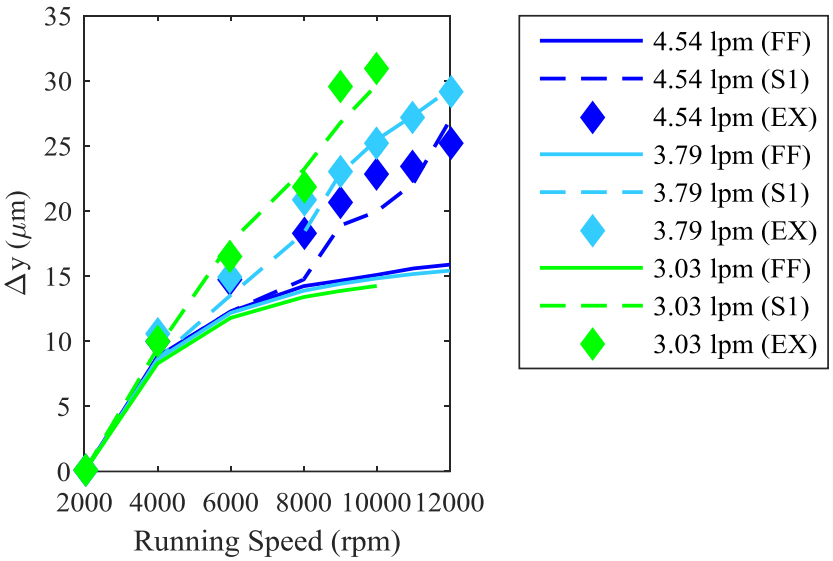

FIGURE 2.11. MEASURED AND PREDICTED VERTICAL OPERATING POSITION (2000 RPM, 0.3 ECCENTRICITY RATIO REFERENCE).

\subsubsection{Motor Input Power}

The electrical current to the motor as provided by an integrated current sensor in the driving VFD was recorded for each speed and oil supply flow rate tested. For the AC induction motor used in this study, the electrical input power is approximately proportional to the input current squared. At a constant operating speed, the major contributors of power loss in the system are windage losses along the rotor and viscous frictional losses in the fluid film bearings. Since the windage losses along the rotor are constant for any given speed, changes in the input power to the motor can be used to estimate changes in bearing power loss with varying oil supply flow rate. Figure 2.12 presents the theoretically calculated and experimentally approximated percentage change in bearing power loss associated with a $20 \%$ increase and decrease in oil supply flow rate from the nominal rate for each operating speed. Both models generally predict lower deviations in power loss at each speed than the experimental approximations. The starved bearing model predicts greater changes in power loss with changes in oil supply flow rate in both directions at each speed and lies closer to the experimental approximations. At the lower operating speeds of $2,000 \mathrm{rpm}, \mathrm{a}+/-20 \%$ variation in oil supply flow rate results in an approximately $+/-5 \%$ change in bearing power loss. At a higher speed 10,000 rpm, an approximately $+/-10 \%$ change in bearing power loss is observed with the variation in flow rate. It should be noted that while the changes in the predicted power loss with oil flow are lower in the flooded bearing model, the actual values of the predicted power loss were observed to be higher in the flooded model than the starved model for all speeds at the nominal flow rate. 


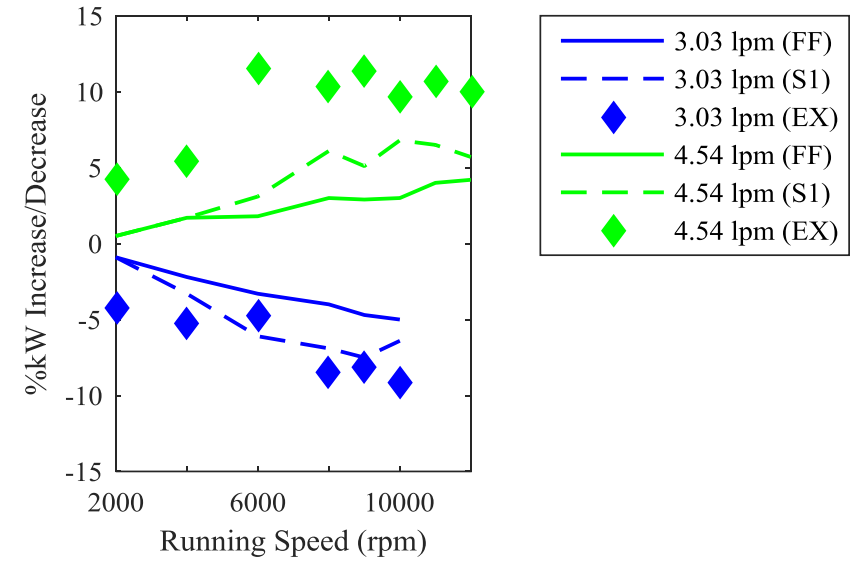

FIGURE 2.12. PERCENTAGE POWER CHANGE WITH OIL SUPPLY FLOW RATE.

\subsection{DISCUSSION}

\subsubsection{Pad Temperatures}

One of the primary purposes of this study was to compare experimental steady-state bearing data at various oil supply flow rates and speeds to both flooded and starved bearing models to see which model more accurately predicts bearing performance. While both models predict nearly identical temperatures along Pad 5 (i.e. TC 5L and TC 5T), noticeable differences in the temperature predictions for TC $4 \mathrm{~T}$ and TC $1 \mathrm{~L}$ were observed at higher speed cases. A look at the predicted pressure profiles of the two bearing models helps explain these dissimilarities. Figures 2.13 and 2.14 illustrate the predicted pressure profiles obtained from the flooded and starved bearing models, respectively, for the nominal oil supply flow rate condition and higher operating speeds ranging from 8,000-12,000 rpm. All pressure profiles in each figure have been normalized to the maximum pressure observed in Pad 5 and listed in the caption of each figure. Inherent to the flooded model flow assumptions, all five pads in Fig. 2.13 show a fully developed hydrodynamic film from leading to trailing edge under all speed conditions. The pressures developed over the pads increase slightly with increasing operating speed. As illustrated by Fig. 2.14, the starved bearing model predicts cavitation at the leading edges of Pads 1 and 2 that increases in severity with increasing operating speed. While Pad 1 remains mostly loaded through the operating speed range, the effective pad arc length is reduced slightly at each increase in speed due to increasing cavitation at the leading edge. Pad cavitation is more apparent in Pad 2 where the pad becomes fully cavitated, and thus unloaded, at speeds above 9,000 rpm. The unloading of Pad 2 and partial cavitation of Pad 1 causes a shift in the pressure distribution

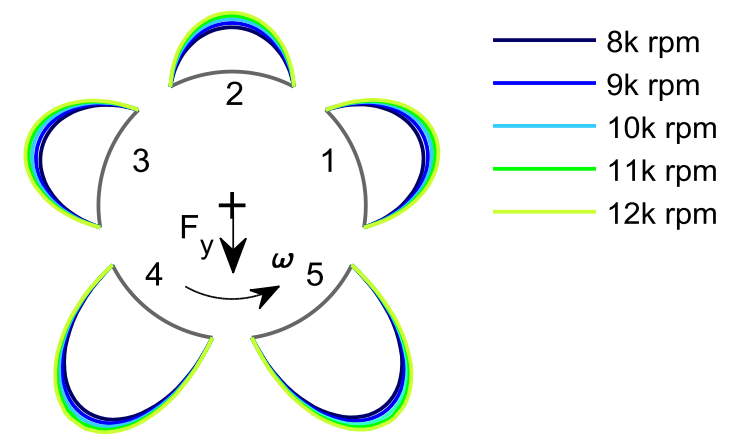

FIGURE 2.13. PREDICTED PRESSURE PROFILES VS SPEED, NOMINAL FLOW RATE, FLOODED MODEL (710 KPA MAX).

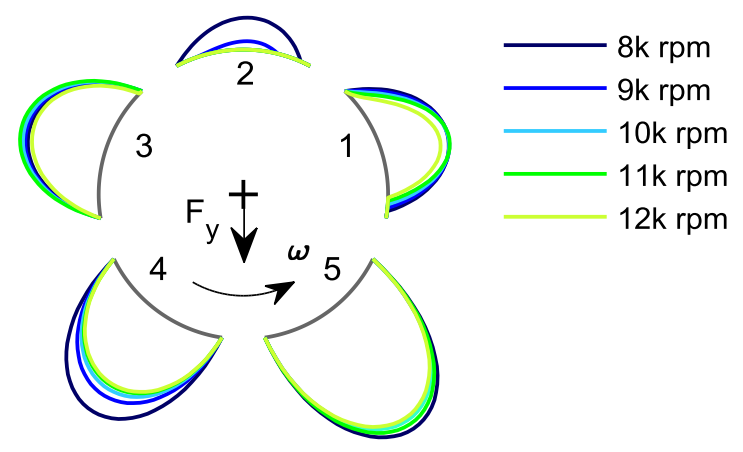

FIGURE 2.14. PREDICTED PRESSURE PROFILES VS SPEED, NOMINAL FLOW RATE, STARVED MODEL (581 KPA MAX).

between all of the pads. This shift causes a reduction in pad pressure over Pad 4 relative to the flooded model predictions which explains the lower predicted temperatures of the starved model at TC 4T. The partial cavitation of Pad 1 in the starved model produces higher temperatures at TC $1 \mathrm{~L}$ when compared to the flooded model. Pressure profiles over Pad 5 are nearly constant with speed for both models, explaining their nearly identical temperature predictions at TCs 5L and 5T.

Unfortunately, these defining trends are not recognizable in the measured data due to the fact that all measured temperatures were lower than the predicted temperatures of both models. Pad temperatures were observed to be steady to $0.1{ }^{\circ} \mathrm{C}$ after the settling period during testing and are believed to be representative of steady-state values. While predicted temperatures are provided at the Babbitt surface, the thermocouples are embedded just beneath the Babbitt surface 
and may account for lower measured temperatures. Model limitations and assumptions provide other possible explanations for the higher predicted temperatures of the models. While thermal conduction in the pads is considered with the temperature on the outer pad surfaces set equal to the calculated sump oil temperature, the analyses used in this study does not account for the effects of heat transfer from the sump oil contained within the bearing cavity through the bearing housing to the surrounding environment. An ambient testing room temperature of $21^{\circ} \mathrm{C}$ and measured sump temperatures of approximately $57{ }^{\circ} \mathrm{C}$ results in temperature differentials of approximately $36^{\circ} \mathrm{C}$. Ignoring the effects of this substantial temperature differential between the sump oil and environment would certainly cause the predicted temperatures to be higher than those experimentally measured.

The uncertainty associated with the hot-oil carryover factor used in the models is also a likely contributor to the higher temperatures seen in the models. As previously stated, an appropriate hot-oil carryover factor can vary between 0.71.0 based on industrial experience and is certainly dependent on bearing type and operating condition. A suggested default model value of 0.95 was used for all theoretical models presented in this study. Figure 2.15 illustrates the sensitivity of the pad temperature at TC $4 \mathrm{~T}$ to the hot-oil carryover factor as predicted by the flooded bearing model for various operating speeds. The hot-oil carryover factor, which was varied from 0.85-0.99, has minimal effect on predicted temperature at low speeds and increases steadily with increasing speed. At 12,000 $\mathrm{rpm}$, the predicted temperature at TC $4 \mathrm{~T}$ drops $6.4{ }^{\circ} \mathrm{C}$ as the hot-oil carryover factor is decreased from 0.99 to 0.85 . Similar sensitivities were observed at all thermocouple locations and for predictions from both the flooded and starved bearing models. In reality, the amount of hot-oil carryover from pad to pad is almost certainly a function of both operating speed and oil supply flow rate. The large amount of uncertainty associated with this factor is one likely cause for the differences observed between the predicted and measured temperatures. Due to the theoretical limitations and uncertainties detailed above, it is not possible to claim that one model is more accurate than another based on temperatures alone.

\subsubsection{Steady-state Vertical Operating Position}

Perhaps the most interesting and meaningful results of this study are found in Fig. 2.11. The flooded and starved bearing models differ substantially in predicted vertical operating position with the starved bearing model very closely matching the measured positions for all speeds and oil supply flow rates. Again, comparisons of the predicted pressure profiles obtained from the flooded and starved bearing models provide insight into the deviations seen between the two models. As illustrated

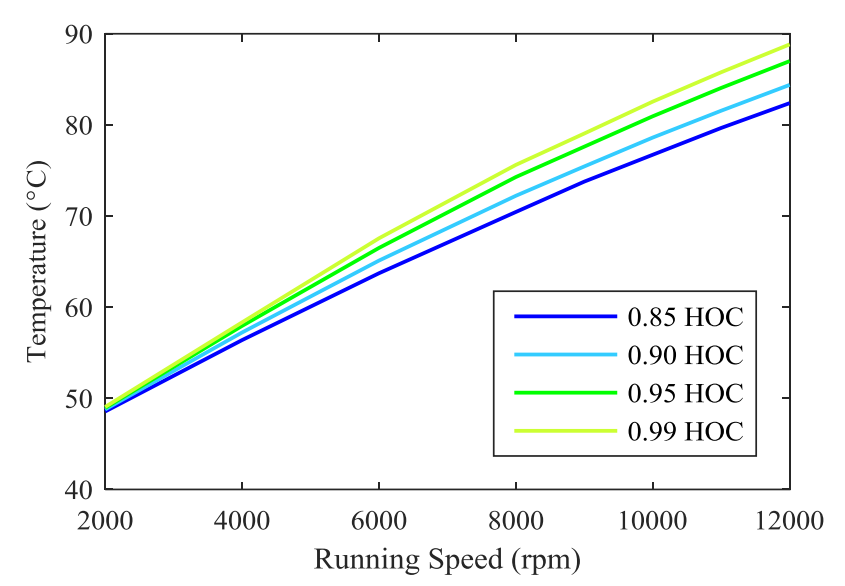

FIGURE 2.15. TC 4T HOT-OIL CARRYOVER SENSITIVITY (FLOODED MODEL, 3.79 LPM).

again by Fig. 2.13, the flooded bearing model predicts fully developed pressure profiles over all five pads that have very little variance with operating speed. These nearly constant pressure profiles at higher speeds explain the flattening of the vertical operating position curve as predicted by the flooded model and shown in Fig. 2.11. As previously explained, the pressure profiles predicted by the starved bearing model and illustrated in Fig. 2.14 show cavitation at the leading edge of Pad 2, the top pad, that increases with increasing speed and results in a fully cavitated, unloaded pad at speeds above 9,000 $\mathrm{rpm}$. The unloading of the top pad at higher speeds results in an increase in the ratio of support provided by the bottom pads to the top pad. This pressure redistribution, in turn, results in a noticeable increase in the journal vertical operating position.

As Figs. 2.13 and 2.14 present pressure profiles that vary with speed for a given oil supply flow rate, Figures 2.16 and 2.17 present predicted pressure profiles from the flooded and starved bearing models, respectively, that vary across the three flow rates tested at an operating speed of 10,000 rpm. Again, all pressure profiles in each figure have been normalized to the maximum pressure observed in Pad 5 and listed in the caption of each figure. Much like the flooded bearing model speeddependent pressure profiles, Fig. 2.16 shows fully developed pad pressures that vary little with oil supply flow rate. These similar pressure profiles explain the nearly identical operating positions predicted by the flooded model for each flow rate at a given speed. Fig. 2.17 highlights the effects of reduced oil supply flow rate on pad pressures as predicted by the starved bearing model. At a flow rate of $4.54 \mathrm{lpm}, 120 \%$ of the nominal, slight leading edge cavitation can be seen in Pads 1 and 2. At the nominal and $80 \%$ flow rates, Pad 2 is completely cavitated. Furthermore, Pad 1 is nearly completely cavitated at the $80 \%$ flow rate. The progressive unloading of Pads 1 and 2 


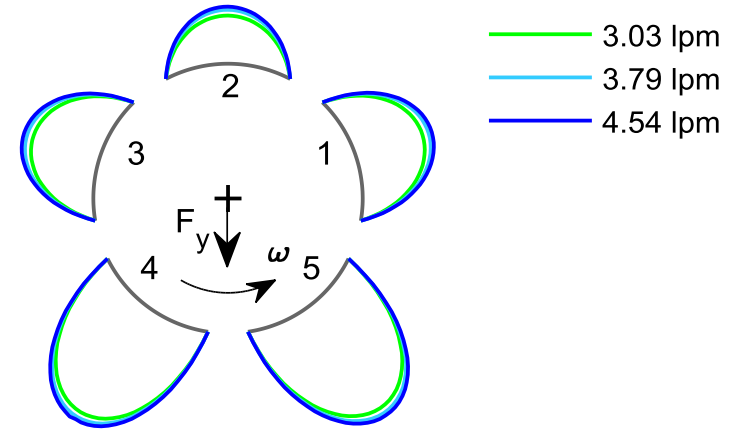

FIGURE 2.16. PREDICTED PRESSURE PROFILES VS FLOW RATE, 10,000 RPM, FLOODED MODEL (696 KPA MAX).

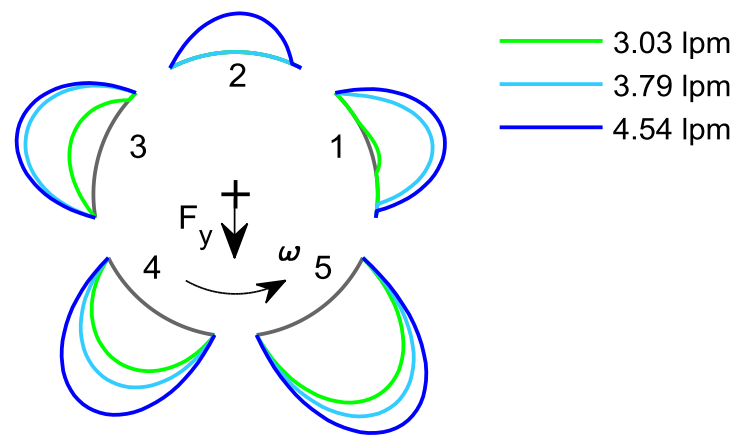

FIGURE 2.17. PREDICTED PRESSURE PROFILES VS FLOW RATE, 10,000 RPM, STARVED MODEL (627 KPA MAX).

explains the rise in journal position with decreasing flow rate predicted by the starved model. Good correlation between the experimentally measured vertical operating positions and starved bearing model predictions suggest that the top pad, or pads, likely experience partial or full cavitation that progresses in scope with higher speeds and lower flow rates. This correlation also suggests that the starved bearing model does, in fact, more accurately predict the bearing behavior observed in this study under reduced oil supply flow rates.

A recent, previous study by the authors reported on the effects of reduced oil supply flow rate on steady-state subsynchronous shaft vibration patterns [17]. At high operating speeds, a high-amplitude peak, subsynchronous vibration component was observed at the first bending mode of the shaft during supercritcal operation. The amplitude of this peak increased dramatically with both increasing speed and decreasing oil supply flow rate under the same bearing load condition reported in the current study. Results from the starved bearing model shown in Figs. 2.14 and 2.17 showing the progressive unloading of Pads 1 and 2 with increasing speed and decreasing flow were used in the previous study to support the conclusion that the subsynchronous peak was likely a forced vibration phenomenon resulting from pad vibrations of an unloaded upper pad or pads. The results of the current study help to strengthen the conclusions of the previous study and further validate the accuracy of the starvation bearing model.

It should be noted that the results presented in the current study are specific to a flooded tilting-pad bearing design operating under lightly loaded conditions. While many advancements in bearing technology have been made, especially regarding oil delivery methods, these style bearings remain widely used today. Performing similar testing on different bearing designs, such as spray-bar blocker designs with evacuated housings, would provide an interesting comparison to these results and is planned for future work in this area. Higher load cases were considered and presented in the aforementioned study pertaining to subsynchronous vibration patterns [17]. At higher loads, the effects of starvation on the predicted pressure profiles were less pronounced due to the inherent unloading of the upper pads under these loads. During these earlier tests, the most interesting predicted results came from the starved model at low load, high speed, and low oil flow conditions. It is under these conditions that cavitation is predicted to develop at the leading edge of the upper pads and progress in nature with increasing speed and decreasing oil flow as shown in Figs. 2.14 and 2.17. This study is meant to focus on these conditions at the onset of pad starvation and provide commentary data for the purposes of validating the starvation model.

\subsection{CONCLUSIONS}

- As previously well documented in the literature, reduced oil supply flow rate results in increased bearing operating temperatures and decreased power losses.

- A $20 \%$ reduction in required motor input power was observed between the maximum and minimum oil supply flow rates tested at higher operating speeds.

- Measured pad temperatures and sump temperatures agree reasonably well with predicted temperatures from both flooded and starved TEHD bearing models but are consistently lower than the predicted temperatures for nearly all operating speed and oil supply flow rate conditions. 
- Higher predicted operating temperatures in comparison to the measured data are attributed to model limitations with regards to thermal boundary conditions and uncertainties in the model hot-oil carryover factor.

- The starved bearing model predicts significantly greater increases in vertical shaft operating position with increasing speed and decreasing flow rate than the flooded model and closely matches the experimental measurements for all speed and flow rate conditions tested.

- Predicted pressure profiles from the starved bearing model predict partial to full cavitation of one or more of the upper bearing pads that increases in severity with increasing speed and decreasing oil supply flow rate. The progressive unloading of these top pads results in a more drastic increase in the vertical shaft operating position when compared to the flooded model.

- Good correlation between the measured shaft operating position and the starved model predictions suggests that one or more of the top pads experienced some level of cavitation during testing, causing them to become partially or fully unloaded.

- The results of this study suggest that the starved bearing model does provide an improvement over the flooded bearing model in instances of inadequate oil supply flow rate, better known as bearing starvation.

- Further experimental studies that provide additional data under reduced oil supply flow rates for various bearing types under various operating conditions should be compared to predicted results from the starved bearing model to further strengthen the claims made in this study. Additional experimental studies that provide insight into how bearing type and/or operating conditions affect the hot-oil carryover factor would be beneficial for improving the model accuracy.

\subsection{REFERENCES}

[1] Fillon, M., Bilgoud, J. C., and Frene, J., 1992. "Experimental study of tilting-pad journal bearings comparison with theoretical thermoelastohydrodynamic results." ASME Journal of Tribology, 114(3), pp. 579-587.

[2] Dmochowski, W., Brockwell, K., DeCamillo, S., and Mikula, A., 1993. "A study of the thermal characteristics of the leading edge groove and conventional tilting pad journal bearings". ASME Journal of Tribology, 115(2), pp. 219-226.

[3] Simmons, J.E.L. and Dixon, S. J., 1994. "Effect of load direction, preload, clearance ratio, and oil flow on the performance of a $200 \mathrm{~mm}$ journal pad bearing." Tribology Transactions, 32(2), pp. 227-236.
[4] Bouchoule, C., Fillon, M., Nicolas, D., and Barresi, F., 1996. "Experimental study of thermal effects in tilting pad journal bearings at high operating speeds." ASME Journal of Tribology, 118(3), pp. 532-538.

[5] Harangozo, A.V., Stolarski, T.A., and Gozdawa, R.J., 1991. "The effect of different lubrication methods on the performance of a tilting-pad journal bearing." Tribology Transactions, 34(4), pp. 529-536.

[6] Tanaka, M., 1993. "Thermohydrodynamic performance of a tilting pad journal bearing with spot lubrication." ASME Journal of Tribology, 113(3), pp. 615-619.

[7] Fillon, M., Bilgoud, J.C., and Frene, J., 1993. "Influence of the lubricant feeding method on the thermoelastohydrodynamic characteristics of tilting-pad journal bearings." In Proceedings of the Sixth International Conference on Tribology, Budapest, Hungary, 4, pp. 7-10.

[8] Brockwell, K., Dmochowski, W., and DeCamillo, S., 1994. "Analysis and testing of LEG tilting pad journal bearing- a new design for increasing load capacity, reducing operating temperatures and conserving energy". In Proceedings of the Twenty-Third Turbomachinery Symposium, pp. 43-56.

[9] DeCamillo, S. and Brockwell, K. 2001. "A study of parameters that affect pivoting shoe journal bearing performance in high-speed turbomachinery". In Proceedings of the Thirtieth Turbomachinery Symposium, pp. 9-22.

[10] Dmochowski, W. and Blair, B., 2006. "Effect of oil evacuation on the static and dynamic properties of tilting pad journal bearings". Tribology Transactions, 49(4), pp. 536-544.

[11] Nicholas, J. C., 1994. "Tilting pad bearing design." In Proceedings of the Twenty-Third Turbomachinery Symposium, College Station, Texas, pp. 179-194.

[12] Nicholas, J. C., 2003. "Tilting pad journal bearings with spray-bar blockers and by-pass cooling for high speed, high load applications." In Proceedings of the ThirtySecond Turbomachinery Symposium, College Station, Texas, pp. 27-37.

[13] He, M., 2003. "Thermoelastohydrodynamic analysis of fluid film journal bearings". Ph.D. Dissertation, University of Virginia, Charlottesville, Virginia.

[14] He, M., Allaire, P. E., Barrett, J., and Nicholas, J. C., 2005. " Thermohydrodynamic modeling of leading-edge groove bearings under starved conditions". Tribology Transactions, 48, pp. 362-369.

[15] Cloud, C. H., 2007. "Stabillity of rotors supported on tilting-pad journal bearings". Ph.D. Dissertation, University of Virginia, Charlottesville, Virginia. 
[16] Nicholas, J. C., Elliott, G., Shoup, T. P., and Martin, E., 2008. "Tilting pad journal bearing starvation effects." In Proceedings of the Thirty-Seventh Turbomachinery Symposium, Houston, Texas.

[17] Nichols, B. R., Fittro, R. L., and Goyne, C. P., In Press. "Subsynchronous vibration patterns under reduced oil supply flow rates". ASME Journal of Gas Turbines and Power. 


\section{CHAPTER 3: SUBSYNCHRONOUS VIBRATION PATTERNS UNDER REDUCED OIL SUPPLY FLOW RATES}

\subsection{INTRODUCTION}

Many high-speed, rotating machines across a wide range of industrial applications depend on fluid film bearings to provide both static support to the rotor and to introduce stabilizing damping forces into the system through a developed hydrodynamic film wedge. These damping forces are necessary to counteract destabilizing cross-coupled forces which act to promote a shaft procession, or whirling motion, in the direction of shaft rotation. Oil whirl and shaft whip are two instability phenomena that generate distinct subsynchronous shaft vibration patterns. One of the earliest explanations and investigations of these incidents can be found in the classic paper by Newkirk and Taylor [1]. Oil whirl is a self-excited bearing instability characterized by a subsynchronous peak at approximately $0.5 \mathrm{x}$ the running speed. It is most commonly experienced in lightly loaded fixed geometry bearings where the shaft eccentricity ratio is small. Tilting-pad bearings were invented, in large part, to attenuate the underlying causes of oil whirl. Shaft whip occurs when any destabilizing forces in the system are greater than the bearing damping forces. Shaft whip is characterized by a vibration component at the first forward bending mode of the shaft and typically occurs subsynchronously in the approximately $0.45-0.55 \mathrm{x}$ running speed range during supercritical operation. During any system instability, the shaft whirl grows without bound until a nonlinear limit cycle is met. It is imperative that the supporting fluid-film bearings provide enough damping to avoid an instability and any potential, associated machine damage.

More recent literature has focused on the causes and effects of other subsynchronous vibration phenomena not associated with whip or whirl instabilities. Adams and Payandeh attributed subsynchronous shaft vibrations occurring at $0.5 \mathrm{x}$ the running speed to the vibrations of statically unloaded pads in traditional, flooded tilting-pad bearings [2]. These pad vibrations are commonly referred to as pad flutter. DeCamillo et al. sought to investigate the origin of a lowfrequency, low amplitude, broadband subsynchronous vibration phenomenon encountered in a number of industrial machines that was termed subsynchronous vibration (SSV) hash [3]. They found that the shaft SSV hash correlated to vibrations in one or more of the pads. Further theoretical investigations concluded that SSV hash is likely a forced vibration phenomenon attributed to the pad motions of fully or partially unloaded pads.

Tilting-pad bearings are dependent on a constant flow of fresh oil to keep the bearing temperature low while developing the required hydrodynamic film layer over the pads. A number of advancements in tilting-pad bearing design have focused on the oil delivery system to the bearing pads allowing for cooler operation under increasing speed and load requirements [4]. Typically, fully-flooded tilting pad bearings are supplied sufficient oil to develop a hydrodynamic film layer from the leading edge to the trailing edge of all of the pads. Reducing the oil supply flow rate below that required to flood the bearing may cause cavitation, or lack of a fully-developed film layer, of one or more of the pads. Bearings running in this condition are often referred to as starved. Reduced oil supply flow rate has the well-documented effects of higher bearing operating temperatures and decreased power losses. Under some operating conditions, it may be possible to reduce the 
amount of oil supplied to a bearing in order to improve machine efficiency while still providing adequate flow to support the rotor and maintain safe bearing temperatures. A number of studies have reported the effects of reduced oil supply flow rate on bearing performance for various tilting-pad bearing designs [5-7].

This study looks at the effects of reduced oil supply flow rate on the subsynchronous shaft vibration signature of a supercritical, flexible rotor. The test rig used in this study was designed to be dynamically similar to a modern, industrial rotating machine with a high critical speed ratio and mode shapes typical of those found in a between-bearing machine [8]. The oil supplied to the two supporting tilting-pad bearings was systematically reduced at a number of operating speeds above the first bending mode of the shaft while vibration measurements were recorded. The results show significant subsynchronous vibration patterns and behaviors that are heavily dependent on load, operating speed, and oil supply flow rate. A discussion on the possible sources of the vibration follows including supporting evidence from thermoelastohydrodynamic (TEHD) bearing modeling results.

\subsection{TEST RIG DESCRIPTION}

All experimental testing was performed on the Rotating Machinery and Controls Laboratory (ROMAC) 'Stability Test Rig' located in the Department of Mechanical and Aerospace Engineering at the University of Virginia in Charlottesville, Virginia. This rig was originally developed to measure damped natural frequencies and damping ratios of an industrial-like rotor as a function of applied, destabilizing cross-coupled forces. The results of these tests, as well as a detailed description of the test rig, can be found in Cloud [8]. Those details pertinent to this study are provided here.

The rig, as depicted in Figure 3.1, consists of a $1.55 \mathrm{~m}$ long, flexible rotor with a $90 \mathrm{~mm}$ mid-span diameter. The rotor is supported by two tilting-pad bearings with a nominal diameter of $70 \mathrm{~mm}$ and a between-bearing span of $1.22 \mathrm{~m}$. Three mid-span disks with a $152 \mathrm{~mm}$ outer diameter provide lumped mass and inertia effects similar to those produced by the blades of a compressor or turbine stage. The rotor also contains three magnetic actuators. Two of these actuators, labeled AMB 1 and $\mathrm{AMB} 2$, are located between the supporting tilting-pad bearings. These magnetic actuators were used to apply static loads to the rotor in order to increase the specific loads acting on the tilting-pad bearings. A third, outboard magnetic actuator, labeled Shaker, was not used in this study. A $7.5 \mathrm{~kW}$, three-phase induction motor with amaximum speed of approximately 12,000 rpm drives the shaft and is controlled with a variable frequency drive (VFD).

Figure 3.2 provides a detailed drawing of the bearings used in this study. The bearings consist of five pads positioned

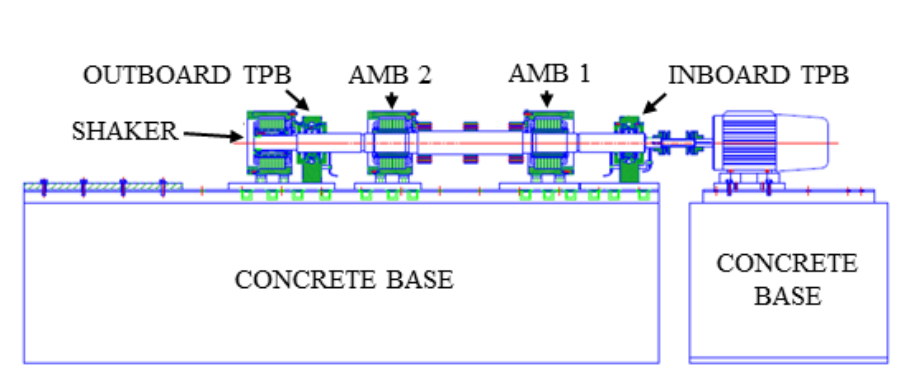

FIGURE 3.1. TEST RIG SET-UP [8].

in a load-between pad (LBP) configuration. Each pad is centrally positioned on a ball-in-socket, spherical pivot where the ball is constructed of steel and the pivot is constructed of brass. The pads are housed in a vintage flooded, pressurized housing design with oil inlet nozzles- the operating principles of which are described in detail by Nicholas [9]. Oil is introduced to the bearing cavity through the oil supply nozzles, located between each of the pads. The majority of the hot sump oil exits the bearing through two smaller discharge holes located on either side of each supply nozzle, while some leaks axially through two tight clearance floating end seals. ISO VG 32 oil was supplied to the bearings at $43.3^{\circ} \mathrm{C}$. Thermocouples embedded in the pads and labeled 'TC' were not utilized in the current study. A summary of the important test bearing parameters can be found in Table 3.1.

\subsection{EXPERIMENTAL METHODS}

The purpose of this study was to investigate the effects of oil supply flow rate on subsynchronous vibration behavior during supercritical operation. To this end, experimental steady-state vibration measurements were recorded for operating speeds ranging from $8,000 \mathrm{rpm}$ to $12,000 \mathrm{rpm}$ in $1,000 \mathrm{rpm}$ increments under a number of oil supply flow rates and loading conditions. The first load condition relied solely on the weight of the shaft to generate bearing specific loads of $124 \mathrm{kPa}$. These loads are considered relatively low for the size of the bearings; therefore, this condition is referred to as the low load or light load case. The second load condition used the mid-span actuators to provide static loads to the rotor to increase the bearing specific loads to $241 \mathrm{kPa}$. It is referred to as the mid load or moderate load case. The third load condition used the mid-span actuators to generate bearing specific loads of $365 \mathrm{kPa}$ and is referred to as the high load or heavy load case. For each speed and load operating condition, three to four different oil supply flow rates were investigated. The nominal flow rate to the bearings was considered to be 3.79 liters per minute (lpm) for all operating conditions. Different flow rates ranging from $60 \%$ to $120 \%$ of the nominal flow rate in $10 \%$ increments were considered based on the speed 


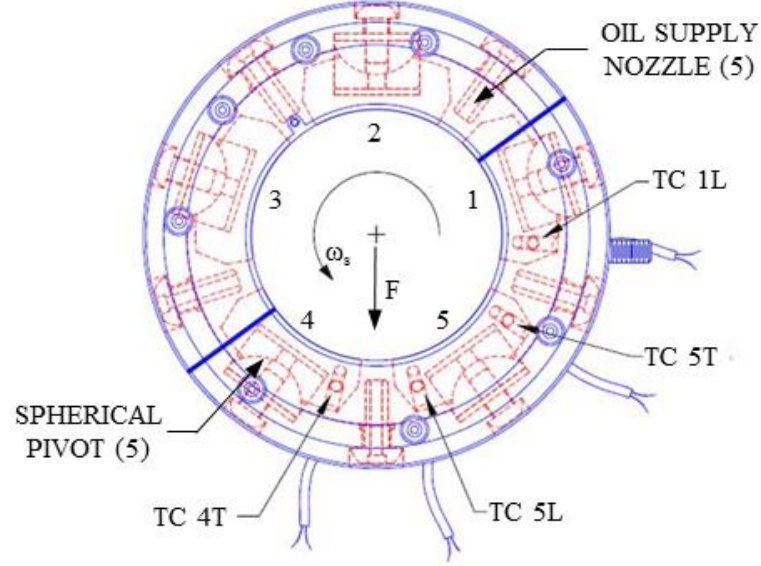

FIGURE 3.2. TEST BEARING DRAWING [8],

TABLE 3.1. TEST BEARING PARAMETERS.

\begin{tabular}{cc}
\hline Journal Diameter $(\mathrm{mm})$ & 70 \\
Pad Length $(\mathrm{mm})$ & 52 \\
Pad Arc Length $(\mathrm{deg})$ & 55 \\
Diametral Clearance $(\mu \mathrm{m})$ & 173 \\
Pad Offset Factor & 0.5 \\
Preload & 0.3 \\
Pad Configuration & LBP \\
Length/Diameter & 0.75 \\
Clearance Ratio $(\mu \mathrm{m} / \mathrm{mm})$ & 2.47 \\
Pad Thickness $(\mathrm{mm})$ & 15.5 \\
\hline
\end{tabular}

and load condition. Operation under some conditions did not allow for testing at lower flow rates due to high vibration levels and bearing temperatures. Flow rates were adjusted accordingly for each condition to produce a sufficient data set while maintaining safe machine operation. Table 3.2 presents the range of flow rates captured by the data as a percentage of the nominal flow rate for each speed and load condition. The nominal flow rate was tested under all operating conditions allowing for comparison of data across all running speeds and load conditions at a consistent flow rate.

Under each speed, load, and flow condition, the rotor was allowed to reach steady-state operating conditions by running for 10 minutes. This period allowed the bearings to reach thermal equilibrium and any transient vibration signatures to settle out. Once the system was at steady-state, vibration measurements in two orthogonal directions at the inboard
TABLE 3.2. OIL SUPPLY FLOW RATE TEST MATRIX (\% OF NOMINAL FLOW RATE, 3.79 LPM).

\begin{tabular}{cccc}
\hline & \multicolumn{3}{c}{ Specific Load } \\
Speed (rpm) & $124 \mathrm{kPa}$ & $241 \mathrm{kPa}$ & $365 \mathrm{kPa}$ \\
\hline 8000 & $60-100$ & $60-100$ & $60-100$ \\
9000 & $70-100$ & $60-100$ & $60-100$ \\
10000 & $80-100$ & $70-100$ & $60-100$ \\
11000 & $80-110$ & $80-110$ & $80-110$ \\
12000 & $90-120$ & $90-120$ & 100 \\
\hline
\end{tabular}

tilting-pad bearing were recorded for a 10 second period at a sampling frequency of 3,000 Hz. All measurements were taken using Bently Nevada 7200 series proximity sensors. For each set of measurements, ten 3,000-point FFTs, each representing one second of data, were averaged to obtain experimental frequency spectra with a frequency resolution of $1 \mathrm{~Hz}$. The samples were averaged in order to reduce the noise floor of the spectra. The frequency spectra in the two orthogonal directions were found to produce similar trends; therefore, only data from a single direction is presented in this paper. Table 3.3 provides the uncertainties associated with the operating conditions and measurements presented in this study.

Bearing models were created and analyzed using the ROMAC computer code MAXBRG, a sophisticated software algorithm based on thermoelastohydrodynamic (TEHD) lubrication theory developed by $\mathrm{He}$ [10]. This algorithm uses iterative numerical techniques to solve for pad pressure profiles, temperature distributions, and deformations. A 2D finite element formulation of the Reynolds equation is solved to obtain pressure profiles in the pad circumferential and axial directions. Velocity components are then calculated from pressure field gradients as a combination of Couette and Poiseuille flow. In turn, these velocity components are used in a 2D energy equation to solve for film temperature distributions in the circumferential and radial directions. Pad mechanical and thermal deformations are also considered. Advanced turbulence and groove mixing models are contained in all models. More details of the code's underlying physics, assumptions, boundary conditions, and numerical methods can be found in $\mathrm{He}[10]$.

A pad starvation model was developed as an improvement over the original flooded model to more accurately capture bearing dynamics and performance under low oil supply flow rate conditions [11]. The model determines if the user defined oil supply flow rate is sufficient to flood each pad by comparing it to the calculated value at the pad inlet obtained 
TABLE 3.3. OPERATING CONDITION AND MEASUREMENT UNCERTAINTIES.

\begin{tabular}{cc}
\hline Specific Load & $+/-5 \%$ \\
Oil Supply Flow Rate & $+/-2 \%$ \\
Displacement & $+/-2 \%$ \\
\hline
\end{tabular}

by integrating the circumferential velocity components. If the available flow rate to one or more of the pads is insufficient, the film onset angle from the leading edge of those pads is adjusted, effectively reducing the pad arc length. As oil supply flow rate is further reduced, pads can also become fullycavitated. A fully-cavitated pad does not develop any hydrodynamic film and is thus, unloaded. Analysis results from the bearing models are used to help gain insight into the experimental results.

\subsection{RESULTS}

\subsubsection{Ramp-up Waterfall Plot}

Ramp-up data was first recorded with the nominal oil supply flow rate under the low load condition in order to get initial measurements of the vibration patterns of the shaft as it ramped up from low speed to maximum operating speed under baseline conditions. Vibration data was obtained as the rotor accelerated from 1,000 rpm to $12,000 \mathrm{rpm}$ at a constant rate of $15 \mathrm{rpm}$ per second over a 12.5 minute time frame. Figure 3.3 illustrates the resulting waterfall plot as obtained from the vibration data. The synchronous (i.e. 1x) line can be seen crossing the spectrum from $16 \mathrm{~Hz}$ at the start of the ramp-up to $200 \mathrm{~Hz}$ at the conclusion. The first bending mode is seen along the synchronous line around 5,000 rpm $(83 \mathrm{~Hz})$. As seen in Fig. 3.3, a severe subsynchronous peak emerges at speeds above $8,000 \mathrm{rpm}(133 \mathrm{~Hz})$ and increases in amplitude with increased running speed. The subsynchronous peak occurs at the first bending mode of the shaft and remains in the approximately $0.45-0.55 \mathrm{x}$ running speed subsynchronous range throughout the conclusion of the ramp-up. At higher speeds, the magnitude of the subsynchronous component exceeds the magnitude of the synchronous component. The following study will provide an in depth look at the effects of speed, load, and oil supply flow rate on these subsynchronous vibrations.

\subsubsection{Subsynchronous Vibration vs. Running Speed}

Steady-state vibration measurements were recorded for all operating speeds at the nominal oil supply flow rate of 3.79 lpm in order to observe the effects of running speed on the

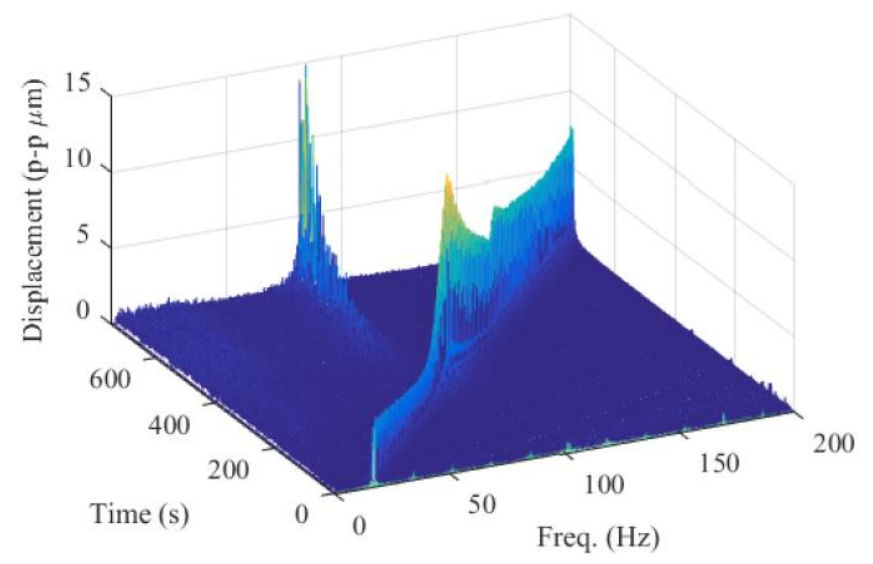

FIGURE 3.3. RAMP-UP WATERFALL PLOT 1,000-12,000 RPM, NOMINAL FLOW RATE, LOW LOAD,

subsynchronous vibration patterns. Testing was first performed under the low load condition with a bearing specific load of $124 \mathrm{kPa}$. Figure 3.4 overlays the frequency response spectrum from $0-200 \mathrm{~Hz}$, corresponding to the maximum operating speed frequency, for all five speed cases. The synchronous frequency components of these tests can be seen as peaks on the right side of the graph starting at $133 \mathrm{~Hz}$ and progressing upward to $200 \mathrm{~Hz}$. For all speed cases, a low-amplitude broadband vibration pattern on the scale of roughly $0.5 \mu \mathrm{m}$ is observed from 0 to approximately $75 \mathrm{~Hz}$. A subsynchronous peak emerges between 75 and $80 \mathrm{~Hz}$ at a running speed of $9,000 \mathrm{rpm}$ at the first bending mode of the shaft. Figure 3.5 provides a closer look at these peaks with a zoomed in frequency range of 40-100 Hz. The subsynchronous peak increases in severity of both amplitude and slope with increased running speed. The frequency of the peak increases slightly with running speed and remains in the approximately $0.45-0.55 x$ running speed subsynchronous range. Next, the tests were repeated under the moderate load condition. The frequency spectrums of the vibration patterns observed under these tests were similar to those seen under the first load condition and are not presented here for brevity purposes.

The bearing specific loads were increased to the high load condition, $365 \mathrm{kPa}$, and the tests were repeated. Figure 3.6 illustrates the frequency response of the five speed cases under the third load condition. Like the first load condition, synchronous frequency components can be seen from 133-200 Hz. A similar broadband, low-amplitude pattern is also observed from approximately 0 to $75 \mathrm{~Hz}$. Unlike the high amplitude subsynchronous peaks seen at the first bending mode under the first two load conditions, the peaks seen around $75 \mathrm{~Hz}$ under the high load condition are much lower in amplitude. Despite a smaller scale, these peaks are still 


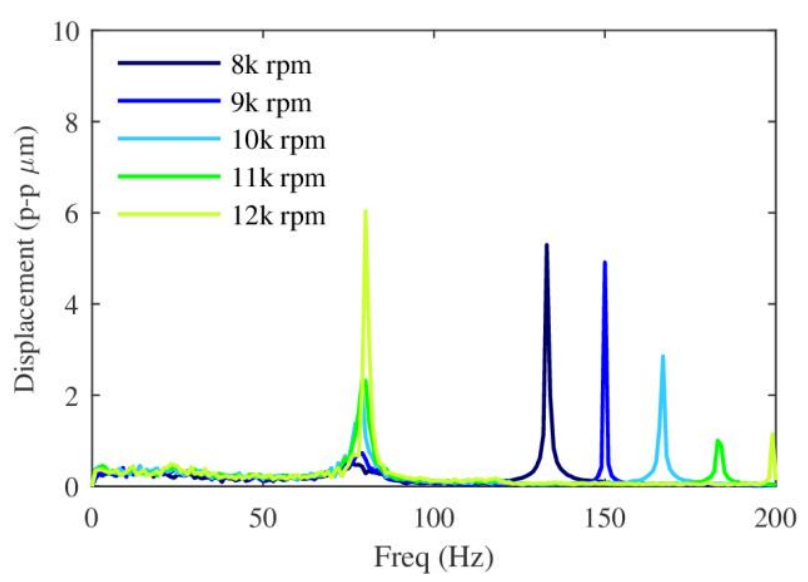

FIGURE 3.4. FREQUENCY RESPONSE VS RUNNING SPEED 0-200 HZ, NOMINAL FLOW RATE, LOW LOAD,

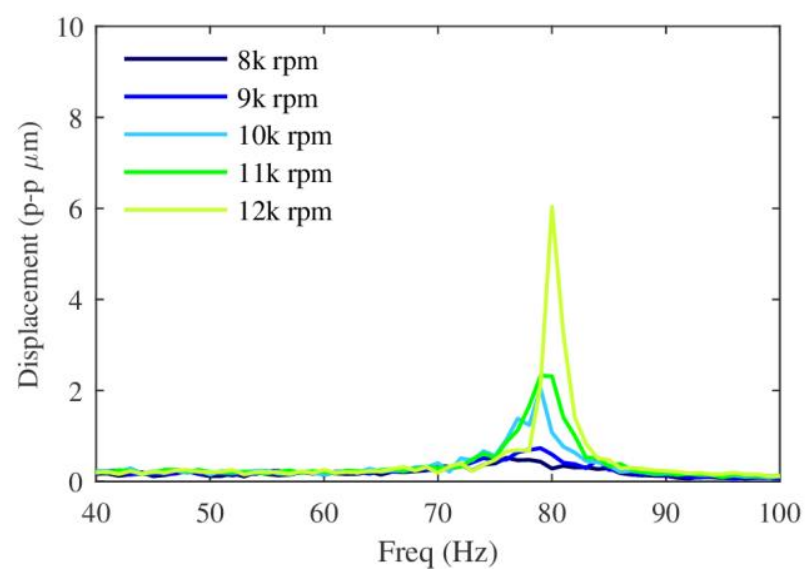

FIGURE 3.5. FREQUENCY RESPONSE VS RUNNING SPEED 0-100 HZ, NOMINAL FLOW RATE, LOW LOAD,

distinguishable and still appear to increase slightly in magnitude with running speed.

The maximum displacements of the subsynchronous components were plotted against running speed for each load condition as shown in Figure 3.7. Under all load conditions, the subsynchronous peak increased with increasing running speed. As observed above, the magnitude of the peak under the highest bearing specific load is smaller than that under the first two loads for nearly all speed cases. Also, the rate of increase in the subsynchronous peak with speed is noticeably less dramatic under the heavy load condition.

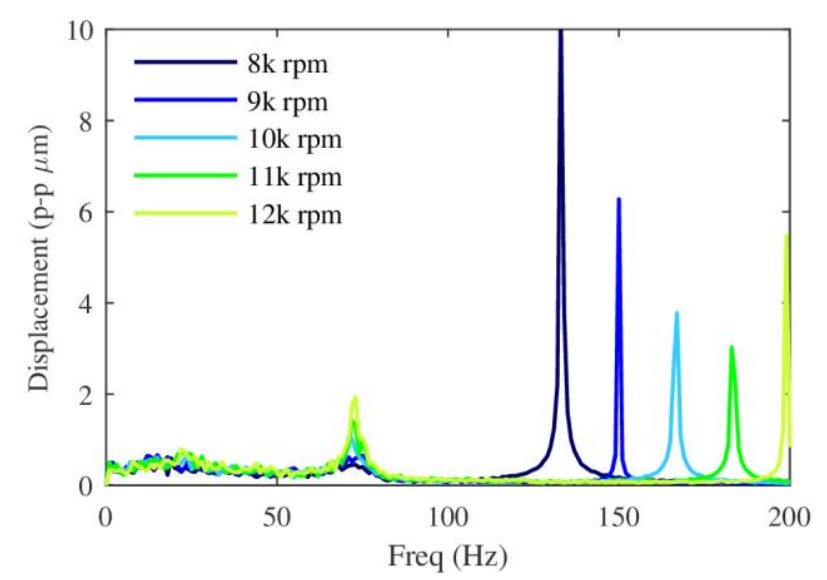

FIGURE 3.6. FREQUENCY RESPONSE VS RUNNING SPEED 0-200 HZ, NOMINAL FLOW RATE, HIGH LOAD,

\subsubsection{Subsynchronous Vibration vs. Oil Supply Flow Rate}

Next, at each load condition and running speed, the oil supply flow rate was adjusted from the nominal rate of 3.79 $1 \mathrm{pm}$ in order to see its effects on the subsynchronous vibration patterns and peaks. All running speeds under the first bearing load of $124 \mathrm{kPa}$ were tested first. Similar broadband lowamplitude vibrations and peaks at the first bending mode of the shaft like those seen in the previous study were observed under all speed and flow conditions. Figure 3.8 illustrates the frequency response spectrum of the rotor operating at 9,000 rpm under the first load condition for four distinct oil supply flow rates ranging from $70-100 \%$ of the nominal flow rate. A synchronous vibration component is seen at $150 \mathrm{~Hz}$ while subsynchronous peaks for the various flow rates are seen between 75 and $80 \mathrm{~Hz}$. The magnitude of the sub-synchronous peak increases with each decrease in oil supply flow rate. The frequency of the peak also decreases slightly as the flow rate is decreased but remains in the approximately 0.5-0.55x running speed subsynchronous region. Figure 3.9 shows the frequency spectrum of the rotor operating at 11,000 rpm under the low load condition for four oil supply flow rates ranging from 80$110 \%$ of the nominal flow rate. The rise in the subsynchronous peak with decreasing flow rate is much more dramatic at higher speeds. Like the previous speed dependent study, similar frequency spectra and trends with respect to flow rate were observed under the moderate load condition and are not presented here for brevity purposes.

Figures 3.10 and 3.11 show the maximum subsynchronous peak displacements for each running speed as a function of flow rate for the low and medium load cases, respectively. For each running speed under both load cases, the peak subsynchronous displacement drops with increasing oil supply 


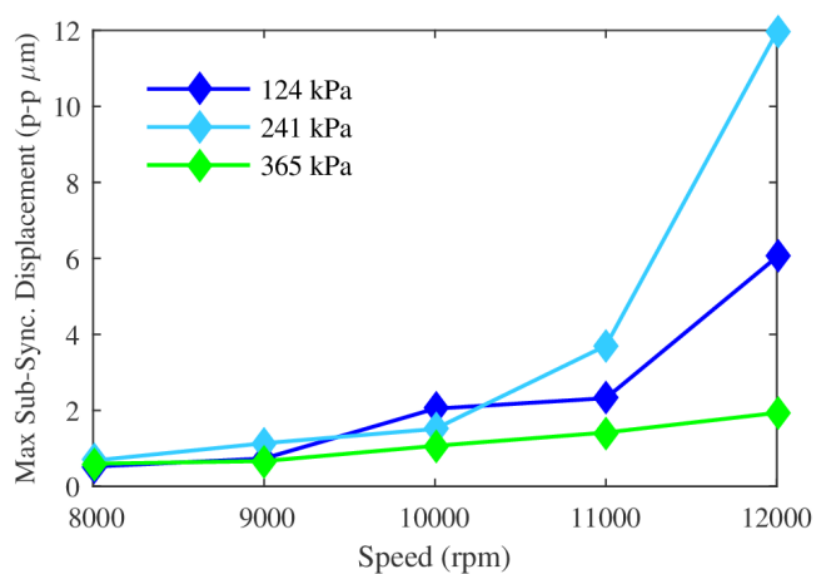

FIGURE 3.7. MAXIMUM SUBSYNCHRONOUS VIBRATION DISPLACEMENT VS SPEED, NOMINAL FLOW RATE,

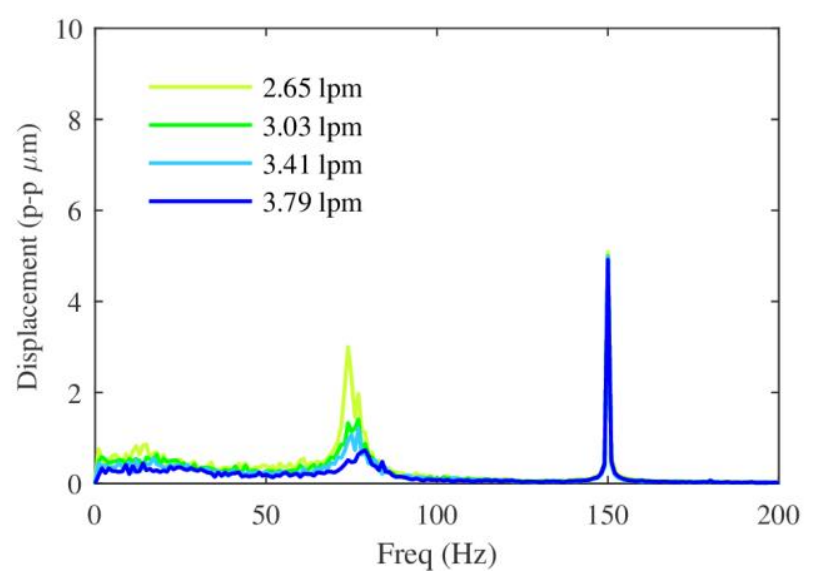

FIGURE 3.8. FREQUENCY RESPONSE VS OIL SUPPLY FLOW RATE 0-200 HZ, 9,000 RPM, LOW LOAD,

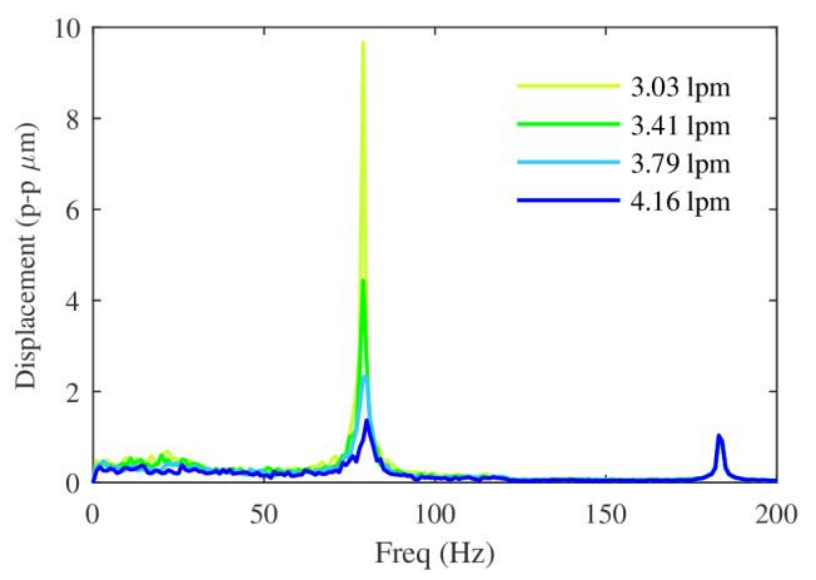

FIGURE 3.9. FREQUENCY RESPONSE VS OIL SUPPLY FLOW RATE 0-200 HZ, 11,000 RPM, LOW LOAD, flow rate. Testing at lower flow rates was stopped for each speed and load case if vibration levels or bearing temperatures became too high and machine operation was deemed unsafe. Typically, audible rumbling and churning in the bearing housings accompanied either high vibration levels or bearing temperatures at the lowest tested oil supply flow rates. It is clear from the flow rates tested that higher operating speeds require greater oil supply flow rates to maintain low subsynchronous peak displacements. For instance, in reference to Fig. 3.10, the subsynchronous peak amplitude could be maintained at $2 \mu \mathrm{m}$ with an appropriate increase in oil supply flow rate with each increase in speed. It is also clear that under the low and moderate load conditions, an increase in oil supply flow rate can significantly reduce the magnitude of the subsynchronous vibration peak.

Similar to the speed dependent study, the magnitude of the subsynchronous peak under the high load condition was much smaller than those seen under the previous two load conditions for all speeds and oil supply flow rates tested. Figure 3.12 illustrates the frequency response of the rotor operating at $11,000 \mathrm{rpm}$ under the high load condition for four oil supply flow rates ranging from $80-110 \%$ of the nominal flow rate. When compared to Figure 3.9, which shows the same speed and flow rates under the low load case, it is clear that the subsynchronous peak is much less severe. Although the peak is still distinguishable at all flow rates, a difference in the magnitude of the peak with flow rate is not discernable. Figure 3.13 shows the maximum displacement of the subsynchronous peak as a function of flow rate for each speed under the high load condition. As previously stated, the magnitude of these peaks is much lower than those seen under the first two load conditions. There is no distinguishable trend between either flow rate or speed and subsynchronous peak amplitude.

\subsection{Discussion}

It is clear from the waterfall plot presented in Fig. 3.3 that the test rig rotor experiences severe subsynchronous vibrations at higher supercritical operating speeds. The peak subsynchronous amplitude occurs at the first bending mode of the shaft at approximately $0.45-0.55 \mathrm{x}$ the operating speed. The peak amplitude increases with increased operating speed, while its frequency remains at the first bending mode. Subsequent testing shows that the peak amplitude increases significantly with both increased running speed and decreased oil supply flow rate under light to moderate load conditions; however, running speed and flow rate have very little effect on the peak amplitude under more heavily loaded conditions. Under all operating conditions a low amplitude, broadband, subsynchronous vibration pattern is observed from 


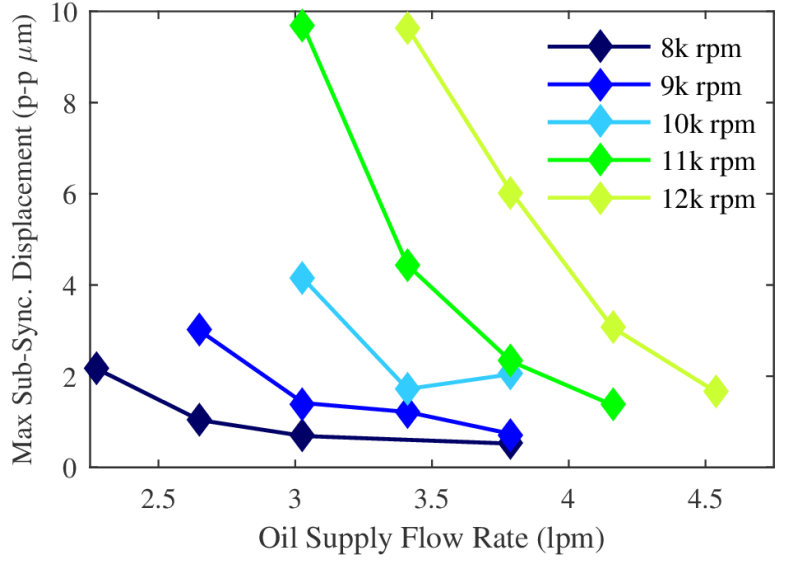

FIGURE 3.10. MAXIMUM SUBSYNCHRONOUS VIBRATION DISPLACEMENT VS FLOW RATE, LOW LOAD,

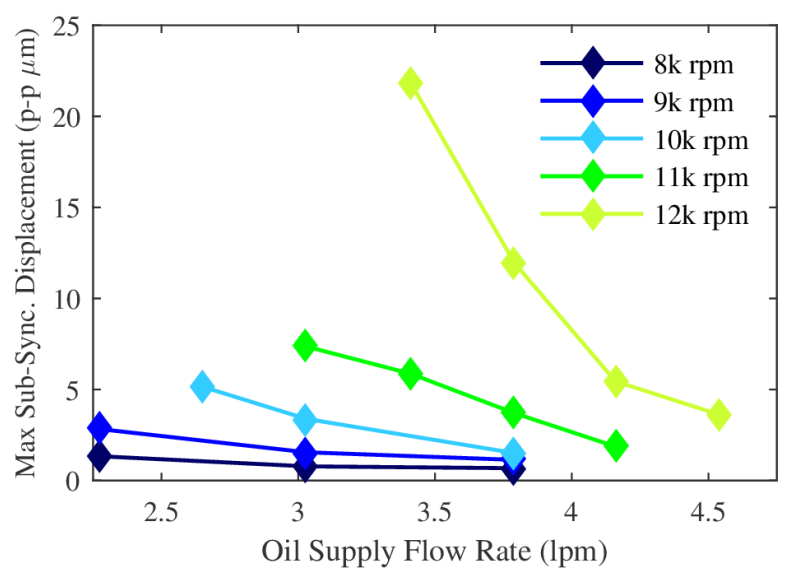

FIGURE 3.11. MAXIMUM SUBSYNCHRONOUS VIBRATION DISPLACEMENT VS FLOW RATE, MEDIUM LOAD,

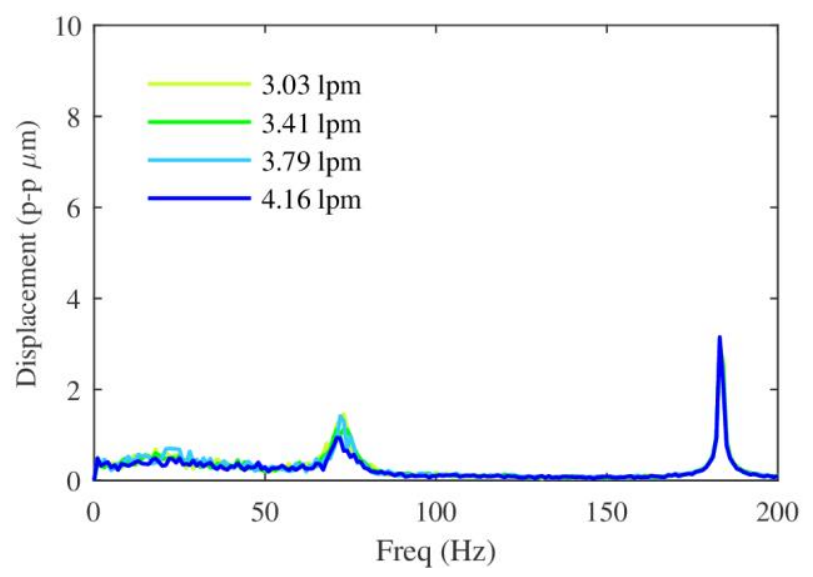

FIGURE 3.12. FREQUENCY RESONSE VS OIL SUPPLY FLOW RATE 0-200 HZ, 11,000 RPM, HIGH LOAD,

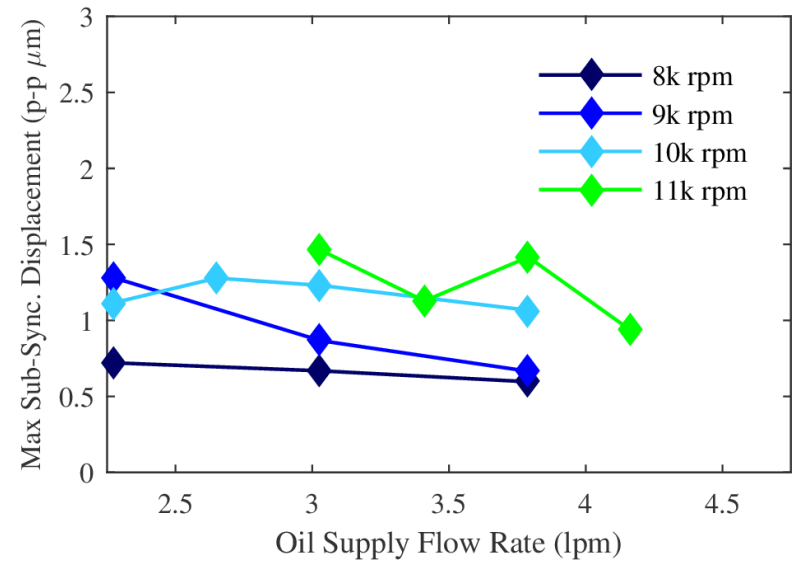

FIGURE 3.13. MAXIMUM SUBSYNCHRONOUS VIBRATION DISPLACEMENT VS FLOW RATE, HIGH LOAD,

approximately 0 to $75 \mathrm{~Hz}$ up to the peak at the shaft bending mode.

The vibration patterns seen in the waterfall plot in Fig. 3.3 present a classic illustration of an oil whip instability; however, these vibrations are believed to be a forced response phenomenon in which the shaft is being excited at its first natural frequency. For all operating conditions, the amplitude of the subsynchronous peak remained constant during the time spent obtaining measurements under a given operating condition. By definition, an instability at the natural frequency would grow without bound or until a non-linear limit cycle was met. A constant peak over time indicates that the rotor remained stable throughout all tests and that any subsynchronous vibration patterns represent the shaft response to some forcing mechanism.

While tilting-pad bearings should inherently produce insignificant levels of cross-coupled stiffness, some studies have observed self-excited whip related vibration phenomena in tilting-pad bearings with heterogeneous bearing clearances [12]. Additionally, similar behavior has been observed in industrial tilting-pad bearings with relatively large spherical pivots. It is possible that pads supported by spherical pivots may encounter some level of pad sticking, especially under lightly loaded operating conditions. If indeed one or more pads are not able to freely rotate about their pivots, those pads would effectively act as fixed pads and could potentially produce destabilizing cross-coupled forces.

During testing, as the rotor was brought up to maximum speed from rest, the shaft centerline was observed to arc noticeably from left to right in a horizontal motion as the shaft rose vertically within the bearing clearance with increasing speed. This arcing motion is typical of fixed geometry bearings and would thus suggest sticking of one or more pads. After 
ramping up to full speed, the shaft centerline would then follow a repeatable, purely vertical path as the rotor speed was decreased and increased through the tested operational speed range. This strictly vertical path is typical of tilting-pad bearings and indicative of freely pivoting bearing pads. This full speed ramp-up procedure, believed to free any pads of sticking to their pivots, was performed prior to all testing; therefore, increased cross-coupled stiffness and self-excitation due to pad sticking are not believed to be a cause of the subsynchronous vibration peaks presented in this study.

The low-amplitude, broadband subsynchronous vibration observed under all tested operating conditions is similar to the SSV hash investigated by DeCamillo et al. [3] and attributed to pad vibrations of partially and/or fully unloaded pads. While the SSV hash in that study typically appeared at frequency ratios of $0-0.10 x$ the running speed, the vibration signatures in this study cover a larger frequency spectrum reaching frequency ratios of $0.45-0.55 \mathrm{x}$ the running speed and encompassing the first shaft bending mode. The prominent subsynchronous peak at the first bending mode is comparable to the $0.5 \mathrm{x}$ the running speed peak observed by Adams and Payandeh [2] in conventional, flooded bearings similar to those used in the present study. These vibrations were attributed to pad flutter of unloaded pads. Based on the subsynchronous vibration patterns observed in this study and previous studies, it is reasonable to conclude that both the lowamplitude, broadband vibration pattern and subsynchronous peak are forced response phenomena resulting from unloaded pad vibrations.

Since pad motion was not measured in the present study, theoretical TEHD modeling results are used to provide insight into possible pad cavitation under all of the operating conditions tested. Figure 3.14 illustrates the pressure profiles as obtained by the starved TEHD bearing model for all speeds at the nominal flow rate and low load condition. The peak pad pressure for all speed conditions is provided at the end of the figure caption. The theoretical results show slight cavitation at the leading edge of the top pad at $8,000 \mathrm{rpm}$ that increases noticeably at $9,000 \mathrm{rpm}$. At the top three speeds from 10,000$12,000 \mathrm{rpm}$, the top pad is predicted to be fully starved and thus, unloaded. Figure 3.15 shows the predicted pressure profiles at $11,000 \mathrm{rpm}$ for the low load case and flow rates ranging from $80-110 \%$ of nominal. The top pad is predicted to be unloaded for all flow rates below $4.16 \mathrm{lpm}$ while the upper right side pad experiences cavitation at the leading edge that increases with decreasing flow rate. The upper right pad is also fully unloaded at the lowest flow condition. In reference to Fig. 3.4, the subsynchronous peak emerges at 9,000 rpm and begins to increase dramatically at $10,000 \mathrm{rpm}$ at the nominal flow rate and low load condition. This is the exact speed range where the starved TEHD model predicts that the top pad will

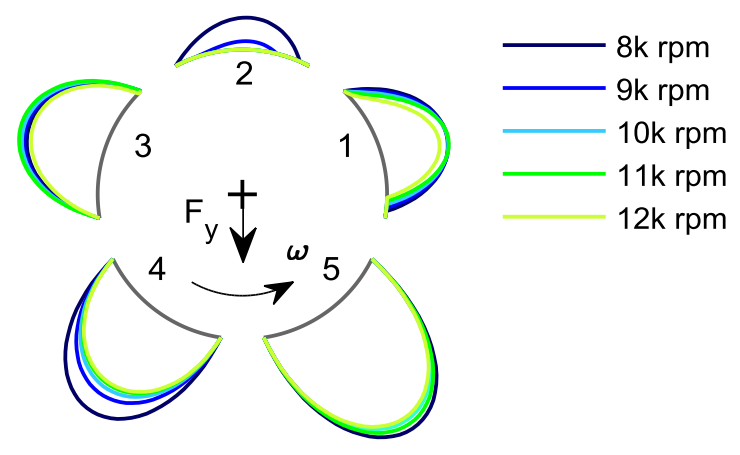

FIGURE 3.14. PREDICTED PRESSURE PROFILES VS SPEED, NOMINAL FLOW RATE, LOW LOAD (581 KPA MAX).

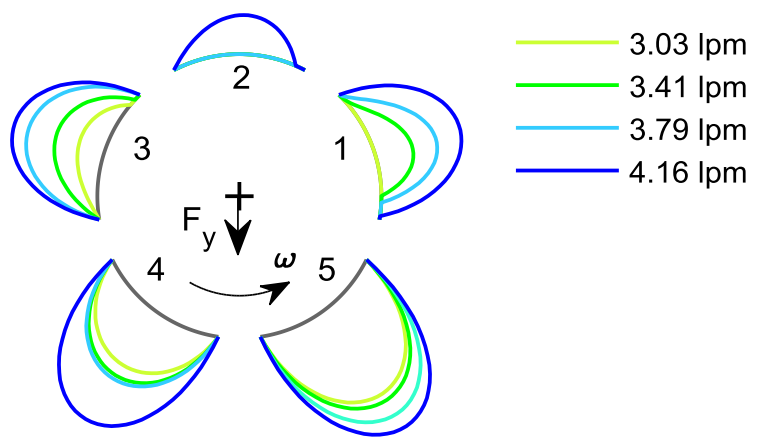

FIGURE 3.15. PREDICTED PRESSURE PROFILES VS FLOW RATE, 11,000 RPM, LOW LOAD (627 KPA MAX).

become unloaded under the same operating conditions as observed in Fig. 3.14. Prominent subsynchronous peaks in Fig. 3.9 increase in amplitude with decreasing flow rate correspond to a predicted unloaded top pad for the lower three flow rates and an increasingly cavitated upper right pad as observed in Fig. 3.15. The predicted pressure profiles obtained from the starved TEHD bearing model under the low load condition support the theory that the subsynchronous response measured in the rotor is a forced vibration response due to upper pad flutter.

Figure 3.16 shows predicted pressure profiles versus running speed for the nominal flow rate and high load conditions. The pressure profiles are nearly identical for all speeds. The top three pads are predicted to be fully unloaded while the bottom two pads have sufficient oil flow to develop a full film wedge and support the shaft. Figure 3.17 illustrates the predicted pressure profiles for flow rates ranging from 80$110 \%$ of the nominal for the high load condition at 11,000 
rpm. Similarly to the speed dependent profiles, the predicted pressures do not change with flow rate with the top pads remaining unloaded and the bottom pads supporting the shaft. Nearly identical pressure profiles for all speed and flow rates presented for the high load case support the very small variations in subsynchronous response observed in Figs. 3.6 and 3.12. The low amplitude, broadband vibrations and small subsynchronous peak amplitudes seen in these figures can still be attributed to pad flutter in one or more of the top three unloaded pads. The smaller amplitude when compared to the lower load cases can be justified by a higher shaft eccentricity ratio that results in increased bearing damping and therefore, an increased attenuation of the first bending mode response.

While the observed data and supporting modeling results suggest that the observed subsynchronous behavior is a forced response to unloaded pad vibrations and that no system instabilities occurred during testing, the sharp increase in the 0.50x the running speed component with changing operating conditions under the first two load conditions does have implications on the system stability. Such an increase in the forced response of the rotor is either the result of an increase in the intensity of the forcing mechanism or a change in the system dynamics- specifically, a decrease in the system damping ratio. Practical considerations as well as a constant amplitude in the low-amplitude, broadband subsynchronous signature for all operating conditions suggest that the drastic increase in the subsychronous peak is not the result of a drastic increase in the driving pad vibrations. It then stands to reason that the rise in the peak amplitude is caused by a decrease in system damping ratio.

The main source of damping for this system can be attributed to the fluid-film bearings; therefore, the system-level damping ratio can be significantly decreased by a decrease in the damping forces supplied by the supporting bearings. As shown in Figs. 3.14 and 3.15 and previously discussed, the TEHD starved bearing model predicts leading edge pad cavitation in the upper and upper right pads that increases in severity with increasing speed and decreasing oil supply flow rate for lightly loaded bearing conditions. This progressive decrease in the development of a hydrodynamic film layer results in a decrease in bearing damping. Under lightly and moderately loaded conditions, this study suggests that insufficient oil supply flow rates at higher speeds may have a detrimental effect on damping ratio and stability margins.

Under the high load condition, running speed and oil supply flow rate had a negligible effect on the subsynchronous peak amplitude. As shown in Figs. 3.16 and 3.17, the TEHD starved bearing model predicts that while the top three pads remain unloaded, there is sufficient oil to fully flood the bottom two pads resulting in little to no change to the pad pressure profiles for the speed and flow rates tested. These

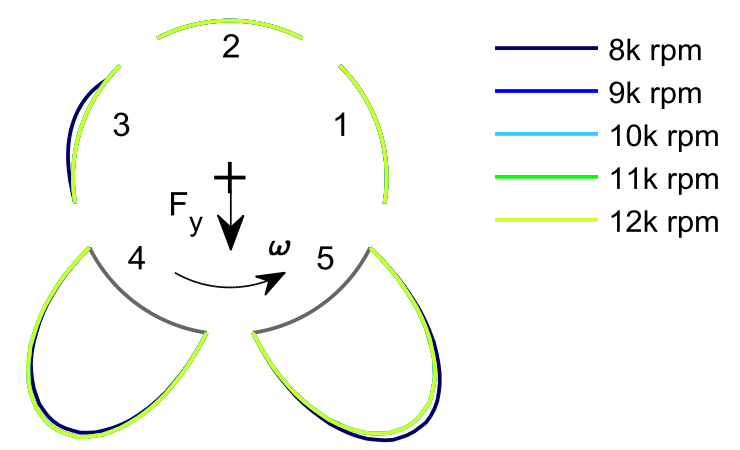

FIGURE 3.16. PREDICTED PRESSURE PROFILES VS SPEED, NOMINAL FLOW RATE, HIGH LOAD $(1,089$ KPA MAX).

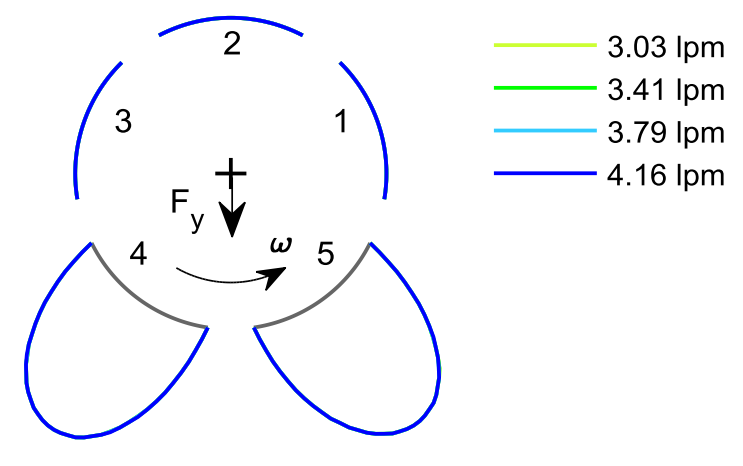

FIGURE 3.17. PREDICTED PRESSURE PROFILES VS FLOW RATE, 11,000 RPM, HIGH LOAD (1,034 KPA MAX).

results suggest that under certain, specific operating conditions, the oil supply flow rate might be reduced to increase machine efficiency without significantly effecting bearing damping. These conditions are highly machine specific. Any reduction in oil supply flow rate should be accompanied by careful vibration and bearing temperature monitoring. Conversely, if high subsynchronous vibrations with the same signature as those observed in this study are observed and unloaded pads are suspected, subsynchronous vibration amplitudes may be decreased with increased oil supply flow rate.

\subsection{CONCLUSIONS}

- Low-amplitude, broadband subsynchronous vibration patterns with a high-amplitude peak component at the first bending mode of the shaft were observed in a flexible rotor during supercritical operation. 
- The subsynchronous peak amplitude increased dramatically with increased operating speed and decreased oil supply flow rate under low and moderate load conditions.

- The subsynchronous peak amplitude was significantly smaller under high loads. Additionally, the subsynchronous vibration signature did not vary significantly with either running speed or oil supply flow rate under these loads.

- TEHD bearing models predict unloaded top pads under high speed and low oil supply flow rate conditions that appear to correlate with the rise in subsynchronous peak amplitude under low and moderate load conditions.

- TEHD bearing models predict nearly identical pressure profiles for all speeds and flow rates tested under the high load condition. These results appear to correlate to nearly constant subsynchronous vibration patterns observed at these operating conditions.

- The TEHD bearing model results coupled with the results reported in previous studies suggest that the subsynchronous vibration patterns observed in the present study are a forced vibration phenomenon resulting from pad vibrations of the unloaded upper pad(s).

- The drastic increase in subsynchronous peak amplitude suggests that both increased running speed and decreased oil supply flow rate result in a decrease in system damping ratio under low and moderate load conditions.

- Results at high loads suggests that there may in fact be some operating conditions where the oil supply flow rate may be reduced in order to increase machine efficiency. It is emphasized that these conditions are highly machine dependent. It is strongly suggested that such operations be approached with caution with vibration levels and bearing operating temperatures closely monitored.

- High subsynchronous vibrations believed to be caused by unloaded pad vibrations may be attenuated with increased oil supply flow rate.

\subsection{REFERENCES}

[1] Newkirk, B. L. and Taylor, H. D., 1925, "Shaft whipping due to oil action in journal bearing". General Electric Review, 28(8), pp. 175-182.

[2] Adams, M. L. and Payandeh, S., 1983, "Self-excited vibrations of statically unloaded pads in tilting-pad bearings". ASME Journal of Lubrication Technology, 105, pp. 377-384.

[3] DeCamillo, S. M., He, M., and Cloud, C. H., 2008. "Journal bearing vibration and SSV hash". In Proceedings of the Thirty-Seventh Turbomachinery Symposium, pp. $11-22$.
[4] Nicholas, J. C., 2003. "Tilting pad journal bearings with spray-bar blockers and by-pass cooling for high speed, high load applications". In Proceedings of the ThirtySecond Turbomachinery Symposium, pp. 27-37.

[5] Brockwell, K., Dmochowski, W., and DeCamillo, S., 1994. "Analysis and testing of LEG tilting pad journal bearing- a new design for increasing load capacity, reducing operating temperatures and conserving energy". In Proceedings of the Twenty-Third Turbomachinery Symposium, pp. 43-56.

[6] DeCamillo, S. and Brockwell, K. 2001. "A study of parameters that affect pivoting shoe journal bearing performance in high-speed turbomachinery". In Proceedings of the Thirtieth Turbomachinery Symposium, pp. 9-22.

[7] Dmochowski, W. and Blair, B., 2006. "Effect of oil evacuation on the static and dynamic properties of tilting pad journal bearings". Tribology Transactions, 49(4), pp. 536-544.

[8] Cloud, C. H., 2007. "Stabillity of rotors supported on tilting-pad journal bearings". Ph.D. Dissertation, University of Virginia, Charlottesville, Virginia.

[9] Nicholas, J. C., 1994. "Tilting pad bearing design." In Proceedings of the Twenty-Third Turbomachinery Symposium, College Station, Texas, pp. 179-194.

[10] He, M., 2003. "Thermoelastohydrodynamic analysis of fluid film journal bearings". Ph.D. Dissertation, University of Virginia, Charlottesville, Virginia.

[11] He, M., Allaire, P. E., Barrett, J., and Nicholas, J. C., 2005. "Thermohydrodynamic modeling of leading-edge groove bearings under starved conditions". Tribology Transactions, 48, pp. 362-369.

[12] Taura, H., and Tanaka, M., 2004. "Self-excited vibration of elastic rotors in tilting pad journal bearings". In Proceedings of the Eight International Conference on Vibrations in Rotating Machinery, pp. 35-43. 


\section{CHAPTER 4: ROTOR DAMPED NATURAL FREQUENCIES AND STABILITY UNDER REDUCED OIL SUPPLY FLOW RATES}

\subsection{INTRODUCTION}

High-speed rotating machines such as pumps, compressors, and turbines across a wide array of industries rely on tilting-pad, fluid-film journal bearings to provide static support to the shaft while introducing stabilizing damping forces into the system through the development of a hydrodynamic film wedge. These damping forces counteract destabilizing, cross-coupled forces that are often caused by dynamic fluid-structure interactions and act to promote a shaft procession, or whirling motion, in the direction of shaft rotation. As the limits of operating speeds and loads of rotating machinery are pushed increasingly higher, these destabilizing forces are becoming ever larger, and greater care must be taken to ensure the stability of these machines. Engineers rely heavily on both existing experimental data and theoretical models of tilting-pad bearings to predict bearing performance and system stability.

Tilting-pad bearings depend on a constant flow of fresh oil to keep bearing temperatures low while providing sufficient oil to support the shaft. Traditionally, oil is supplied at an adequate flow rate to flood the bearing pads, producing a fully developed film layer over all pad surfaces. Reduction of the oil supply flow rate may cause cavitation, or lack of a fullydeveloped film layer, over one or more of the pads. This condition is commonly referred to as starved. The extent of bearing starvation is heavily dependent on the oil delivery method, housing design, and operating condition. Numerous experimental studies have looked at the effects of reduced oil supply flow rate on steady-state bearing performance for various bearing designs and operating conditions [1-3]. It is well-documented that reduced oil supply flow rates result in decreased operational power losses at the expense of increased operating temperatures. While these effects are widely known, fewer studies have been published that focus on the effects of flow rate on dynamic bearing performance or system stability.

Dmochowski and Blair [4] investigated the effects of reduced oil flow rate and housing evacuation on the stiffness and damping coefficients of tilting-pad bearings. While a $30 \%$ reduction in the horizontal stiffness and damping coefficients was reported in the evacuated design, insignificant changes to dynamic bearing performance were observed in the flooded design. DeCamillo et al. [5] observed the effects of oil supply flow rate and bearing evacuation on a low-frequency, low amplitude, broadband subsynchronous vibration phenomenon encountered in a number of industrial machines. The study shows increasing amplitude of this vibration signature with decreasing flow rate in flooded bearings across a number of operating conditions, with the effects of flow rate less consistent, and more dependent on operating conditions, in evacuated designs.

A previous study by the authors [6] looked at the effects of oil supply flow rate on subsynchronous vibration signatures of a flexible shaft during supercritical operation. A test rig designed to be dynamically similar to a modern, industrial machine and supported by tilting-pad bearings in conventional, flooded housings was used in the study. An approximately $0.5 \mathrm{x}$ subsynchronous vibration peak was observed at the first bending mode of the shaft that increased significantly in 
amplitude with decreasing flow rate under lightly loaded bearing conditions. After applying some load to the bearings, the peak amplitude was greatly attenuated and the effects of oil supply flow rate on the peak were negligible. TEHD modeling results showed a progressive increase in starvation over the upper pads under the lightly loaded condition. It was concluded that a decrease in film development under these conditions attributed to a decrease in system damping ratio and, in turn, an increase in the subsynchronous peak amplitude.

The present study builds on the results of the previous study and adds to the limited body of literature pertaining to the effects of oil supply flow rate on dynamic bearing performance and system stability. Using the same test rig as the aforementioned study, the oil supply flow rate to the bearings is systematically reduced under a number of supercritical operating speeds and bearing load conditions. At each condition, the shaft is perturbed to measure modal properties, specifically damped natural frequency and damping ratio, through common system identification techniques. Experimentally identified damping ratios are compared to theoretical predictions using dynamic coefficients obtained from TEHD bearing models. Both flooded and starved bearing flow assumptions are considered in the bearing models and compared to the data. The effects of operating speed, bearing load, and oil supply flow rate on system stability under the tested bearing design are presented. Trends from the flooded and starved bearing models are compared to experimental trends in an effort to determine which flow assumption is more valid for the bearings and operating conditions tested.

\subsection{TEST RIG AND BEARING DESCRIPTION}

This rig used in this study was originally developed to measure system damped natural frequencies and damping ratios as a function of applied, destabilizing cross-coupled forces. It was designed to have dynamic characteristics similar to those found in modern, industrial rotating machines including a critical speed ratio greater than two and mode shapes analogous to those of a between-bearing machine. The results of these tests, as well as a detailed description of the test rig, can be found in Cloud [7]. Those details pertinent to this study are provided here.

The rig, as depicted in Figure 4.1, consists of a $1.55 \mathrm{~m}$ long, flexible rotor with a $90 \mathrm{~mm}$ mid-span diameter. The rotor is supported by two tilting-pad bearings with a nominal diameter of $70 \mathrm{~mm}$ and a between-bearing span of $1.22 \mathrm{~m}$. Three mid-span disks with a $152 \mathrm{~mm}$ outer diameter provide lumped mass and inertia effects similar to those produced by the blades of a compressor or turbine stage. The rotor also contains three magnetic actuators. Two of these actuators, labeled AMB 1 and AMB 2, are located between the

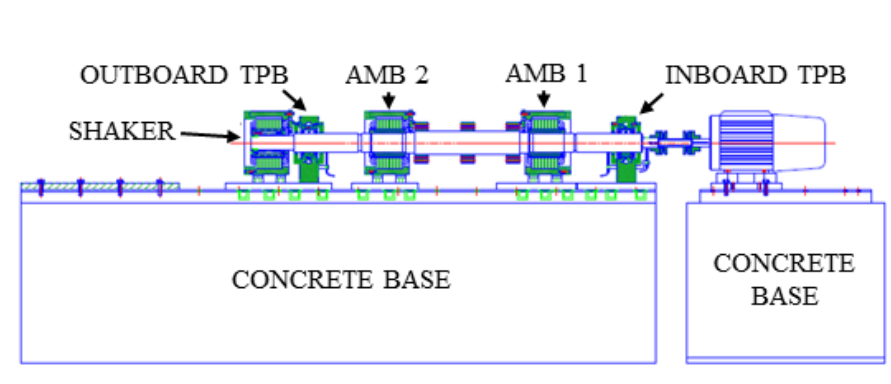

FIGURE 4.1. TEST RIG SET-UP [7].

supporting tilting-pad bearings. These actuators are used to apply static loads to the rotor in order to increase the specific loads acting on the tilting-pad bearings. A third, outboard magnetic actuator, labeled Shaker, is used to perturb the shaft for system parameter identification purposes as discussed in detail below. A $7.5 \mathrm{~kW}$, three-phase induction motor with a maximum speed of approximately 12,000 rpm drives the shaft and is controlled with a variable frequency drive (VFD).

Figure 4.2 provides a detailed drawing of the bearings used in this study including pad numbers and load orientation. The bearings consist of five pads positioned in a load-between pad (LBP) configuration. Each pad is centrally positioned on a ball-in-socket, spherical pivot where the ball is constructed of steel and the pivot is constructed of brass. The pads are housed in a vintage flooded, pressurized housing design with oil inlet nozzles- the operating principles of which are described in detail by Nicholas [8]. Oil is introduced to the bearing cavity through the oil supply nozzles, located between each of the pads. The majority of the hot sump oil exits the bearing through two smaller discharge holes located on either side of each supply nozzle, while some leaks axially through two tight clearance floating end seals. Figure 4.3 provides an illustration of the these oil flow path features. ISO VG 32 oil was supplied to the bearings at $43.3{ }^{\circ} \mathrm{C}$. Flow rate to each bearing housing was controlled through two valves located just outside each housing and monitored via hydraulic oil flowmeter. Thermocouples embedded in the pads and labeled 'TC' were not utilized in the current study. A summary of the important test bearing parameters can be found in Table 4.1 .

\subsection{EXPERIMENTAL METHODS}

The primary purpose of this study was to investigate the effects of reduced oil supply flow rates to supporting tiltingpad bearings on damped natural frequency and system damping ratio under various operating conditions. To this end, a system identification method was employed to measure damped natural frequencies and damping ratios for a number of operating speeds ranging from $2,000 \mathrm{rpm}$ to $12,000 \mathrm{rpm}$ under a number of oil supply flow rate and specific load 


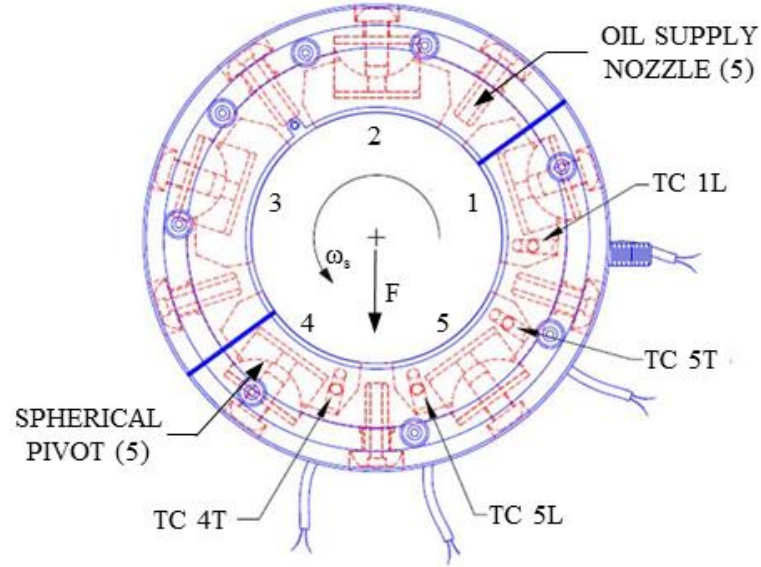

FIGURE 4.2. TEST BEARING DRAWING [7].

TABLE 4.1. TEST BEARING PARAMETERS.

\begin{tabular}{cc}
\hline Journal Diameter $(\mathrm{mm})$ & 70 \\
Pad Length $(\mathrm{mm})$ & 52 \\
Pad Arc Length $(\mathrm{deg})$ & 55 \\
Diametral Clearance $(\mu \mathrm{m})$ & 173 \\
Pad Offset Factor & 0.5 \\
Preload & 0.3 \\
Pad Configuration & LBP \\
Length/Diameter & 0.75 \\
Clearance Ratio $(\mu \mathrm{m} / \mathrm{mm})$ & 2.47 \\
Pad Thickness $(\mathrm{mm})$ & 15.5 \\
\hline
\end{tabular}

conditions. The nominal load condition consists solely of the weight of the shaft and generates bearing specific loads of 124 $\mathrm{kPa}$. A second load condition is also considered that utilizes the mid-span AMBs to impart static loads on the rotor so as to increase the specific loads on the bearings to $365 \mathrm{kPa}$.

Some studies have provided successful methods for estimating the required oil supply flow rate to prevent starvation [2,9]. These methods often involve adjusting the flow rate until a specific oil temperature rise or bearing temperature is met. It would therefore follow that the nominal oil supply flow rate would increase with both operating speed and specific load. In many cases, recommended flow rates are provided to the end-user by the bearing manufacturer. Based on the recommendation of the manufacturer of the bearings used in this study, the nominal flow rate is considered to be 3.79 liters per minute $(\mathrm{lpm})$ per bearing for all speed and load

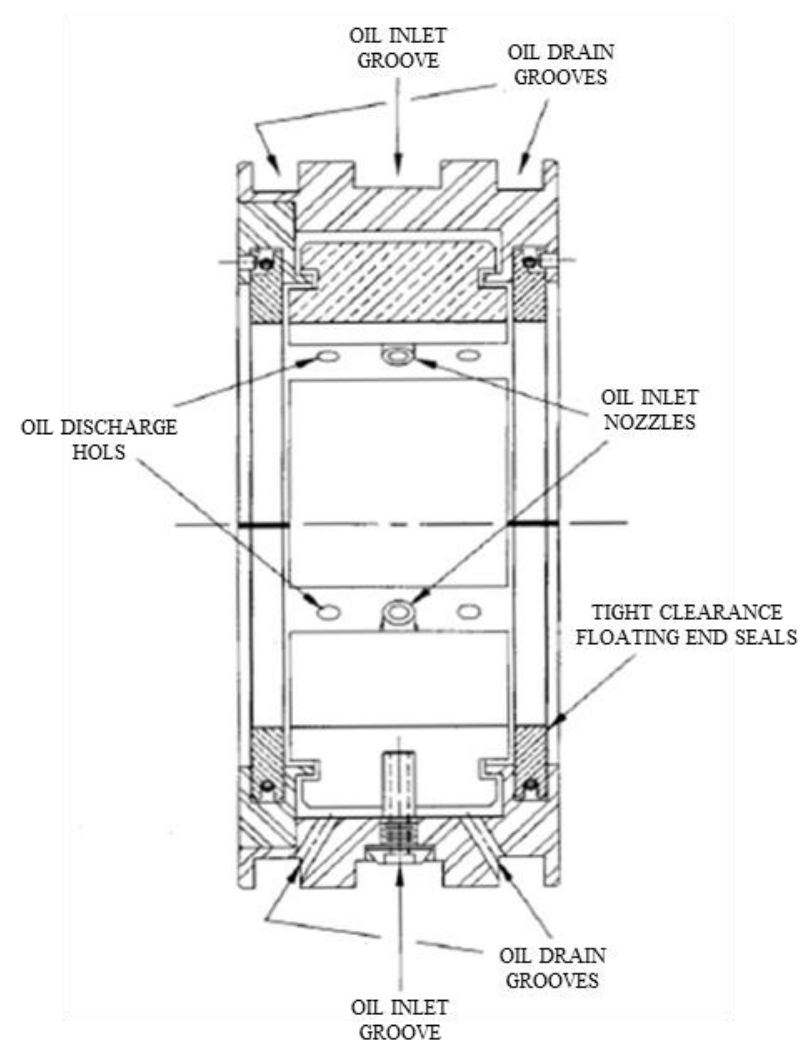

FIGURE 4.3. FLOODED, PRESSURIZED HOUSING OIL FLOW PATH FEATURES [8].

conditions. Different flow rates ranging from $60 \%$ to $120 \%$ of the nominal flow rate were tested based on speed and load conditions. Flow rates were systematically reduced under each operating condition until practical operational limits were reached based on high vibration levels and bearing temperatures. Table 4.2 presents the range of flow rates captured by the data as a percentage of the nominal flow rate for each speed and load condition.

Under each speed, load, and flow rate condition, the system was allowed to reach steady-state operating conditions by running for 10 minutes. This period allowed the bearings to reach thermal equilibrium and any transient vibration signatures to settle out. Once the system was at steady-state, the electromagnetic shaker was used to excite the shaft over a frequency range of $66-105 \mathrm{~Hz}$. This frequency range is approximately centered about the first bending mode of the shaft with sufficient margins on either side. A stepped sinesweep excitation was employed with a frequency step of $1 \mathrm{~Hz}$. Vibration measurements and shaker currents were recorded simultaneously at each excitation frequency for a 7 second period at a sampling frequency of $3,000 \mathrm{~Hz}$. At each frequency, seven 3,000-point Fast Fourier Transforms (FFTs), 
TABLE 4.2. OIL SUPPLY FLOW RATE TEST MATRIX (\% OF NOMINAL FLOW RATE, 3.79 LPM).

\begin{tabular}{ccc}
\hline & \multicolumn{2}{c}{ Specific Load } \\
Speed (rpm) & $124 \mathrm{kPa}$ & $365 \mathrm{kPa}$ \\
\hline 2000 & 100 & - \\
4000 & 100 & - \\
6000 & 100 & - \\
8000 & 100 & 6080100 \\
9000 & 8090100 & 6080100 \\
10000 & 8090100 & 6080100 \\
11000 & 90100110 & 100 \\
12000 & 100110120 & 100 \\
\hline
\end{tabular}

TABLE 4.3. OPERATING CONDITIONS AND MEASUREMENT UNCERTAINTIES.

\begin{tabular}{cc}
\hline Specific Load & $+/-5 \%$ \\
Oil Supply Flow Rate & $+/-2 \%$ \\
Displacement & $+/-2 \%$ \\
Shaker Force & $+/-5 \%$ \\
\hline
\end{tabular}

each representing one second of data, were averaged to obtain experimental frequency spectra with a frequency resolution of $1 \mathrm{~Hz}$. These samples were averaged in order to reduce the noise floor of the spectra. Vibration measurements were obtained with eddy-current proximity sensors while shaker currents were obtained from integrated current sensors in the driving power amplifiers. These currents were in turn used in a calibrated circuit model of the electromagnetic actuator to estimate the forces applied by the shaker. Table 4.3 provides the uncertainties associated with the operating conditions and measurements used in the following identification procedure.

\subsection{IDENTIFICATION METHOD}

Physical characteristics of many systems can be obtained from frequency response functions (FRFs), which provide the gain and phase relationship of a system's response, $B(j \omega)$, to an applied stimulus, $A(j \omega)$, as a function of frequency. The FRF, $H(j \omega)$, is calculated as a ratio of the cross power spectrum of the measured stimulus and response signals, $S_{A B}$, to the auto power spectrum of the measured stimulus signal, $S_{A A}[10]$. The cross power spectrum is calculated as the cross product of the
FFT of the time-domain response signal, $b(t)$, and the complex conjugate of the FFT of the time-domain stimulus signal, $a(t)$. The auto power spectrum is calculated as the FFT of the timedomain stimulus signal with its complex conjugate. The formulation of the FRF is given by Equation 1.

$$
H(j \omega)=\frac{S_{A B}(j \omega)}{S_{A A}(j \omega)}=\frac{F F T(b(t)) \times F F T^{*}(a(t))}{F F T(a(t)) \times F F T^{*}(a(t))}
$$

In the case of the test rig used in this study, the $2 \times 2$ FRF matrix, $\boldsymbol{H}(\boldsymbol{j} \omega)$, relates the measured shaft displacements at the bearing locations, $X(j \omega)$ and $Y(j \omega)$, in two orthogonal directions, to the applied forces of the electromagnetic shaker, $F_{X}(j \omega)$ and $F_{Y}(j \omega)$, in two orthogonal directions. This relationship is given by Equation 2.

$$
\left[\begin{array}{l}
X(j \omega) \\
Y(j \omega)
\end{array}\right]=\left[\begin{array}{ll}
H_{x x} & H_{x y} \\
H_{y x} & H_{y y}
\end{array}\right]\left[\begin{array}{l}
F_{x}(j \omega) \\
F_{y}(j \omega)
\end{array}\right]
$$

A single-input, multiple-output (SIMO) technique was implemented in which two independent sets of shaft responses were measured in the two orthogonal directions to singledirection force excitations, first in the $x$-direction, and then in the $y$-direction. The single-direction, input force signals and multi-direction, output response signals were then used to calculate the four components of the FRF matrix as shown in Equations 3 and 4.

$$
\begin{aligned}
& {\left[\begin{array}{l}
H_{x x} \\
H_{y x}
\end{array}\right]=\left[\begin{array}{l}
X_{1}(j \omega) \\
Y_{1}(j \omega)
\end{array}\right] F_{x}(j \omega)^{-1}} \\
& {\left[\begin{array}{l}
H_{x y} \\
H_{y y}
\end{array}\right]=\left[\begin{array}{l}
X_{2}(j \omega) \\
Y_{2}(j \omega)
\end{array}\right] F_{y}(j \omega)^{-1}}
\end{aligned}
$$

Due to the gyroscopic mass effects inherently found in rotating machinery, the forward and backward processional modes occur at different frequencies that are typically close in frequency at lower rotating speeds and deviate more at higher speeds. While different excitation techniques can be applied to maximize the contributions of one mode or the other (i.e. forward or backward), the four components of the FRF matrix will almost always contain contributions of both modes. A mathematical technique was implemented to separate the contribution of the two modes through analysis in the complex 
number field [11]. Complex displacement, $r(t)$, and force, $f_{r}(t)$, variables are introduced that relate the original displacement and force signals in the two orthogonal directions through a complex transformation matrix, $\boldsymbol{J}(\boldsymbol{j} \boldsymbol{\omega})$. These complex variables and their complex conjugates, as well at the transformation matrix are found in Equations 5 through 7.

$$
\begin{aligned}
{\left[\begin{array}{l}
r(t) \\
\bar{r}(t)
\end{array}\right] } & =\left[\begin{array}{cc}
1 & j \\
1 & -j
\end{array}\right]\left[\begin{array}{l}
x(t) \\
y(t)
\end{array}\right] \\
{\left[\begin{array}{l}
f_{r}(t) \\
f_{\bar{r}}(t)
\end{array}\right] } & =\left[\begin{array}{cc}
1 & j \\
1 & -j
\end{array}\right]\left[\begin{array}{l}
f_{x}(t) \\
f_{y}(t)
\end{array}\right] \\
\boldsymbol{J} & =\left[\begin{array}{cc}
1 & j \\
1 & -j
\end{array}\right]
\end{aligned}
$$

The real number field FRF matrix, $\boldsymbol{H}(\boldsymbol{j} \boldsymbol{\omega})$, can then be used to calculate a complex number field FRF matrix, $\boldsymbol{G}(\boldsymbol{j} \omega)$, through the transformation matrix, as shown in Equation 8. In this new matrix, the forward and backward modal contributions are separated with the forward mode contributions being contained in the $G_{r r}$ component and the backward mode contributions being contained in the $G_{\overline{r r}}$ component. A fourth order state space model was then fit to the complex number field FRF matrix using a prediction-error minimization algorithm to obtain experimentally identified modal parameters, specifically damped natural frequency and damping ratio.

$$
\left[\begin{array}{ll}
G_{r r} & G_{r \bar{r}} \\
G_{\bar{r} r} & G_{\overline{r r}}
\end{array}\right]=\boldsymbol{J}\left[\begin{array}{ll}
H_{x x} & H_{x y} \\
H_{y x} & H_{y y}
\end{array}\right] \boldsymbol{J}^{-1}
$$

Each discrete point of each element of the experimentally obtained frequency response function matrices was found at the specific excitation frequency of the magnetic shaker using the measured shaft displacements and shaker force as described above. The averaging technique described in the previous section acts to reduce the influence of noise associated with these values thus reducing any random uncertainties. Systematic uncertainties associated with the displacement and force measurements are found in Table 4.3. Systematic uncertainties in the displacements measurements can be attributed to the calibration and positioning of the eddycurrents sensors. The calibrated circuit model of the electromagnetic shaker used to estimate shaker force based on measured currents assumes shaft centerline operation at the magnetic center of the actuator. Any deviations from this position would, in turn, produce a systematic uncertainty and is included in the uncertainty value provided for the force measurements. Knowing the uncertainties associated with the displacement and force measurements, the single-sample experimental uncertainty theory developed by Kline and McClintock [12] was used to estimate the uncertainty in the identified FRF matrices. The uncertainty associated with a compliance function such as a FRF matrix is simply equal to the root mean square of the uncertainties of the force and displacement measurements; therefore, the uncertainty associated with each point of every component of each measured FRF matrix under each of the operating conditions tested in this study has an uncertainty value of $\pm 5.4 \%$. Imposing these bounds on the measured FRF matrices provides an envelope of possible functions to which the curve fit is applied and modal properties are obtained. It was found that the uncertainty associated with the FRF have a marginal effect on the shape of the curve and thus, little effect on the resulting damping ratios and damped natural frequencies. Investigations into these effects found the uncertainties associated with the reported modal properties to be $\pm 2 \%$. It should be noted that all damping ratios are presented as percentages and that this uncertainty represents a percent difference of those percentages, not a dimensional range of damping ratio percent.

\subsection{THEORETICAL MODELING METHODS}

All experimentally tested bearing operating conditions were analyzed using a sophisticated algorithm based on TEHD lubrication theory developed by $\mathrm{He}[13,14]$. The algorithm uses numerical methods to solve a finite element formulation of the 2D Reynolds equation for the pad pressure field in the circumferential and axial directions. A finite element formulation of the generalized $2 \mathrm{D}$ energy equation is used to obtain the film temperature distribution in the circumferential and radial directions. Turbulence effects are included using the near-wall eddy viscosity model while cross-film viscosity variations are accounted for through exponential interpolation of the temperature dependent Reynolds model. Pad and pivot mechanical deformations, as well as pad, shaft, and shell thermal deformations, are also considered. Pivot stiffness is calculated based on Hertzian contact stress analysis and is dependent on the resultant oil film pressure field over each pad. Full bearing stiffness and damping coefficients explicitly containing pad degrees of freedom are obtained analytically by solving the perturbed Reynolds equation.

Both flooded and starved model flow assumptions are considered in this study. For both models, a total oil supply flow rate to the bearing, that of which delineates the results of 
the study, is prescribed. In the flooded model, it is assumed that the bearing has sufficient oil flow such that a continuous hydrodynamic film develops at the leading edge of all bearing pads, regardless of the prescribed flow rate. Flow rates into

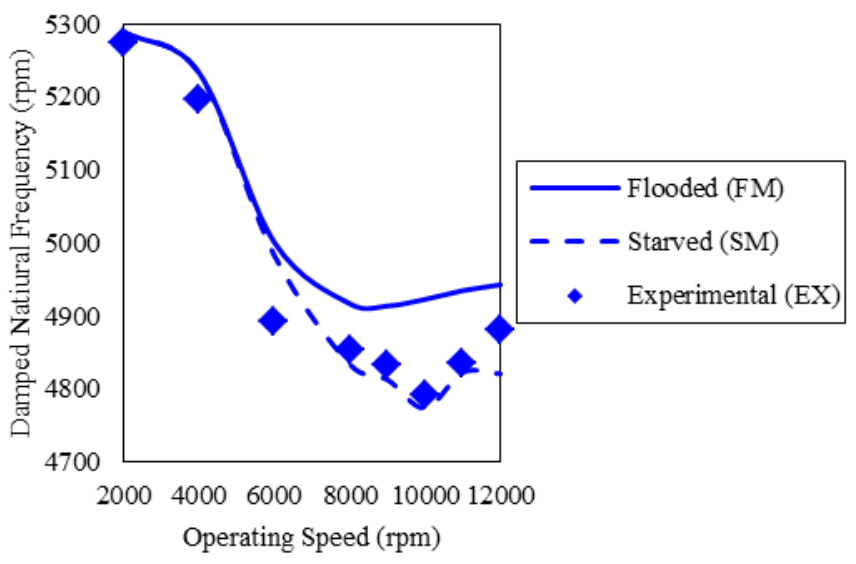

FIGURE 4.4. DAMPED NATURAL FREQUENCY VS SPEED, 124 KPA SPECIFIC LOAD.

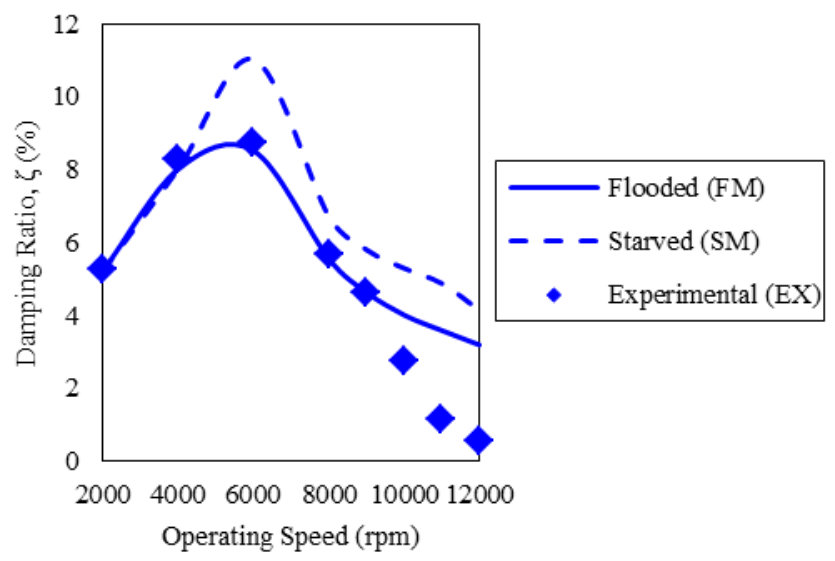

FIGURE 4.5. DAMPING RATIO VS SPEED, $124 \mathrm{KPA}$ SPECIFIC LOAD.

and out of each pad are calculated from the integrated velocity profiles at the pad boundaries. The prescribed flow rate is only used in a limited fashion in the flooded flow model through its inclusion in the energy balance equation for calculating sump temperature. This sump temperature is then used in the bearing shell deformation calculations and ultimately affects the calculated pressure and temperature fields through the iterative solving process.

In the starved bearing model, the prescribed oil supply flow rate is divided evenly among all pads. This 'available' pad flow rate is compared to the leading edge flow rate as calculated from the integrated velocity profile at the pad inlet. If the available flow rate is less than the calculated value, the continuous film onset angle is moved circumferentially along the pad until the available and calculated flow rate values converge. In this case, the pad arc length is effectively reduced, representing the effects of pad starvation (i.e. film cavitation) at the leading edge of the pad. In these cavitated regions, the pressure is assumed to be ambient and a reduced axial length is assumed through the effective length method and used in the energy equations. These regions do not contribute to the calculation of the bearing dynamic coefficients. In reality, some oil is dragged along the surface of the shaft in streamlets of gas and liquid in the cavitated regions; however, these two-phase flow effects are not considered in the models.

Full rotor dynamic analyses of the test rig are performed through a finite element formulation of the system's equations of motion to obtain predicted modal parameters. Full bearing coefficients containing pad degrees of freedom are added to a 2D beam-element model of the shaft. Flexible foundation effects are accounted for through measured transfer functions of the two bearing pedestals and associated substructure. Negative open-loop stiffness effects of the magnetic shaker are included in all models. Negative stiffness effects of the midspan magnetic actuators are also included for the high load condition where the actuators are used to load the shaft. System results containing bearing coefficients from both the flooded and starved bearing models are presented in the results.

\subsection{RESULTS}

\subsubsection{Damped Natural Frequency and Damping Ratio vs. Running Speed}

In order to establish a baseline of system behavior, modal property system identification was first performed under the nominal load and flow rate conditions at speeds ranging from 2,000 to $12,000 \mathrm{rpm}$. Figure 4.4 presents the predicted and experimentally identified damped natural frequencies as a function of running speed. As the forward mode of the rotor is typically of more importance due to its natural excitation from rotor unbalance, it is the only mode presented in this study. Both of the models and the data show similar trends. As the running speed of the shaft increases to $6,000 \mathrm{rpm}$, the damped natural frequency drops noticeably. At speeds above 6,000 rpm the damped natural frequency levels out somewhat and remains relatively constant between 8,000 and $12,000 \mathrm{rpm}$. While the two models agree with each other at lower speeds, the starved bearing model predicts lower damped natural frequencies than the flooded model at higher operating speeds. 

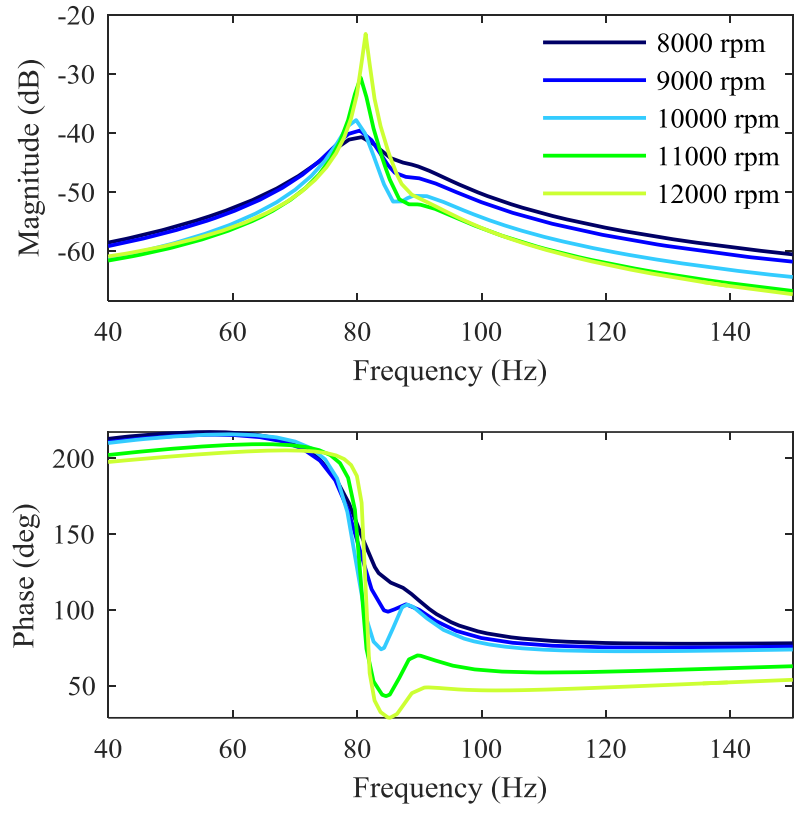

FIGURE 4.6. IDENTIFIED FREQUENCY RESPONSE FUNCTIONS VS SPEED, FORWARD MODE CONTRIBUTION, Grr.

The experimentally identified damped natural frequencies closely follow the starved model predictions at all speeds.

Figure 4.5 shows the predicted and experimentally identified damping ratios as a function of running speed. Again, both of the models and the data show similar trends. The damping ratio increases with increasing speed during lower speed operation, peaking around 6,000 rpm. At speeds above $6,000 \mathrm{rpm}$, the damping ratio decreases drastically. The models deviate at speeds greater than $4,000 \mathrm{rpm}$ with the starved bearing model predicting greater damping ratios than the flooded model. The experimentally identified damping ratios closely follow the flooded model predictions at all speeds through 9,000 rpm; however, at higher speeds, the identified damping ratios drop much more rapidly with increasing running speed and fall below the predictions of either model. At maximum speed, the flooded and starved models predict damping ratios of $3.18 \%$ and $4.14 \%$, respectively, while the identified damping ratio is just $0.54 \%$.

At low to moderate speeds, the system is well damped with damping ratios greater than $5 \%$. At higher speeds above $8,000 \mathrm{rpm}$, both of the models and the data show a drastic decrease in damping ratio with speed. These higher speeds are above the first bending mode of the shaft with critical speed ratios ranging from 1.5-2.5. This supercritical, higher speed range with lower, decreasing damping ratios is of highest

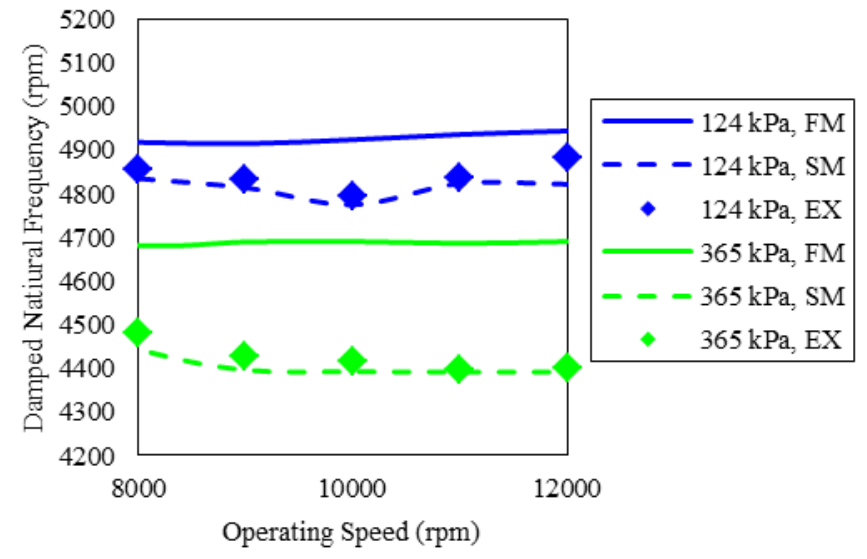

FIGURE 4.7. EFFECT OF BEARING LOAD ON DAMPED NATURAL FREQUENCY.

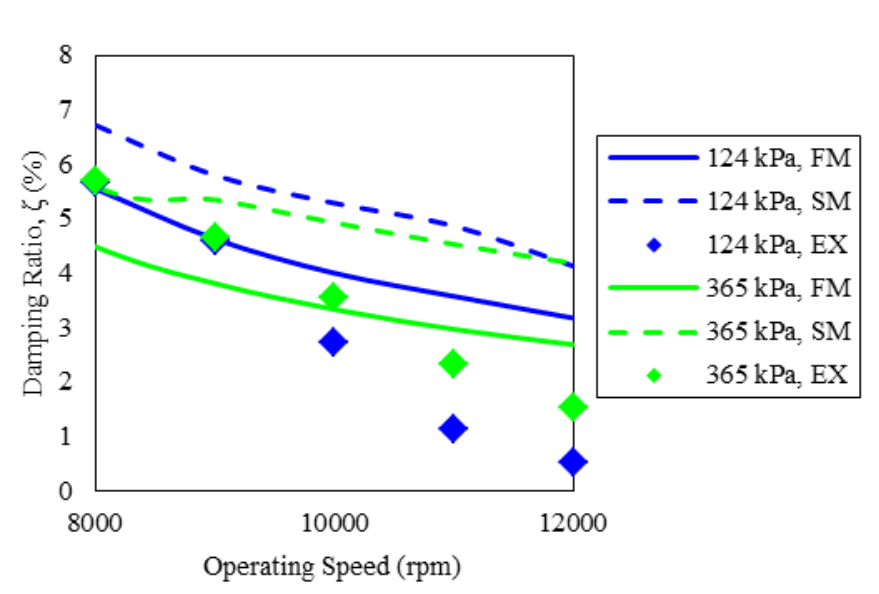

FIGURE 4.8. EFFECT OF BEARING LOAD ON DAMPING RATIO.

interest and is therefore the focus of the remaining results. Figure 4.6 provides an alternative illustration of the severity of the drop in damping ratio with speed through the compliance function of the forward mode contribution from which, in part, the dynamic parameters are identified. The peaks at approximately $80 \mathrm{~Hz}$ correspond to the first bending mode of the shaft. The amplitude and slope of the peak increase noticeably with increasing running speed and correspond to the decrease in damping ratio seen in Fig. 4.5.

\subsubsection{Effect of Bearing Load on System Dynamics}

Next, while maintaining the nominal oil supply flow rate, system perturbation and identification techniques were performed under an increased bearing specific load in order to 
observe its effects on damping ratio and damped natural frequency. Figure 4.7 illustrates the predicted and identified damped natural frequencies of both the original and increased bearing specific load cases for operating speeds ranging from 9,000 to $12,000 \mathrm{rpm}$. In general, both of the models and the data show a relatively constant damped natural frequency with speed that drops with increased bearing load. This decrease in natural frequency with load can be attributed to the negative stiffness effects of the magnetic actuators used to load the bearings. The starved bearing model predicts lower damped natural frequencies than the flooded bearing model for each respective load case as well as a larger drop in frequency with increased bearing load. For both load cases, the experimental data very closely matches the starved model predictions.

Figure 4.8 shows the predicted and identified damping ratios under both load conditions through the higher operating speed range. Both models predict a decrease in damping ratio with increased bearing load. For each load, the starvation model consistently predicts higher damping ratios than the flooded model. The experimentally identified damping ratios lie closer to the lower flooded model predictions; however, neither model accurately captures the data across the speed range. As before, the identified damping ratios drop more dramatically with speed than either model predicts and fall below all model predictions at high speeds. Unlike the trends seen in both models, the data shows an increase in damping ratio with increased bearing load with the difference between loads increasing with speed. For instance, at maximum speed, the identified damping ratio under the increased load condition is $1.54 \%$ as opposed to just $0.54 \%$ for the nominal load case.

\subsubsection{Effect of Oil Supply Flow Rate on System Dynamics}

The oil supply flow rate to both supporting tilting-pad bearings was systematically adjusted at a number of operating speeds under the nominal load condition in order to observe the effects of flow rate on system dynamics. Flow rate was found to have a marginal effect on damped natural frequency and is therefore not presented here. Figure 4.9 shows the predicted and identified damping ratios for a number of oil supply flow rates and operating speeds ranging from 9,000 to $12,000 \mathrm{rpm}$ under the nominal load condition. Predicted damping ratios are presented for both the flooded and starved bearing models for flow rates of 80,100 , and $120 \%$ of the nominal flow rate. Due to an increased requirement for oil flow to maintain acceptable vibration levels and safe operation at higher speeds, the data at lower speeds represents lower flow rates while the data at higher speeds represents higher flow rates. Again, the starved model consistently predicts higher damping ratios than the flooded model. Both models predict an increase in damping ratio with decreasing oil supply

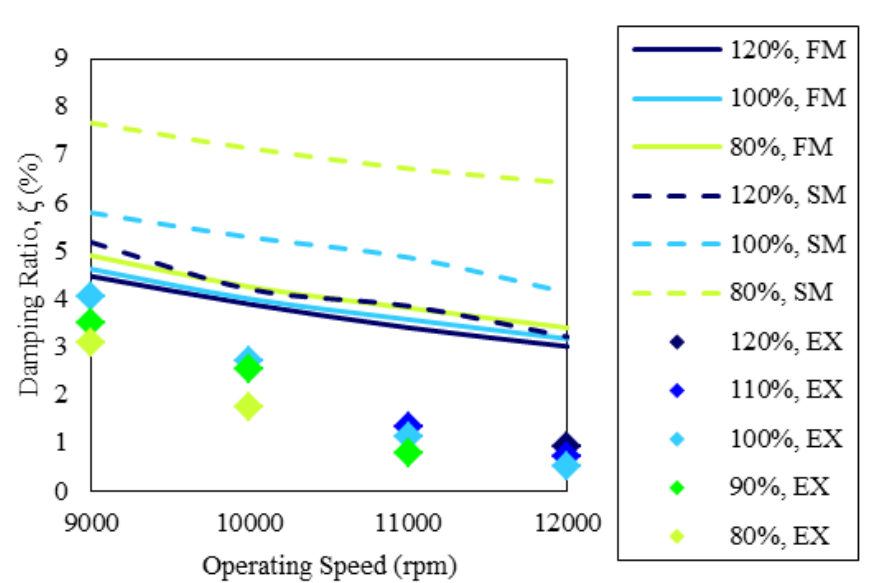

FIGURE 4.9. EFFECT OF OIL SUPPLY FLOW RATE ON DAMPING RATIO, 124 KPA SPECIFIC LOAD.

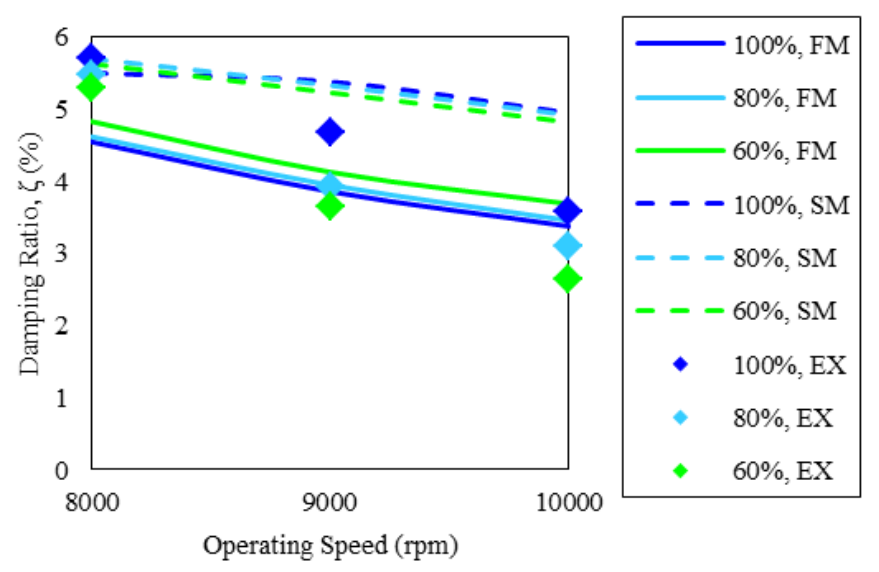

FIGURE 4.10. EFFECT OF OIL SUPPLY FLOW RATE ON DAMPING RATIO, 365 KPA SPECIFIC LOAD.

flow rate with this increase being much more pronounced in the starved model. The experimentally identified damping ratios fall below model predictions for all speeds and flows. Unlike the predictions of both models, the data shows a decrease in damping ratio with decreasing oil supply flow rate across all speed cases. For instance, at 10,000 rpm, a flow rate decrease from 100 to $80 \%$ increases the predicted damping ratio of the starved model by $35 \%$ while decreasing the identified value by $35 \%$. While the damping ratio values appear close to one another, especially at higher speeds, it should be noted that each point lies well outside the uncertainties associated with all neighboring points.

Next, oil supply flow rates were varied under the increased bearing load case for a number of operating speeds 
ranging from 8,000 to $10,000 \mathrm{rpm}$. Figure 4.10 illustrates the predicted and identified damping ratios under these conditions. In comparison to the nominal bearing load condition, lower flow rates were achievable while maintaining safe machine operation under the higher load condition and were varied between 60 and $100 \%$ of the nominal flow rate. Starved model damping ratio predictions are again consistently higher than flooded model predictions for all flow rates. While the flooded model shows a slight increase in predicted damping ratio with decreasing oil supply flow rate as in the nominal load case, the effect of flow rate on damping ratio is nearly indiscernible in the starved model. The identified damping ratios lie closer to the predicted values than with the previous load case, generally falling within the range of values produced by the two models. The data lies very close to the starved model predictions at $8,000 \mathrm{rpm}$ while lying closer to the flooded model predictions at higher speeds. As with the nominal load case, the identified damping ratios decrease with each decrease in oil supply flow rate for each speed tested. At 10,000 rpm, the experimentally identified damping ratio drops from $3.6 \%$ to $2.6 \%$ as the flow rate is decreased from 100 to $60 \%$.

\subsection{DISCUSSION}

The primary purpose of this study was to compare predicted system dynamic properties using both flooded and starved bearing models to experimentally identified damping ratios and damped natural frequencies under a number of speed, load, and oil supply flow rate conditions. Examining the differences in the two models and comparing predicted trends across varying operating conditions to experimental trends is the principle focus of this discussion. To help understand these differences and trends, predicted dynamic coefficients (i.e. stiffness and damping) from both models are presented. For a given support stiffness, there is an optimal bearing damping that maximizes damping ratio [15]. While increases in damping generally work to lower damped natural frequencies, they can either increase or decrease damping ratio based on their location along the optimal bearing damping curve. In general, increases in stiffness work to raise damped natural frequencies and lower damping ratios. Additionally, increased bearing stiffness lowers the maximum achievable damping ratio. Support stiffness generally has a greater impact on natural frequencies while support damping generally has a greater impact on damping ratio. It should be noted that while full coefficients explicitly containing pad degrees of freedom were used in the full system models, synchronously reduced coefficients are presented in this discussion. Also, only the vertical coefficients are presented here for brevity. The primary, horizontal coefficients were observed to produce similar trends as the vertical components while cross-coupled

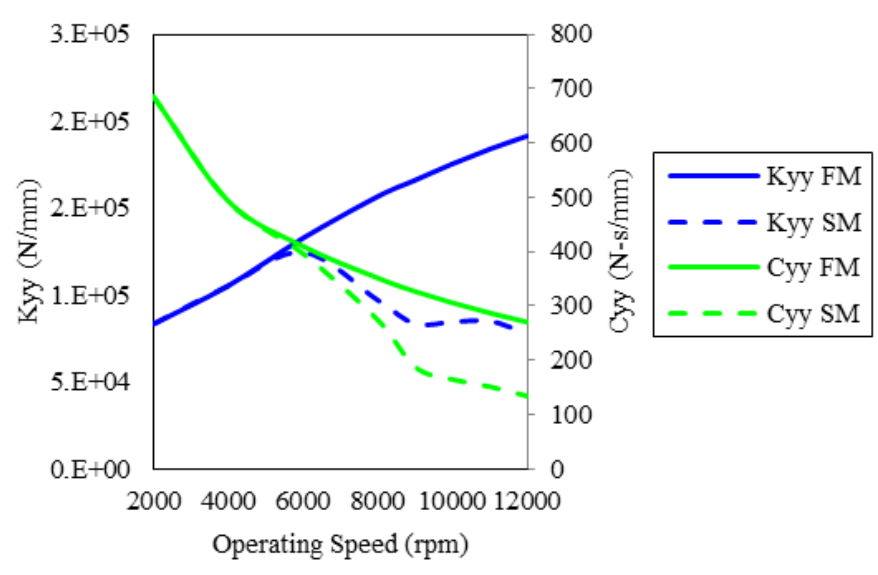

FIGURE 4.11. VERTICAL STIFFNESS AND DAMPING COEFFICIENTS, 124 KPA SPECIFIC LOAD, 100\% FLOW RATE.

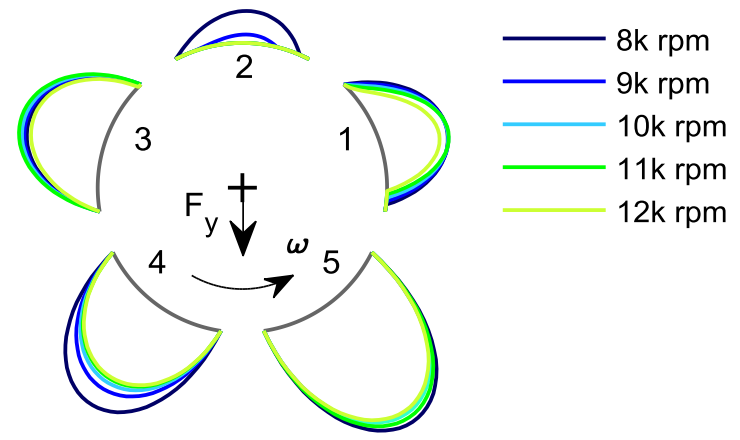

FIGURE 4.12. PRESSURE PROFILES VS OPERATING SPEED, 124 KPA SPECIFIC LOAD, 100\% FLOW RATE.

terms were significantly smaller than primary terms, thus having a negligible impact on system dynamics.

Predicted pressure profiles from the starved bearing model across varying operating conditions are also presented to further understand trends in the predicted bearing coefficients and to help correlate these trends to the experimental data. As previously discussed, the purpose of the starved model is to predict partial or full pad cavitation due to starvation based on the provided oil supply flow rate and calculated pad pressure fields. The flooded model inherently assumes a fully developed film over the entirety of all pads regardless of the provided oil supply flow rate or operating condition. While slight changes to these profiles are observed through changes in operating conditions, they do not significantly add to this discussion and are not presented here. 


\subsubsection{Damped Natural Frequency and Damping Ratio vs. Running Speed}

As previously reported in Figures 4.4 and 4.5, the starved model predicts lower damped natural frequencies and higher damping ratios than the flooded model at higher operating speeds under the nominal load and oil supply flow rate conditions. Figure 4.11 provides the primary, vertical stiffness and damping coefficients predicted by both models across the tested operating speed range under these conditions. While the flooded model predicts a steady increase in stiffness with speed, the starved model predicts lower stiffness values at higher speeds that decrease with increasing speed. Both models predict a steady decrease in damping with increasing speed with the starved model producing lower damping values at higher speeds. As described above, lower bearing stiffness and damping at higher speeds in the starved model have counteracting effects on the predicted damped natural frequencies in comparison to those of the flooded model. The resulting lower natural frequencies of the starved model indicate that the decrease in bearing stiffness in this model is driving down the predicted damped natural frequencies. The higher damping ratios of the starved model can also be attributed to this decrease in bearing stiffness. Over predicted bearing damping in both models might also explain the higher damping ratios of the starved model. At generally higher damping values, changes in stiffness are more influential in the resulting damping ratio, as observed in the two models. Generally lower bearing damping values in both models would act to bring the damping ratio predictions of the starved model closer to those of the flooded model in the presence of lower bearing stiffness.

Figure 4.12 illustrates the predicted pressure profiles of the starved bearing model over the higher operating speed range for the nominal load and flow conditions. Leading edge cavitation can be seen in the upper pads that increases in severity with increasing speed, lessening the load on the lower pads. This progressive decrease in the scope and magnitude of the developed hydrodynamic film layer results in the decrease in bearing stiffness and damping seen in Fig. 4.11. The experimentally identified damped natural frequencies agree very well with the starved model predictions while the identified damping ratios are consistently lower than the model predictions. These trends suggest that while the starved model is accurately predicting bearing stiffness, it may be over predicting bearing damping. Additionally, the starved bearing model does not capture the severity of the drop in stability at higher speeds seen in the experimental data. It is possible that the starved model does not accurately predict the extent of pad cavitation seen in the bearing under high speeds; however, good correlation between the model and identified damped

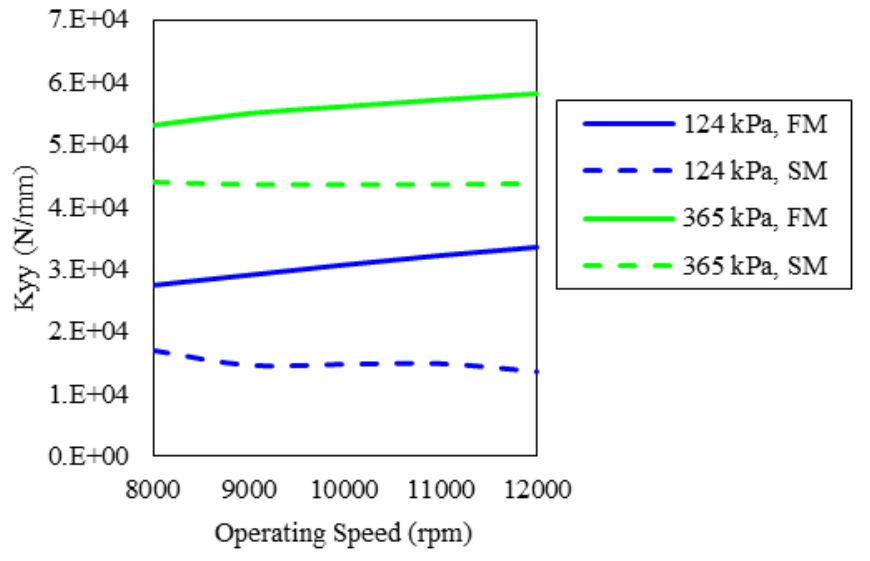

FIGURE 4.13. VERTICAL STIFFNESS COEFFICIENTS VS LOAD, 100\% FLOW RATE.

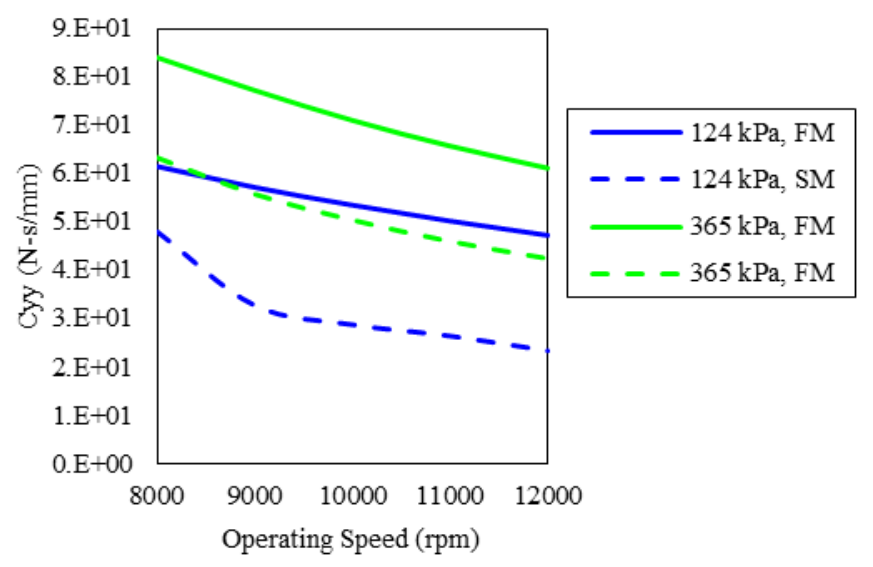

FIGURE 4.14. VERTICAL DAMPING COEFFICIENTS VS LOAD, 100\% FLOW RATE.

natural frequencies suggest that the predicted pressure profiles are reasonably accurate. It is more likely that some other complex physical phenomena are occurring in the bearing to reduce the system damping ratio that aren't captured by the simplified bearing model.

\subsubsection{Effect of Bearing Load on System Dynamics}

Both the flooded and starved bearing models predict a decrease in damping ratio, or system stability, with increased bearing load, as shown in Figure 4.8. Furthermore, for each given load case, the starved model consistently predicts higher damping ratios than the flooded model. Figures 4.13 and 4.14 illustrate the predicted vertical stiffness and damping coefficients of both models for both bearing load cases over 


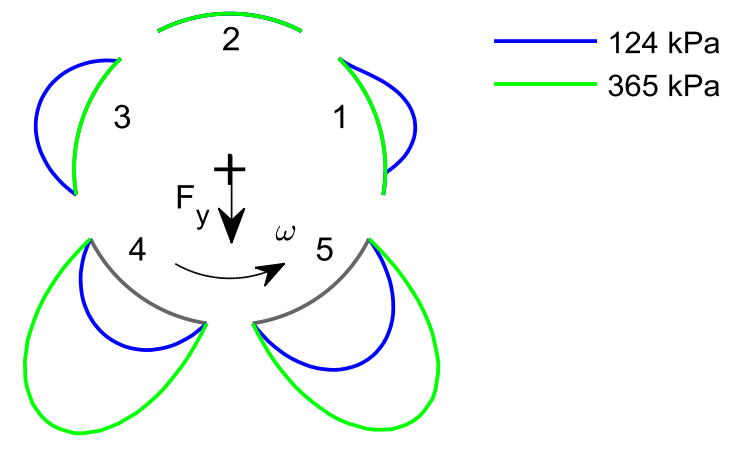

FIGURE 4.15. PRESSURE PROFILES VS BEARING LOAD, 12,000 RPM, 100\% FLOW RATE.

the higher operating speed range. In both the flooded and starved models, increased bearing load results in an increase in both stiffness and damping over all speeds. Increases in damping ratio with load in both models suggest that the increase in stiffness with load is driving these trends. For each load, the starved model predicts lower bearing stiffness and damping than the flooded model across all speeds. Higher predicted damping ratios and lower damped natural frequencies in the starved model again suggest that the differences in stiffness values are dominating the trends seen in the resulting modal properties.

Figure 4.15 shows the predicted pressure profiles of the starved bearing model under both load conditions at the nominal flow rate and $12,000 \mathrm{rpm}$. Under the increased bearing load, the predicted pressure on the bottom two pads increases significantly, as expected. Also, upper pads that are partially or lightly loaded under the nominal load condition are completely cavitated under the increased load. The net result is the increase in bearing stiffness and damping with load seen in Figs. 4.13 and 4.14. For both load conditions, the experimentally identified damped natural frequencies fall very close to the starved model predictions while the identified damping ratios are consistently lower than starved model predictions and fall closer to the flooded model predictions. Again, these trends suggest that the starved model accurately predicts bearing stiffness, as it tends to dominate natural frequency results, however, over predicts bearing damping. More importantly, the data shows a clear increase in system stability with increased bearing load, while both models predict the opposite trend. Generally, increased bearing loads result in increased operating eccentricities and, in turn, increased system stability, as seen in the data. These modeling trends suggest that the models are either over predicting the increase in stiffness with load or generally over predicting

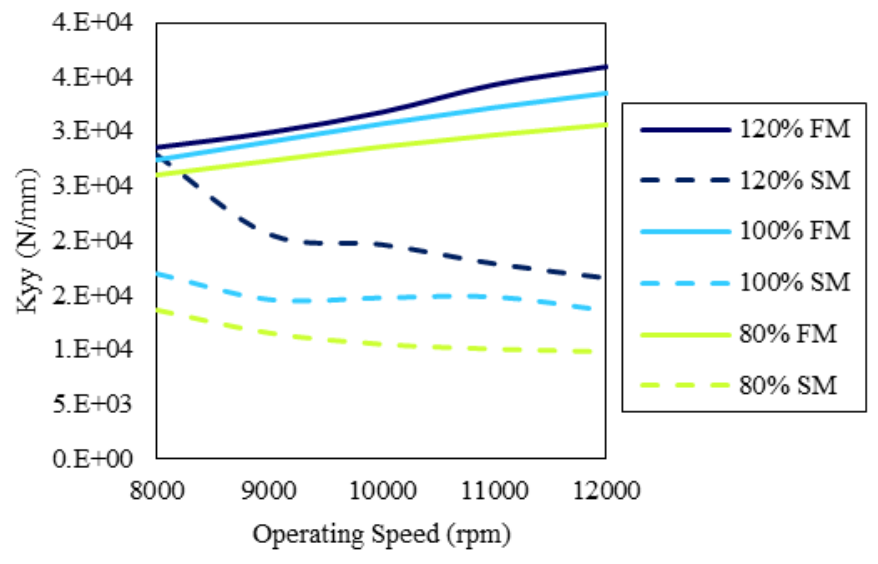

FIGURE 4.16. VERTICAL STIFFNESS COEFFICIENTS VS OIL SUPPLY FLOW RATE, 124 KPA SPECIFIC LOAD.

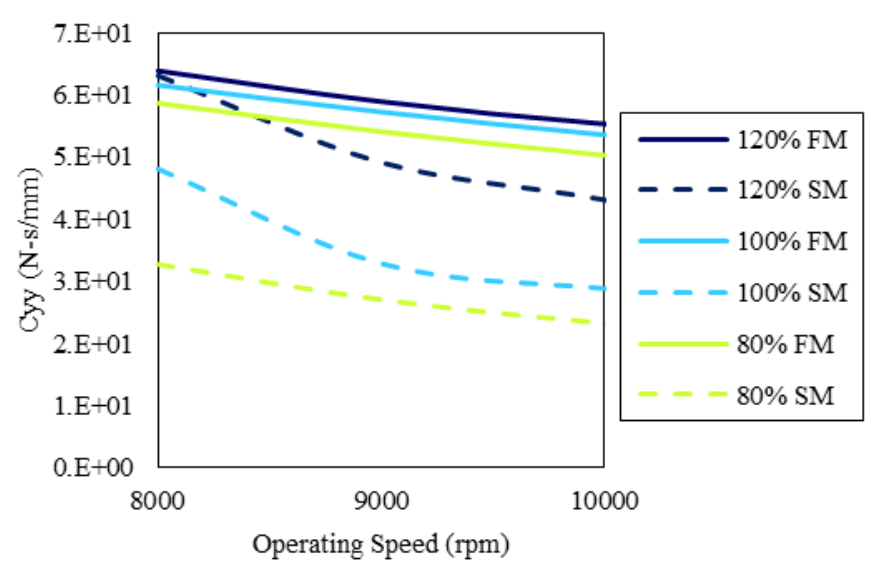

FIGURE 4.17. VERTICAL DAMPING COEFFICIENTS VS OIL SUPPLY FLOW RATE, 124 KPA SPECIFIC LOAD.

bearing damping. Good correlation between the starved model damped natural frequencies and the experimental data for both load conditions suggest that predicted damping values are likely the cause.

\subsubsection{Effect of Oil Supply Flow Rate on System Dynamics}

Both the flooded and starved bearing models predict an increase in damping ratio, or system stability, with decreasing oil supply flow rate under the nominal bearing load condition, as shown in Figure 4.9. Again, the starved model consistently predicts higher damping ratios than the flooded model for all oil flow conditions. Figures 4.16 and 4.17 show the predicted vertical stiffness and damping values of both bearing models 


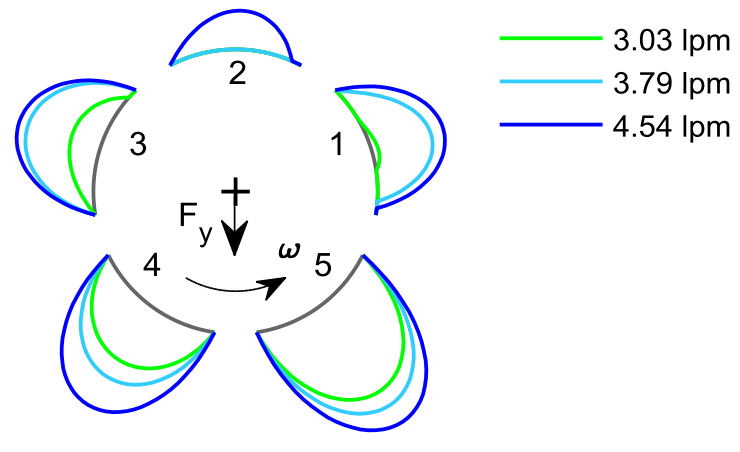

FIGURE 4.18. PRESSURE PROFILES VS OIL SUPPLY FLOW RATE, 10,000 RPM, 124 KPA SPECIFIC LOAD.

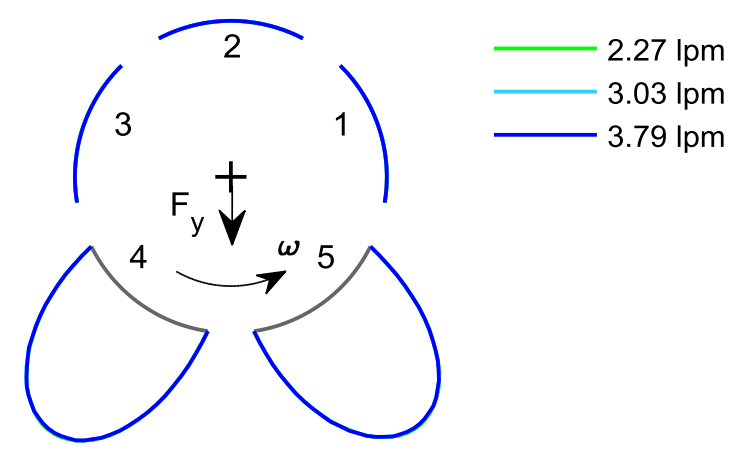

FIGURE 4.19. PRESSURE PROFILES VS OIL SUPPLY FLOW RATE, 10,000 RPM, 365 KPA SPECIFIC LOAD.

for the $124 \mathrm{kPa}$ specific load case and flow rates of 80,100 , and $1201 \%$ of nominal. In both the flooded and starved models, decreasing oil supply flow rates result in decreasing bearing stiffness and damping. Increased predicted damping ratios with decreasing flow in both models suggest that the decreasing bearing stiffness is defining this trend. For all oil flow conditions, the starved model predicts lower stiffness and damping values than the flooded model across all speeds. Higher predicted damping ratios in the starved model suggest that the lower stiffness values are, once again, defining the trends seen in the resulting modal properties.

Figure 4.18 illustrates the predicted pressure profiles of the starved bearing model for varying oil supply flow rates under the nominal load condition at 10,000 rpm. Similar to the speed dependent pressure profiles in Fig. 4.12, cavitation can be seen in the upper pads that increases in severity with decreasing oil supply flow rate, lessening the load on the lower pads. Again, a decrease in hydrodynamic film development in the upper pads and reduced loading of the lower pads result in the decreased bearing stiffness and damping seen in Figs. 4.16 and 4.17. As with the load dependent observations, the models and data produce opposite trends. While the data clearly shows a decrease in damping ratio, or system stability, with decreasing flow rate, both models predict an increase in stability with decreasing flow rate. This increase is less pronounced in the flooded model predictions than the starved model predictions where it is quite significant. These trends suggest that the models are most likely over predicting bearing damping.

Unlike the nominal load condition, oil supply flow rate has a very marginal effect on the predicted damping ratios of the starved model at the higher, $365 \mathrm{kPa}$ load condition as shown in Figure 4.10. The starved model still, however, predicts greater damping ratios and system stability than the flooded model under these conditions. Figure 19 illustrates the predicted pressure profiles of the starved bearing model for varying oil supply flow rates under the increase bearing load condition at 10,000 rpm. For the range of flow rates tested in this study, oil supply flow rate has no noticeable effect on pad pressures. As expected from these results, predicted stiffness and damping coefficients vary little with oil supply flow rate and are not presented here. The relatively large decreases in bearing stiffness and damping with decreasing flow rate predicted by the starved model in the lower load case are nonexistent under the higher load condition. At higher speeds and loads, the starved model predicts fully cavitated upper pads and fully developed film over the bottom pads carry the load.

In general, the data lies closer to the range of damping ratios predicted by the two models than in the nominal load case. While the starved model suggests that oil supply flow rate has a marginal impact on system stability under this increased load condition, the experimental data clearly shows a decrease in damping ratio with each decrease in flow rate. Assuming the lower pads have adequate flow to develop a full film, it is likely that some other physical phenomena not captured by either model are occurring within the bearing to reduce the system damping ratio.

\subsection{CONCLUSIONS}

This study presents a detailed investigation of the effects of oil supply flow rate on system dynamics under a number of bearing load and operating speed conditions through both experimental parameter identification and computational modeling. Flooded and starved oil flow model assumptions have both been compared to experimental data. The starved model shows excellent correlation with the experimentally identified damped natural frequencies while consistently over predicting damping ratio. Under lightly loaded conditions, predicted pressure profiles from the starved model show 
cavitation of the upper pads that increases in severity with both increasing speed and decreasing oil supply flow rate resulting in decreased bearing stiffness and damping. Excellent correlation with the experimentally measured damped natural frequencies suggests that the pressure profiles and resulting stiffness values from the starved model are reasonably accurate but the bearing damping is being over predicted. Additionally, the starved model predicts higher damping ratios than the flooded model for every operating condition tested. Despite the inability to predict pad cavitation due to starvation and any associated decreases in bearing stiffness, the flooded bearing model consistently predicts lower damping ratios and thus, provides a more conservative approach when identifying system stability margins.

The experimental data shows a clear increase in system stability with increasing bearing load and oil supply flow rate. Both the flooded and starved bearing models predict a decrease in system stability with increasing bearing load and oil supply flow rate. Predicted dynamic coefficients from both models show an increase in bearing stiffness and damping with increasing bearing load and oil supply flow rate. While these changes in dynamic coefficients are expected, the resulting changes in system stability are unexpected and oppose the trends seen in the experimental data. The predicted results from both models suggest that the changes to stiffness are dominating the resulting modal properties in the presence of generally over predicted damping values from both models. Lower damping values in both models would act to bring the predicted damping ratios of the two models closer together in the presence of decreased bearing damping observed in the starved model predictions.

For all oil supply flow rates under the nominal load condition, the data shows a drastic decrease in damping ratio with increasing speed not captured by either model. Under the higher load condition both models predict relatively constant damping ratios with varying flow rate for a given speed while the data shows a clear decrease in damping ratio with decreasing oil supply flow rate. If the pressure profiles of the starved model are believed to be reasonably accurate, these trends suggest that some physical phenomenon is occurring in the bearing that is not captured by either model and acts to decrease the system damping ratio. There are many complex occurrences in the bearing such as complex groove mixing of the oil, two-phase flow streamlets in cavitated pad region, and the potential for oil aeration that are not considered by the models. The effects of these types of flow phenomena on bearing dynamics are not readily known and are a topic of future research. More investigations like the one presented here for varying bearing geometries, design types, and operating conditions are necessary for further understanding of these complex flow phenomena and the effects of reduced oil supply flow rate on bearing dynamics.

\subsection{REFERENCES}

[1] Fillon, M., Bilgoud, J.C., and Frene, J., 1993. "Influence of the lubricant feeding method on the thermoelastohydrodynamic characteristics of tilting-pad journal bearings." In Proceedings of the Sixth International Conference on Tribology, Budapest, Hungary, 4, pp. 7-10.

[2] Brockwell, K., Dmochowski, W., and DeCamillo, S., 1994. "Analysis and testing of LEG tilting pad journal bearing- a new design for increasing load capacity, reducing operating temperatures and conserving energy". In Proceedings of the Twenty-Third Turbomachinery Symposium, pp. 43-56.

[3] DeCamillo, S. and Brockwell, K. 2001. "A study of parameters that affect pivoting shoe journal bearing performance in high-speed turbomachinery". In Proceedings of the Thirtieth Turbomachinery Symposium, pp. 9-22.

[4] Dmochowski, W. and Blair, B., 2006. "Effect of oil evacuation on the static and dynamic properties of tilting pad journal bearings". Tribology Transactions, 49(4), pp. 536-544.

[5] DeCamillo, S. M., He, M., and Cloud, C. H., 2008. "Journal bearing vibration and SSV hash". In Proceedings of the Thirty-Seventh Turbomachinery Symposium, pp. 11-22.

[6] Nichols, B. R., Fittro, R. L., and Goyne, C. P., In Press. "Subsynchronous vibration patterns under reduced oil supply flow rates". ASME Journal of Gas Turbines and Power.

[7] Cloud, C. H., 2007. "Stabillity of rotors supported on tilting-pad journal bearings". Ph.D. Dissertation, University of Virginia, Charlottesville, Virginia.

[8] Nicholas, J. C., 1994. "Tilting pad bearing design." In Proceedings of the Twenty-Third Turbomachinery Symposium, College Station, Texas, pp. 179-194.

[9] Nicholas, J. C., Elliott, G., Shoup, T. P., and Martin, E., 2008. "Tilting pad journal bearing starvation effects." In Proceedings of the Thirty-Seventh Turbomachinery Symposium, Houston, Texas.

[10] National Instruments, 2009. "The fundamentals of FFTbased signal analysis and measurement in LabVIEW and LabWindows/CVI." Available at: www.ni.com/white-paper/4278/en

[11]Lee, C. 1991. "A complex modal testing theory for rotating machinery." Mechanical Systems and Signal Processing, 5(2), pp. 119-137. 
[12]Kline, S. J. and McClintock, F. A., 1953. "Describing uncertainties in single-sample experiments." Mechanical Engineering, pp. 3-8.

[13] He, M., 2003. "Thermoelastohydrodynamic analysis of fluid film journal bearings". Ph.D. Dissertation, University of Virginia, Charlottesville, Virginia.

[14]He, M., Allaire, P. E., Barrett, J., and Nicholas, J. C., 2005. "Thermohydrodynamic modeling of leading-edge groove bearings under starved conditions". Tribology Transactions, 48, pp. 362-369.

[15]Barrett, L. E., Gunter, E. J., and Allaire, P. E. 1978. "Optimum bearing and support damping for unbalance response and stability of rotating machinery". Journal of Engineering for Power, 100, pp. 89-94. 


\section{CHAPTER 5: CONCLUSION}

\subsection{CONCLUSIONS}

The following list of final conclusions summarizes the most important observations of this work for the turbomachinery industry for the operation and modeling of tilting-pad bearings under reduced oil supply flow rate conditions.

- The results of this work are specific to the design of the bearings tested- five pad, load-between-pad, tilting-pad bearings in a conventional, flooded housing designs with oil supply nozzles. Many advancements in tilting-pad bearing technology regarding oil delivery methods such as leading-edge grooves and spray-bar blockers have been made that are meant to reduce bearing operating temperatures under lower oil supply flow rates. The effects of oil supply flow rate on the performance of these different bearing designs may differ than those of the design of the bearings tested in this work. While further testing of other bearing designs under reduced flow rates is recommended as a compliment to this work, the bearing designs tested here remain widely used in industry today.

- The bearing specific loads tested in these studies are lower than those typically seen in modern, industrial machines. Results presented under the $124 \mathrm{kPa}$ specific load conditions are considered very lightly loaded by industrial standards. While not as common, some industrial applications call for the high speed, low load conditions tested in these studies. Additionally, it is under these conditions that progressive cavitation of the upper pads is predicted by the starved oil flow bearing model and is of greatest interest for validation of that model.

- While the higher load condition of $365 \mathrm{kPa}$ is still considered relatively low by industrial standards, it was moderate enough to produce distinct differences in bearing performance of the conventional, flooded tiltingpad bearing. The distinction between a very lightly loaded or "no" load bearing and a moderately loaded bearing should be considered while interpreting the results of this work.

- Under high speed, lightly loaded bearing operating conditions, dynamic bearing performance is very sensitive to oil supply flow rate with reduced flow rates resulting in decreased system stability accompanied by severe increases in subsynchronous vibrations at the first bending mode of the shaft in the conventional, flooded bearing design. Oil supply flow rate can be increased to increase system stability and attenuate large subsynchronous vibrations. Higher speeds require higher flow rates to maintain greater system stability.

- Under lightly loaded conditions, the starved bearing model predicts leading edge cavitation of the upper, unloaded bearing pads that increases in severity with increasing speed and decreasing oil supply flow. This progressive decrease in film development over the upper bearing pads results in a redistribution of pad pressures and a lessening of the load imparted on the lower pads.

- Correlation between the decrease in system stability and rise in subsynchronous vibration observed in the 
experimental data and the progressive decrease in hydrodynamic film development with increasing speed and decreasing flow rate suggests that the starved model is accurately predicting the onset and progression of pad cavitation under low flow rate conditions for lightly loaded bearings.

- Under moderately loaded bearing conditions, system stability increases and dynamic bearing performance is much less sensitive to oil supply flow rate. Although decreases in system stability with decreasing flow rate were measured under these loads, higher system stability under lower tested oil supply flow rates were observed in comparison to lightly loaded bearing conditions. The amplitude of the subsynchronous vibration signature occurring at the first bending mode of the shaft is much lower under increased bearing load and is not significantly affected by increasing speed or decreasing oil supply flow rate.

- Under the moderately loaded condition, the starved bearing model predicts nearly identical pressure profiles for all speeds and flow rates tested. Under these conditions, the top three bearing pads are fully-cavitated with full film development over the bottom two pads carrying the load of the rotor. These invariable pressure profiles correlate with the practically constant subsynchronous vibration signature.

- For moderately loaded flooded bearing designs, oil supply flow rate may be reduced in order to decrease operational power losses and increase machine efficiency. Any purposeful starved bearing operation should initially be accompanied by close temperature and vibration monitoring.

- Under both lightly and moderately loaded conditions, the starved model predicts lower damped natural frequency than the flooded model that are in excellent agreement with the measured data. These lower frequencies result from lower predicted bearing damping due to upper pad starvation. These results provide further confidence of the starved bearing model pressure profiles and also suggest that this model accurately calculates bearing stiffness.

- Both the flooded and starved bearing models predicted increases in stability with decreasing load and oil supply flow rate. The opposite trends are observed in the data. It is concluded that both models over predict bearing damping.

- While the experimental data shows an increase in system stability with increased bearing load and increasing oil supply flow rate, results from both the flooded and starved oil flow bearing model coefficients predict the opposite effects. Both models predict increases in bearing stiffness and damping with increased bearing load and increasing oil supply flow rate, as expected. This increased stiffness acts to lower the predicted damping ratios with its effect more influential at higher bearing damping values. It is concluded that both models are likely over predicting bearing damping resulting in trends dominated by bearing stiffness values.

- Under all operating conditions tested, the starved oil flow bearing model consistently results in greater system stability predictions than the flooded oil flow model. Under almost all conditions tested, the starved model results in decreased bearing stiffness and damping due to a decrease in predicted hydrodynamic film development in comparison to the flooded model predictions. It is concluded that the decrease in stiffness of the starved model results in higher predicted damping ratios in the presence of generally over predicted bearing damping values of both models.

- Under moderately loaded conditions, the experimental data shows a clear decrease in system stability with decreasing oil supply flow rate while both models predict negligible changes in system stability with flow rate. If the predicted pressure profiles of the starved oil flow bearing model are believed to be reasonably accurate, which much of the data presented in this work suggests, this observation implies that some other physical phenomena are occurring in the bearing that act to reduce system stability that aren't captured by the simplified bearing models. The effects of two-phase flow of streamlets in cavitated pad regions and potential oil aeration under reduced flow conditions are two possible explanations.

\subsection{RECOMMENDED TEHD MODELING GUIDELINES}

The following guidelines are recommended for evaluating flooded and starved oil flow TEHD bearing model performance predictions under reduced oil supply flow rate conditions based on the observations presented in this work.

- For the conventional, flooded bearing design and envelope of operating conditions tested in this study, the starved oil flow model accurately predicts the onset and extent of pad starvation under reduced oil flow rate conditions. This effect is most noticeable under high speed, low load, low oil supply flow rate conditions.

- In addition to accurately predicting pad cavitation and associated pressure profiles, the starved oil flow model accurately predicts bearing stiffness under low oil supply flow rate conditions.

- The starved model full dynamic coefficients produce more accurate predictions of system damped natural frequencies 
that the flooded model coefficients under low oil supply flow rate conditions due to the increased accuracy of the bearing stiffness predictions.

- Both the flooded and starved oil flow bearing models tend to over predict bearing damping and can result in the over prediction of system damping ratio and stability margin. Additionally, the general over prediction of bearing damping in both models produces inaccurate trends in system stability with regards to changes in bearing load and oil supply flow rate.

- Under lightly loaded conditions, the over prediction of system stability resulting from the starved bearing model worsens with decreasing oil supply flow rate. While still having the tendency to over predict system stability, predicted damping ratios resulting from the flooded bearing model are less sensitive to changes in oil supply flow rate.

- Under moderately loaded conditions, oil supply flow rate has a marginal effect on predicted system stability resulting from both the flooded and staved oil flow bearing models.

- For all operating conditions tested in this study, the flooded model coefficients consistently predict lower system damping ratios than the starved model coefficients, thus providing a more conservative approach when identifying rotor stability margin.

\subsection{CONTRIBUTIONS TO THE FIELD OF TURBOMACHINERY}

The work provides the following contributions to the field of turbomachinery that follow closely with the primary objectives set forth in Chapter 1.

- This work has provides the first study that demonstrates the effects of oil supply flow rate in conventional, flooded bearings on dynamic system modal properties, specifically damped natural frequency and damping ratio, through both experimental measurements and theoretical modeling predictions.

- This work has provides the first study that compares steady-state bearing performance measures experimentally obtained from conventional, flooded tilting-pad bearing designs operating under systematically reduced oil supply flow rates to theoretical predictions from both flooded and starved oil flow TEHD bearing models.

- This work has provides the first study that compares predicted modal parameters (i.e. damped natural frequencies and damping ratios) resulting from the full dynamic coefficients of both flooded and starved oil flow TEHD bearing models to experimentally identified values under varying speed, load, and oil supply flow rate conditions.

- This study has provided recommended guidelines for evaluating flooded and starved oil flow TEHD bearing model performance predictions under reduced oil supply flow rate conditions, most notably, system stability predictions obtained from the dynamic coefficients of both models.

- This study has added to the currently limited body of available experimental data on both the steady-state and dynamic performance of conventional, flooded tilting-pad bearings operating under reduced oil supply flow rate conditions.

\subsection{FUTURE WORK}

The following are recommended as logical next steps for the continued understanding of the effects of oil supply flow rate on tilting-pad bearing performance and potential improvement of the currently available TEHD bearing models.

- Similar studies on additional tilting-pad bearing designs such as leading-edge groove and spray-bar blocker bearings with evacuated housings operating under systematically reduced oil supply flow rates would provide a nice compliment and comparison to the results presented in this work.

- Future investigations performed on the test rig used in this study regarding the effects of oil supply flow rate on bearing performance should be accompanied by the installation of additional instrumentation to measure cavity pressure and pad motion, especially of the upper, lightly loaded pads.

- Further investigations into complex flow phenomena such as hot-oil carryover and oil air entrainment under various speed, load, and oil supply flow rate conditions would help shed further light on some of the results presented in this work and have the potential to help improve the currently available TEHD models.

- If the pressure profiles and damping of the starved oil flow bearing model are believed to be reasonably accurate, which this work suggests, alternative means of calculating damping coefficients should be investigated. The TEHD models currently obtain damping coefficients analytically through the solution of the perturbed Reynolds equation. Perhaps numerical perturbation methods of the pressure solution could be explored and compared to the current results. The effects of assumed perturbation size could also be investigated in numerical perturbation techniques. 


\section{APPENDIX A: SUPPLEMENTARY TEMPERATURES AND VERTICAL SHAFT OPERATING POSITIONS UNDER INCREASED LOAD FOR CHAPTER 2}

Temperature data at the four bearing thermocouple locations and the sump were recorded under an increased bearing specific load condition of $365 \mathrm{kPa}$ at higher operating speeds ranging from 8,000 to $12,000 \mathrm{rpm}$. Those results are presented here. It should be noted that the oil supply flow rates tested under this condition were lower than those presented in Chapter 2 under the $124 \mathrm{kPa}$ bearing load condition. The flow rates presented in this appendix represent rates of 100,80 , and 60 percent of the nominal rate of $3.79 \mathrm{lpm}$. Additionally, predicted changes in vertical shaft operating position from both the flooded and starved oil flow bearing models are presented under the increased load. While this experimental data was not recorded, comparisons to these predictions may be interesting in any future work done on the test rig used in this study.

\section{A.1. PAD TEMPERATURES UNDER HIGH LOAD CONDITION, $365 \mathrm{KPA}$}
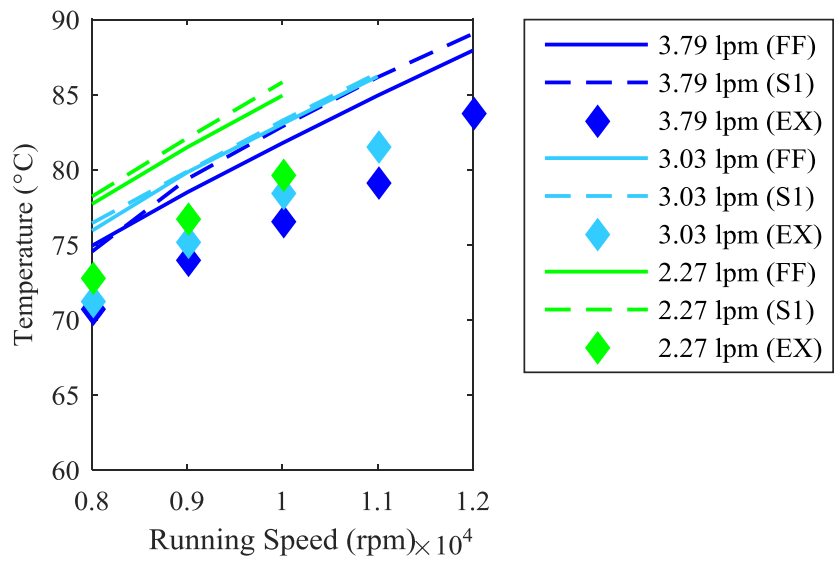

FIGURE A.1. TC 5L MEASURED AND PREDICTED TEMPERATURES, 365 KPA.
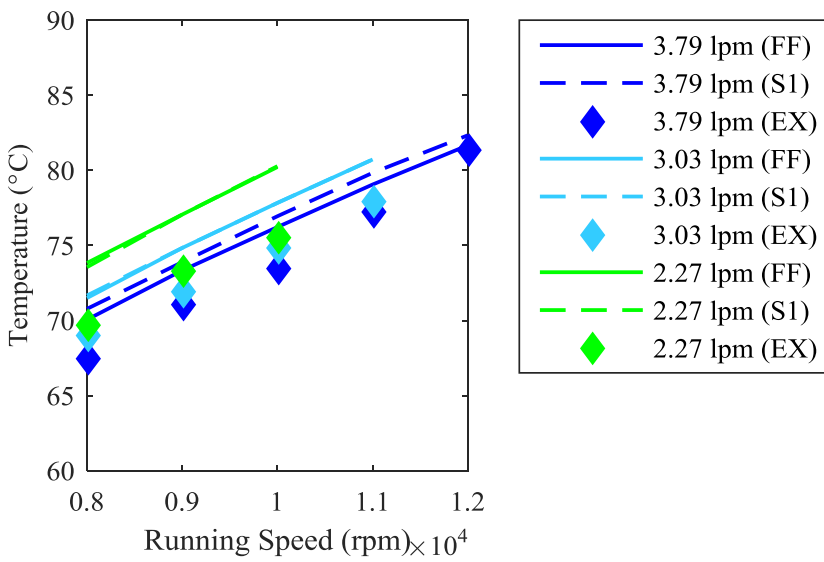

FIGURE A.2. TC 5T MEASURED AND PREDICTED TEMPERATURES, 365 KPA.
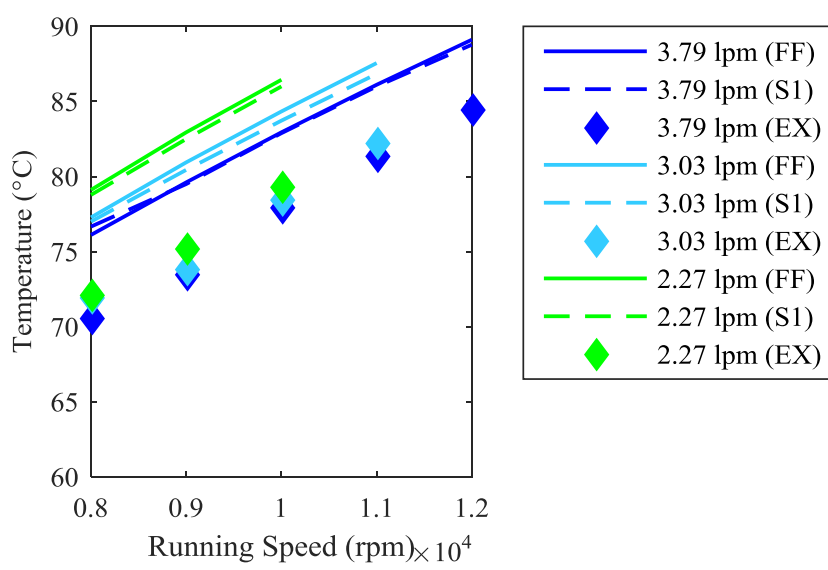

FIGURE A.3. TC 4T MEASURED AND PREDICTED TEMPERATURES, 365 KPA. 


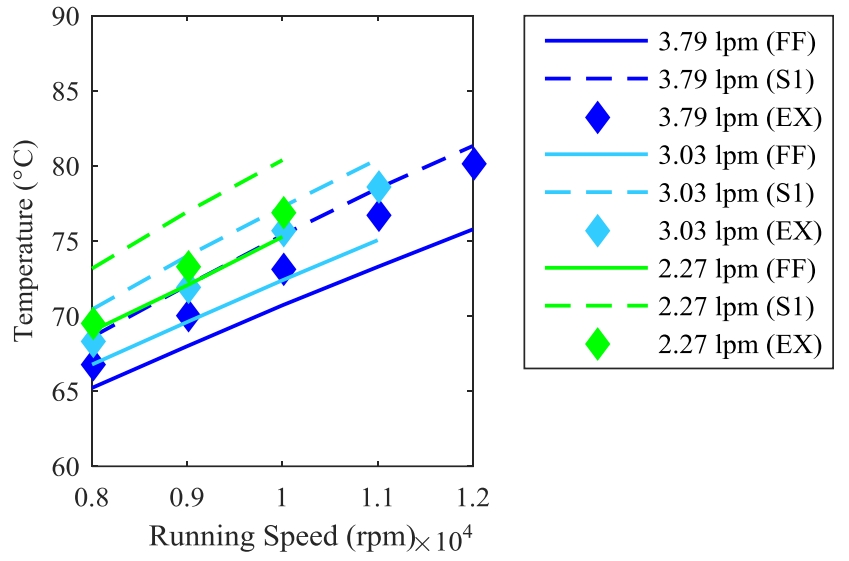

FIGURE A.4. TC 1L MEASURED AND PREDICTED TEMPERATURES, 365 KPA.

\section{A.2. SUMP TEMPERATURES UNDER HIGH LOAD CONDITION, 365 KPA}

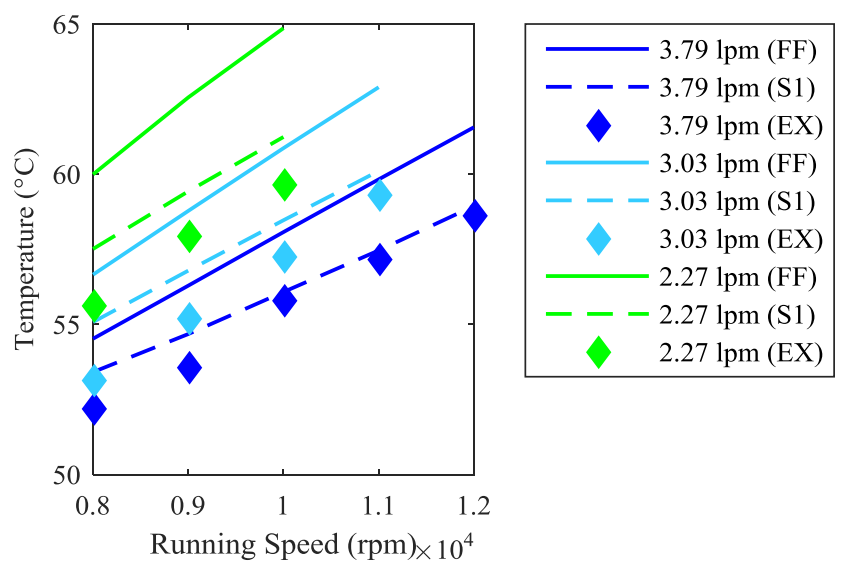

FIGURE A.5. MEASURED AND PREDICTED SUMP TEMPERATURES, 365 KPA.

\section{A.3. STEADY-STATE VERTICAL OPERATING POSITION, 365 KPA}
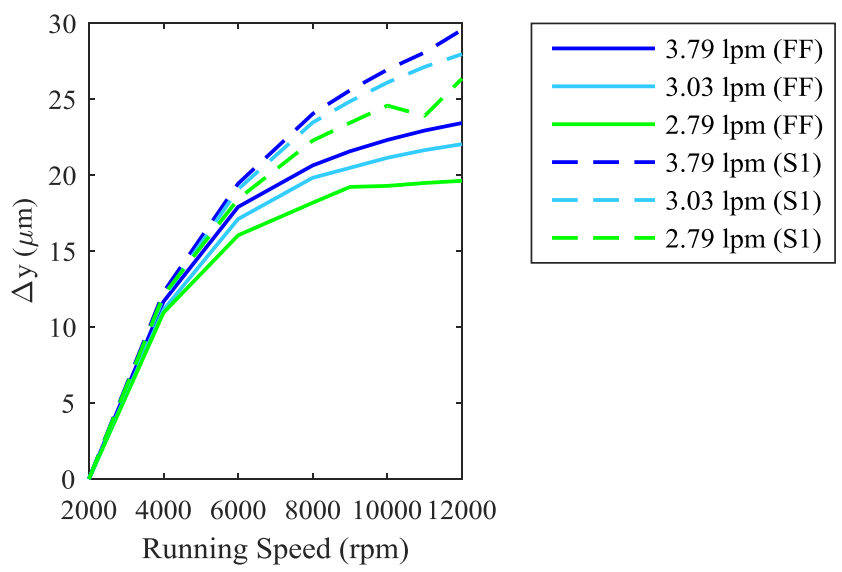

FIGURE A.6. PREDICTED VERTICAL OPERATING POSITION, 365 KPA (2000 RPM, 0.55 ECCENTRICITY RATIO REFERENCE). 


\section{APPENDIX B: SUPPLEMENTARY VIBRATION SPECTRA AND PREDICTED PRESSURE PROFILES PERTAINING TO CHAPTER 3}

A number of measured frequency spectra and starved model predicted pressures profiles corresponding to the various operating conditions listed in the test matrix in Table 3.2 were referenced but not explicitly presented in the text of Chapter 3 for brevity. Those frequency response and pressure plots are presented here. As found in the text, the maximum developed pressure over all pads for all operating conditions pictured in each pressure profile figure is listed in the caption of that figure.

\section{B.1. LOW LOAD, $124 \mathrm{KPA}$, VIBRATION SPECTRA}

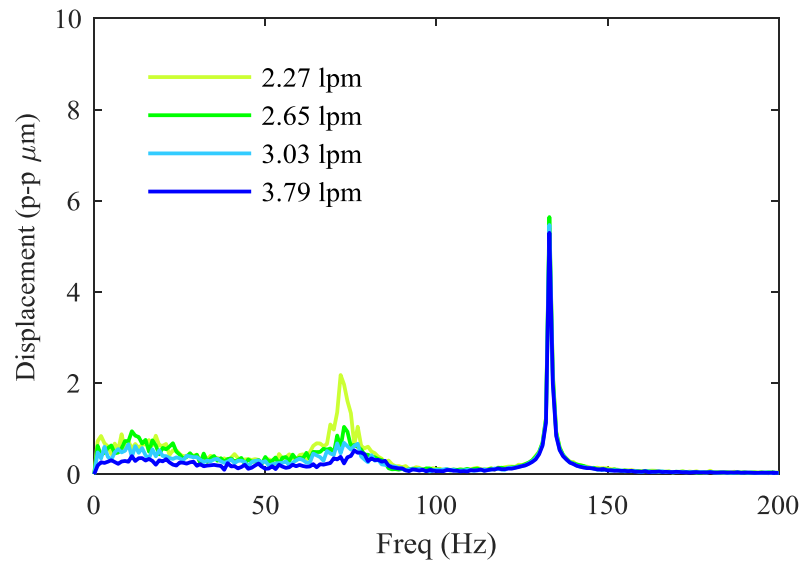

FIGURE B.1. FREQUENCY RESPONSE VS OIL SUPPLY FLOW RATE 0-200 HZ, 8,000 RPM, LOW LOAD.

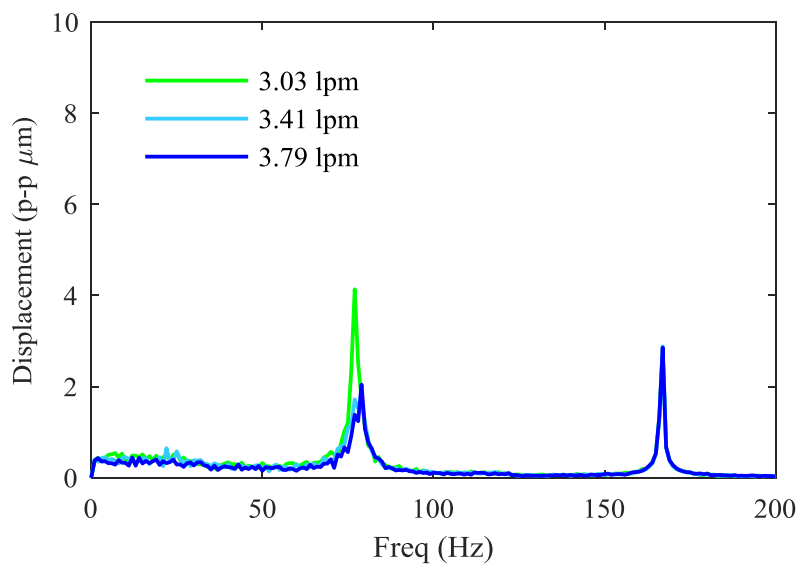

FIGURE B.2. FREQUENCY RESPONSE VS OIL SUPPLY FLOW RATE 0-200 HZ, 10,000 RPM, LOW LOAD.

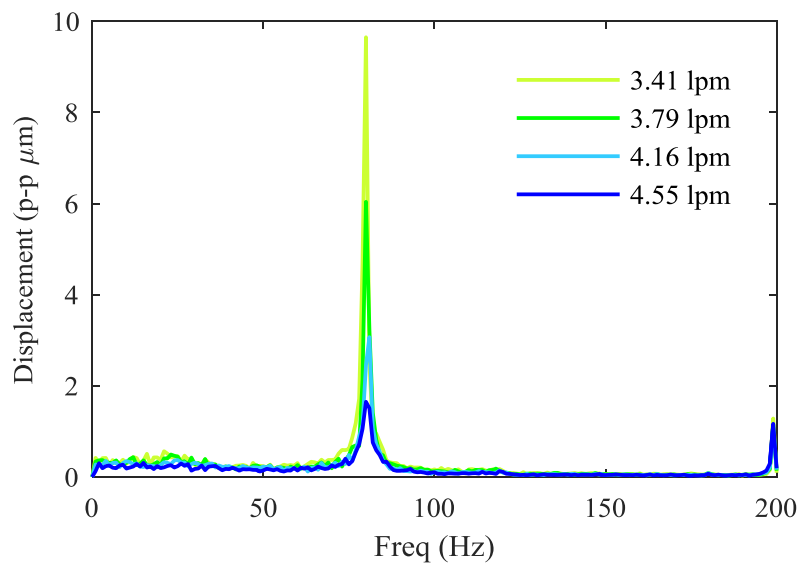

FIGURE B.3. FREQUENCY RESPONSE VS OIL SUPPLY FLOW RATE 0-200 HZ, 12,000 RPM, LOW LOAD. 


\section{B.2. MID LOAD, $241 \mathrm{KPA}$, VIBRATION SPECTRA}

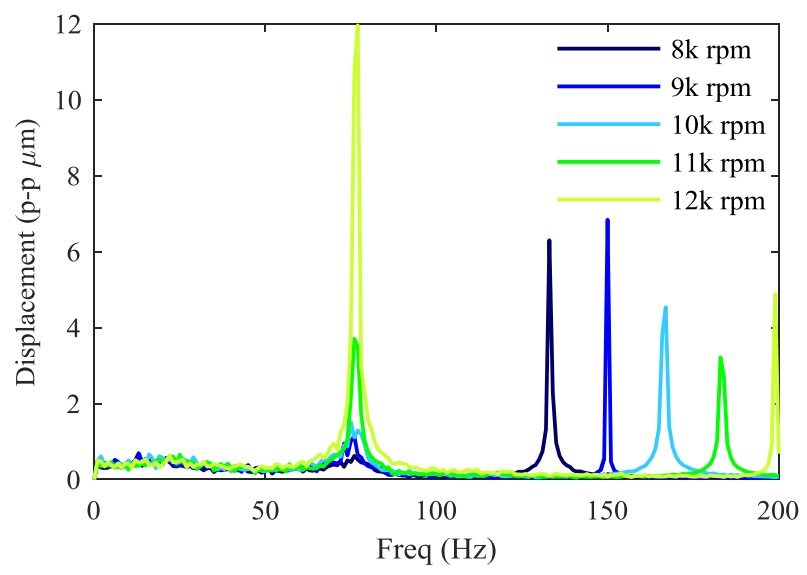

FIGURE B.4. FREQUENCY RESPONSE VS RUNNING SPEED 0-200 HZ, NOMINAL FLOW RATE, MID LOAD

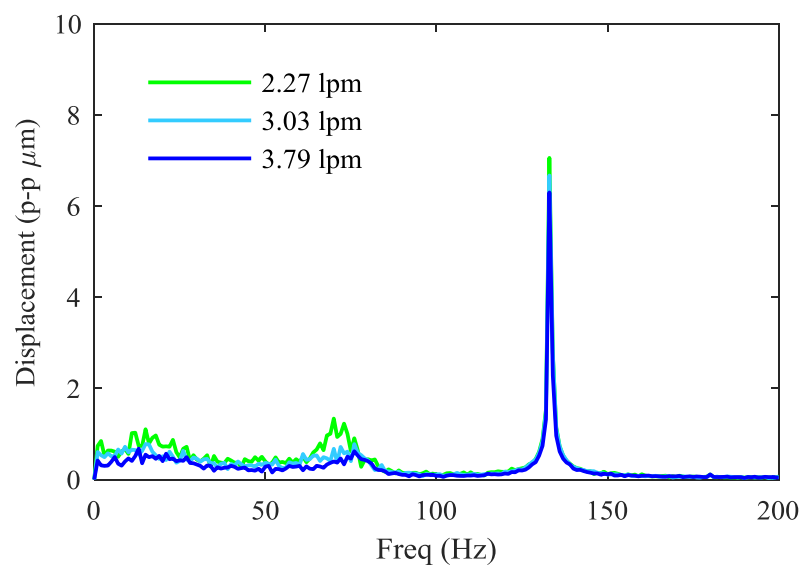

FIGURE B.5. FREQUENCY RESPONSE VS OIL SUPPLY FLOW RATE 0-200 HZ, 8,000 RPM, MID LOAD.

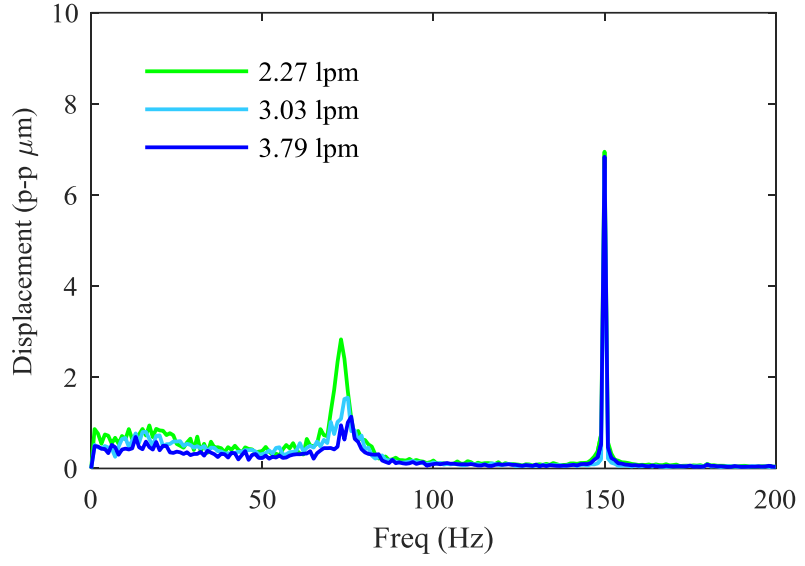

FIGURE B.6. FREQUENCY RESPONSE VS OIL SUPPLY FLOW RATE 0-200 HZ, 9,000 RPM, MID LOAD.

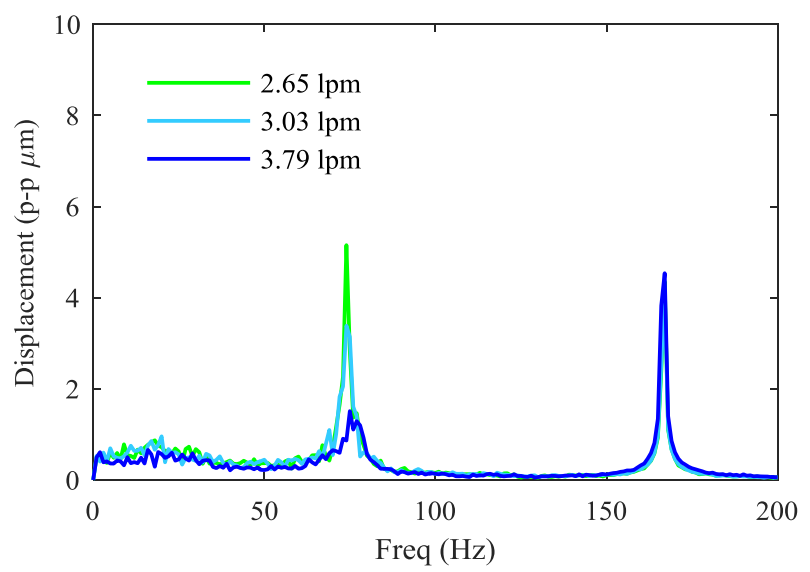

FIGURE B.7. FREQUENCY RESPONSE VS OIL SUPPLY FLOW RATE 0-200 HZ, 10,000 RPM, MID LOAD.

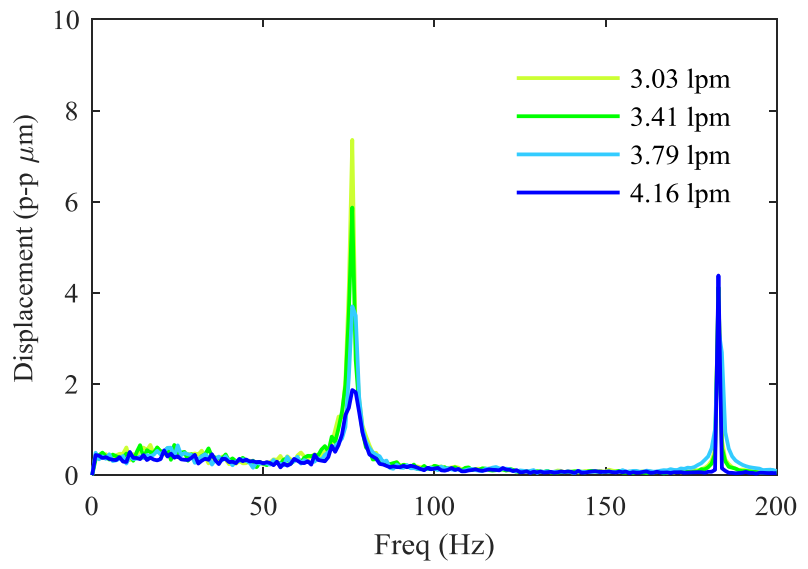

FIGURE B.8. FREQUENCY RESPONSE VS OIL SUPPLY FLOW RATE 0-200 HZ, 11,000 RPM, MID LOAD. 


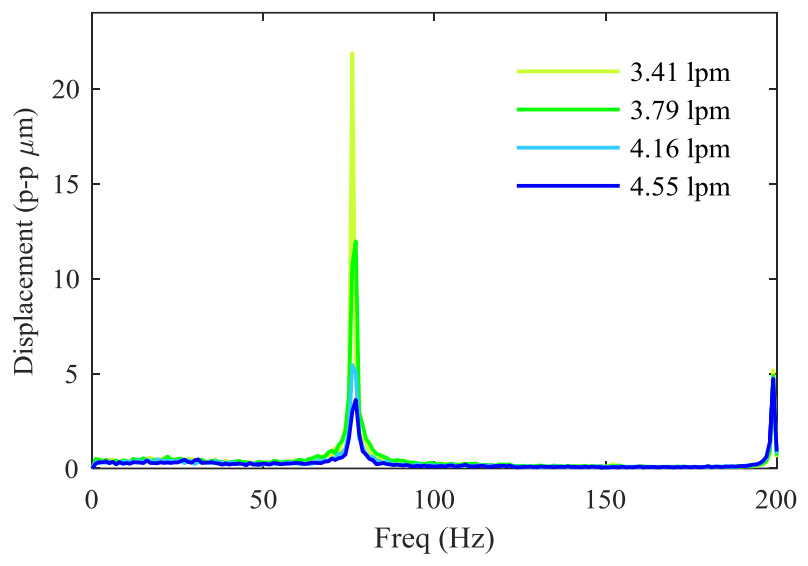

FIGURE B.9. FREQUENCY RESPONSE VS OIL SUPPLY FLOW RATE 0-200 HZ, 12,000 RPM, MID LOAD.

\section{B.3. HIGH LOAD, 365 KPA, VIBRATION SPECTRA}

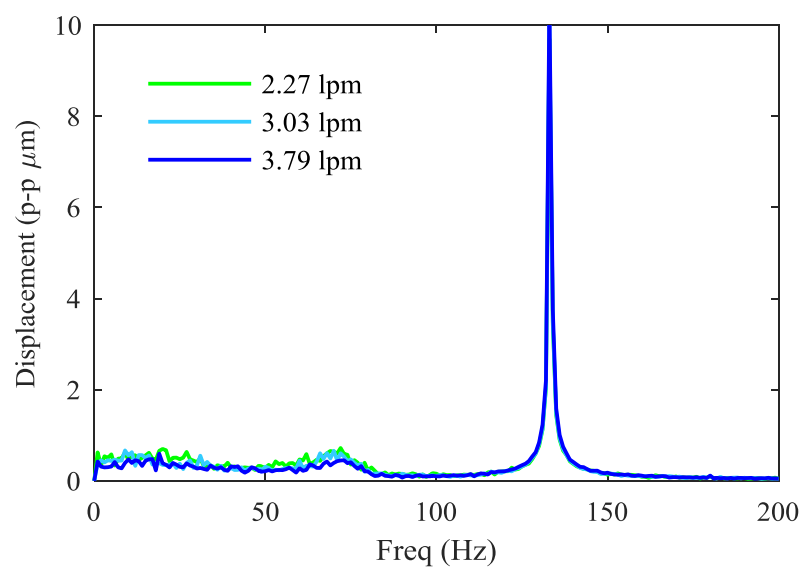

FIGURE B.10. FREQUENCY RESPONSE VS OIL SUPPLY FLOW RATE 0-200 HZ, 8,000 RPM, HIGH LOAD.

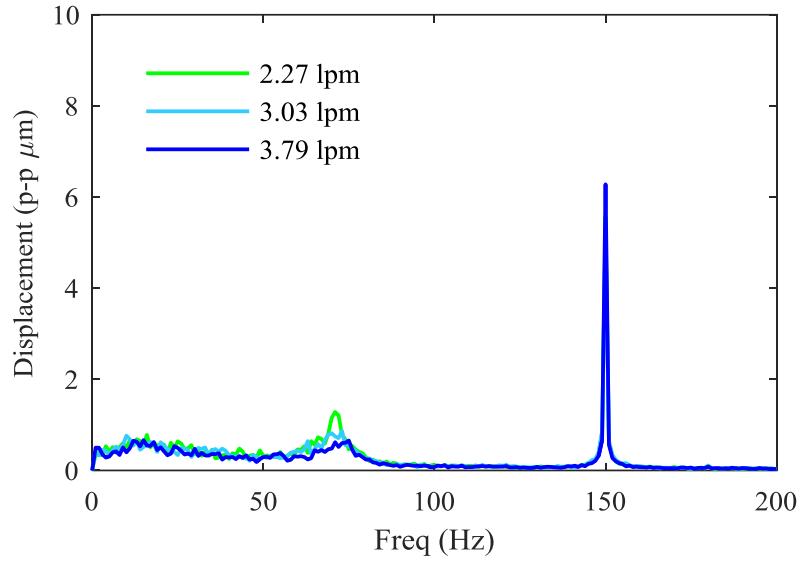

FIGURE B.11. FREQUENCY RESPONSE VS OIL SUPPLY FLOW RATE 0-200 HZ, 9,000 RPM, HIGH LOAD.

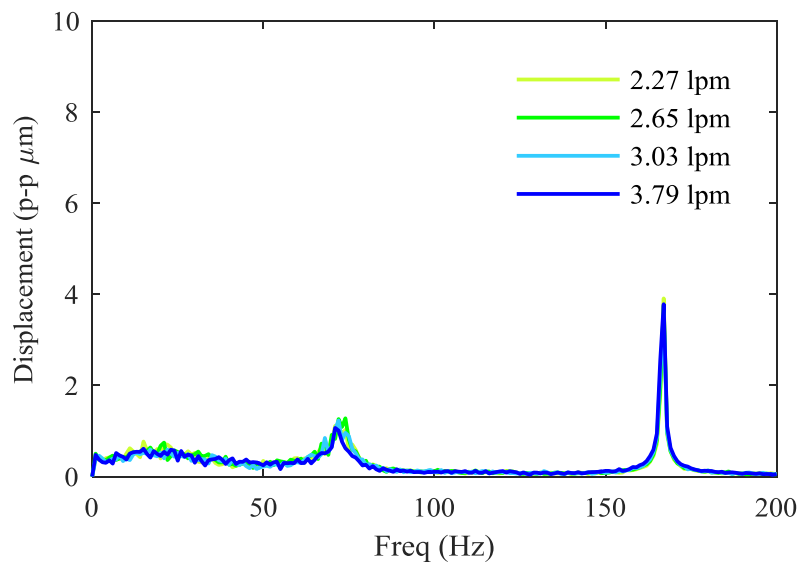

FIGURE B.12. FREQUENCY RESPONSE VS OIL SUPPLY FLOW RATE 0-200 HZ, 10,000 RPM, HIGH LOAD. 


\section{B.4. LOW LOAD, 124 KPA, STARVED MODEL PREDICTED PRESSURE PROFILES}

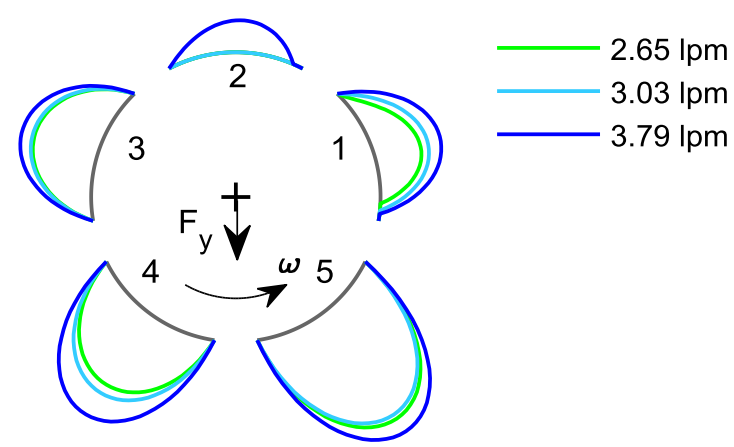

FIGURE B.13. PREDICTED PRESSURE PROFILES VS FLOW RATE, 8,000 RPM, LOW LOAD (581 KPA MAX).

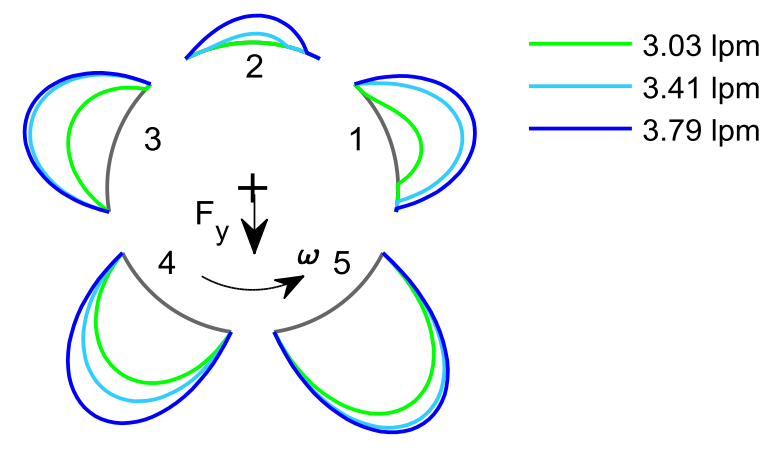

FIGURE B.14. PREDICTED PRESSURE PROFILES VS FLOW RATE, 9,000 RPM, LOW LOAD (557 KPA MAX).

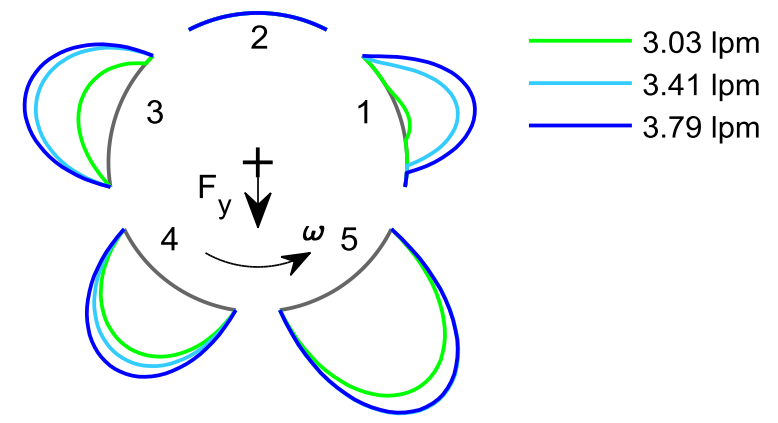

FIGURE B.15. PREDICTED PRESSURE PROFILES VS FLOW RATE, 10,000 RPM, LOW LOAD (543 KPA MAX).

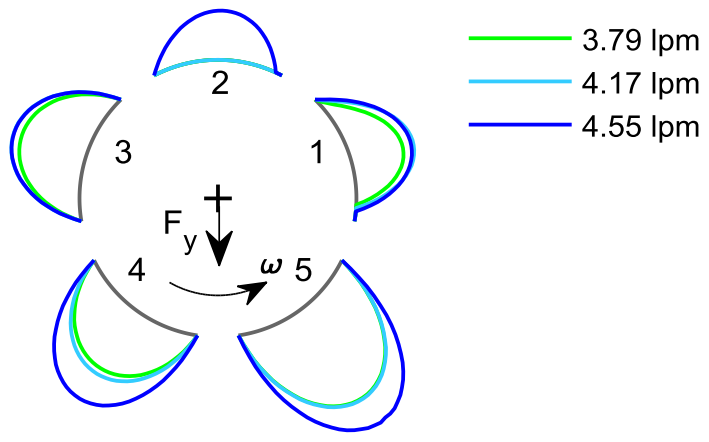

FIGURE B.16. PREDICTED PRESSURE PROFILES VS FLOW RATE, 12,000 RPM, LOW LOAD (717 KPA MAX).

\section{B.5. MID LOAD, 241 KPA, STARVED MODEL PREDICTED PRESSURE PROFILES}

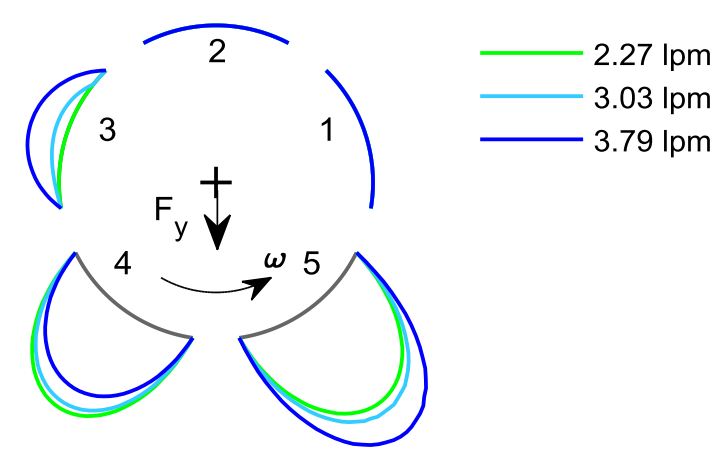

FIGURE B.17. PREDICTED PRESSURE PROFILES VS FLOW RATE, 8,000 RPM, MID LOAD (917 KPA MAX).

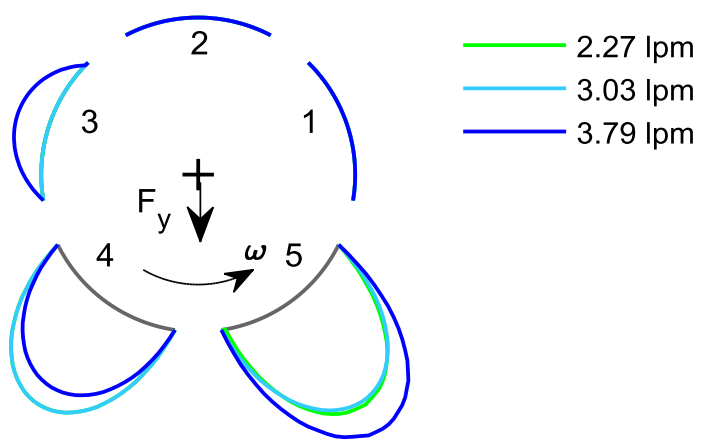

FIGURE B.18. PREDICTED PRESSURE PROFILES VS FLOW RATE, 9,000 RPM, MID LOAD (876 KPA MAX). 


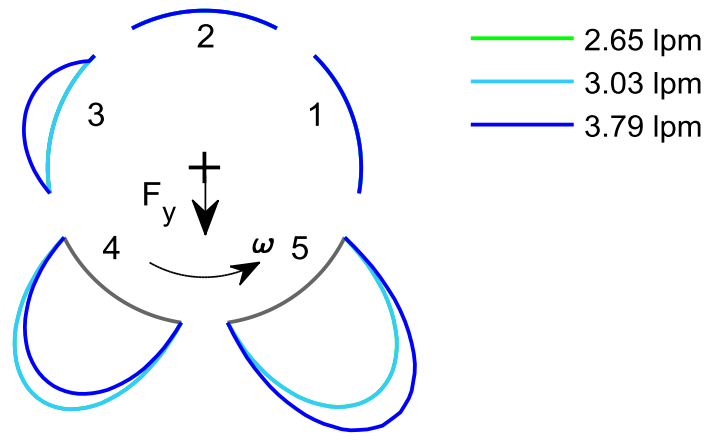

FIGURE B.19. PREDICTED PRESSURE PROFILES VS FLOW RATE, 10,000 RPM, MID LOAD (841 KPA MAX).

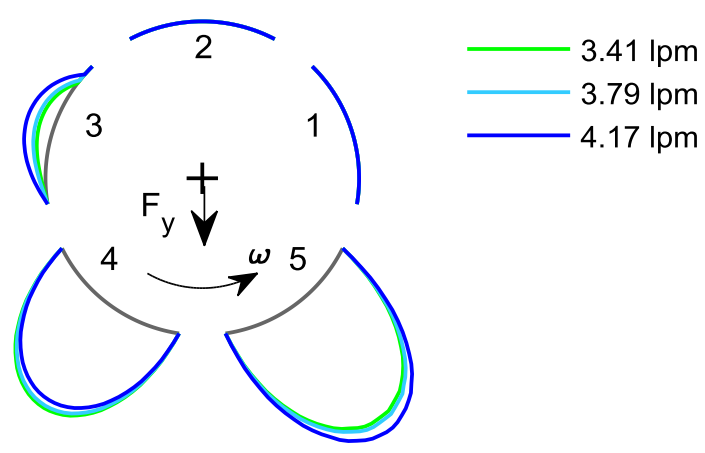

FIGURE B.20. PREDICTED PRESSURE PROFILES VS FLOW RATE, 11,000 RPM, MID LOAD (827 KPA MAX).

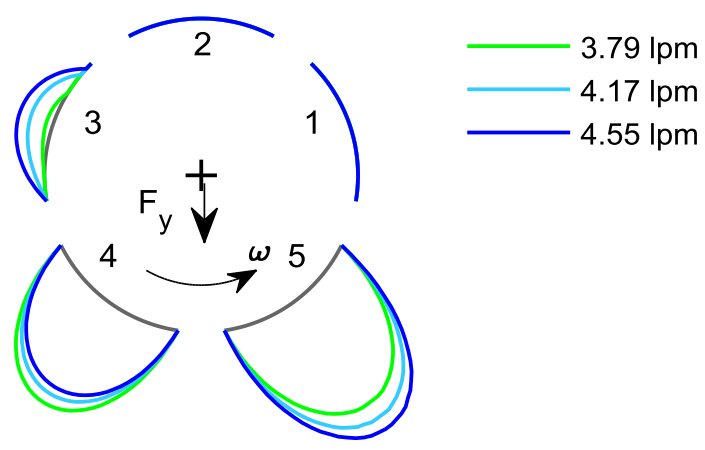

FIGURE B.21. PREDICTED PRESSURE PROFILES VS FLOW RATE, 12,000 RPM, MID LOAD (876 KPA MAX).
B.6. HIGH LOAD, 365 KPA, STARVED MODEL PREDICTED PRESSURE PROFILES

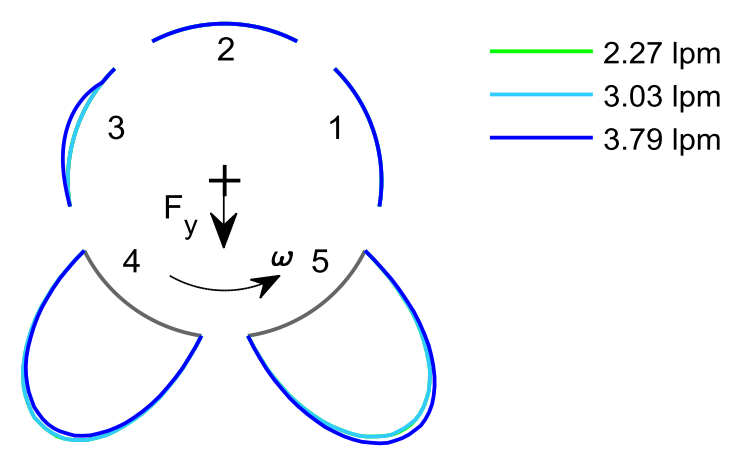

FIGURE B.22. PREDICTED PRESSURE PROFILES VS FLOW RATE, 8,000 RPM, HIGH LOAD (1,089 KPA MAX).

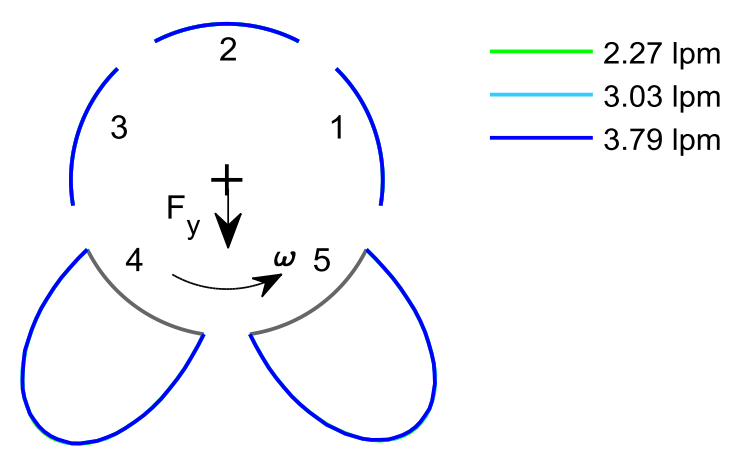

FIGURE B.23. PREDICTED PRESSURE PROFILES VS FLOW RATE, 9,000 RPM, HIGH LOAD (1,041 KPA MAX).

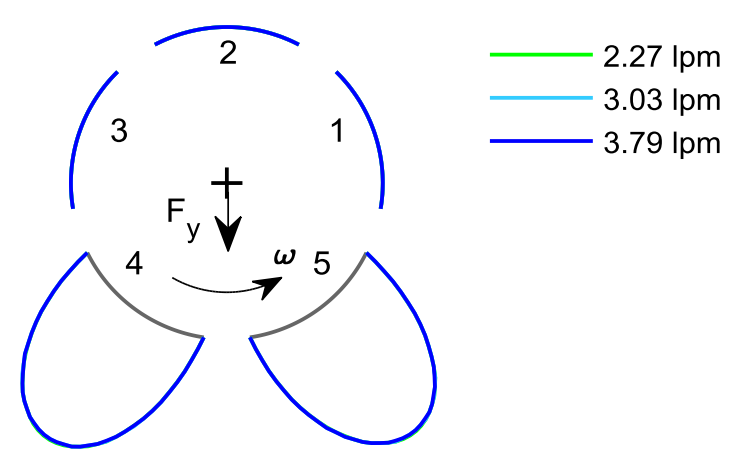

FIGURE B.24. PREDICTED PRESSURE PROFILES VS FLOW RATE, 10,000 RPM, HIGH LOAD (1,041 KPA MAX). 


\section{B.7. PRE-AVERAGED FREQUENCY RESPONSE VS SPEED}

Figures B.25 and B.26 provide an illustration of the raw frequency response spectra versus running speed for the nominal oil supply flow rate and load conditions prior to averaging procedures to reduce noise floor. These graphs provide a better measure of the amplitude of the subsynchronous vibration hash signature amplitude before it is reduced and smoothed through the averaging procedure.

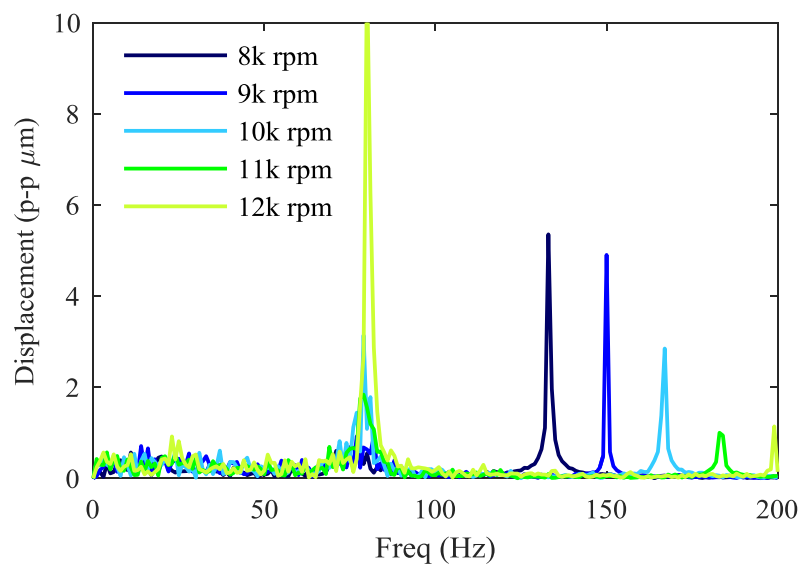

FIGURE B.25. PRE-AVERAGED FREQUENCY RESPONSE VS RUNNING SPEED 0-200 HZ, NOMINAL FLOW RATE, LOW LOAD.

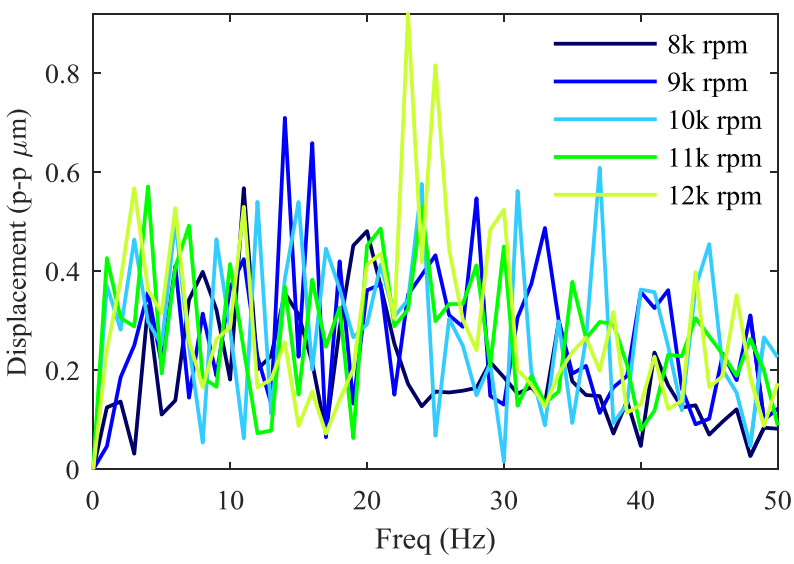

FIGURE B.26. PRE-AVERAGED FREQUENCY RESPONSE VS RUNNING SPEED 0-50 HZ, NOMINAL FLOW RATE, LOW LOAD. 


\section{APPENDIX C: SUPPLEMENTARY PREDICTED DYNAMIC COEFFICIENTS AND DETAILED SYSTEM IDENTIFICATION EXAMPLE FOR CHAPTER 4}

Synchronously reduced vertical stiffness and damping coefficients of both the flooded and starved oil flow bearing models are presented in Chapter 4 to help explain trends seen in the resulting modal properties of the full system analyses. The complimentary horizontal dynamic coefficients are presented here. Additionally, a detailed example is provided which steps through the system identification procedure used to obtain the experimentally identified damped natural frequencies and damping ratios.

\section{C.1. PREDICTED SYNCHRONOUSLY REDUCED HORIZONTAL DYNAMIC COEFFCIENTS}

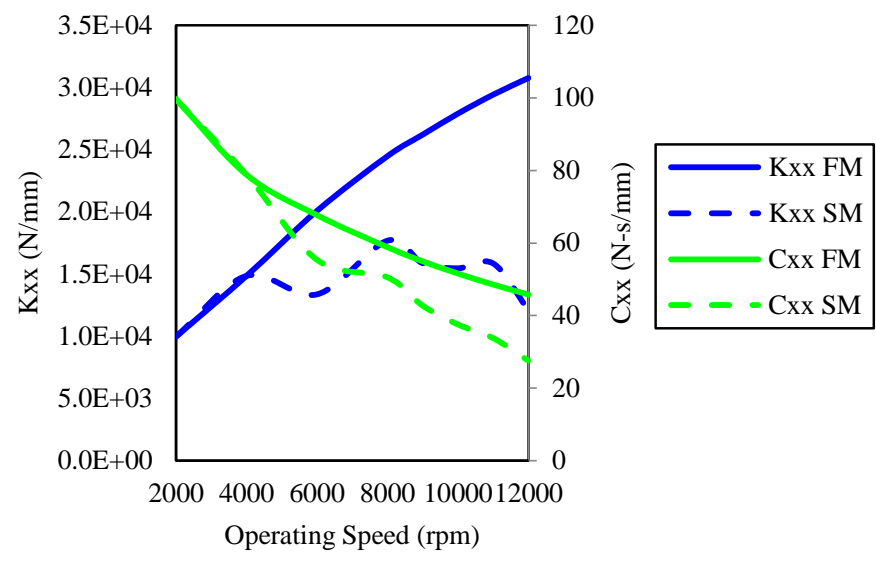

FIGURE C.1. HORIZTONAL STIFFNESS AND DAMPING COEFFICIENTS, 124 KPA SPECIFIC LOAD, 100\% FOW RATE.

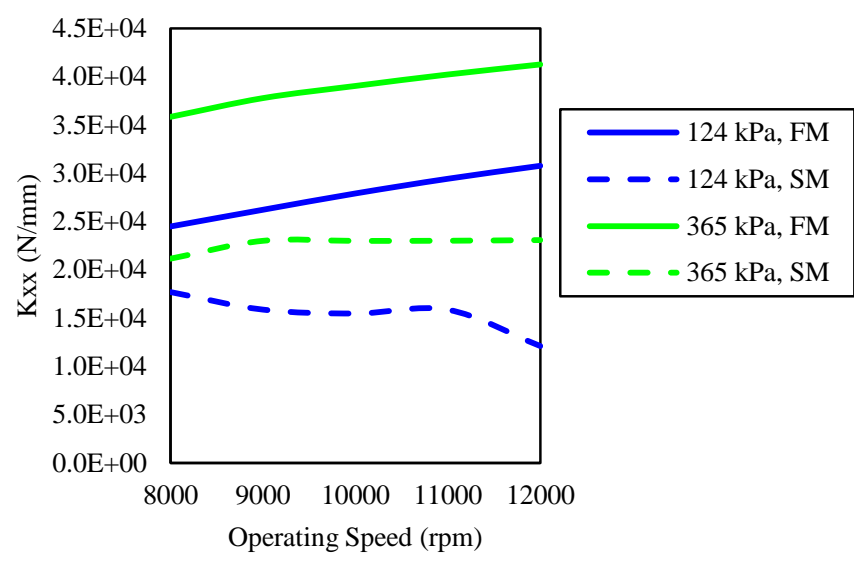

FIGURE C.2. HORIZONTAL STIFFNESS COEFFICIENTS VS LOAD, 100\% FLOW RATE.

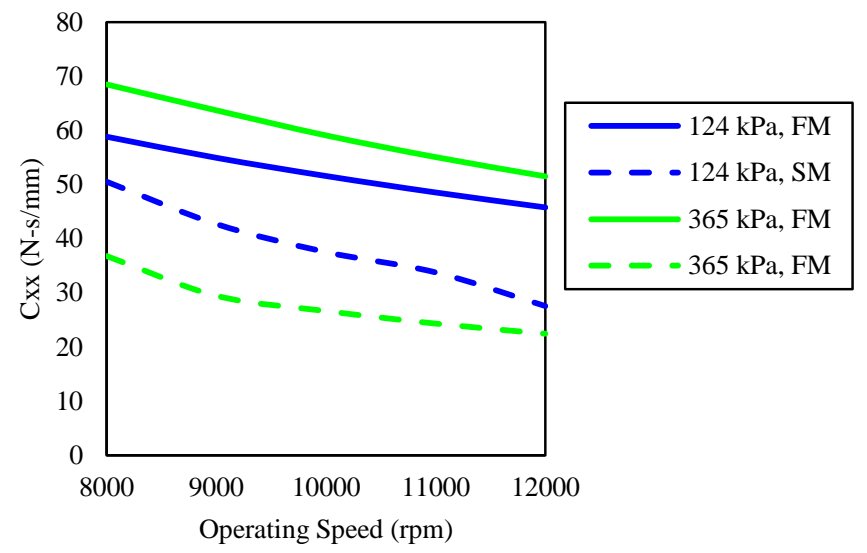

FIGURE C.3. HORIZONTAL DAMPING COEFFICIENTS VS LOAD, 100\% FLOW RATE. 


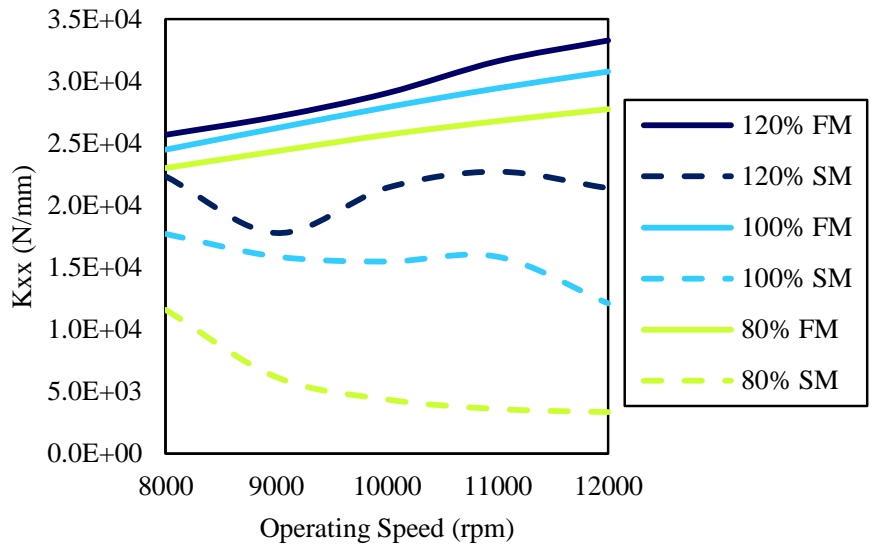

FIGURE C.4. HORIZONTAL STIFFNESS COEFFICIENTS VS OIL SUPPLY FLOW RATE, 124 KPA SPECIFIC LOAD.

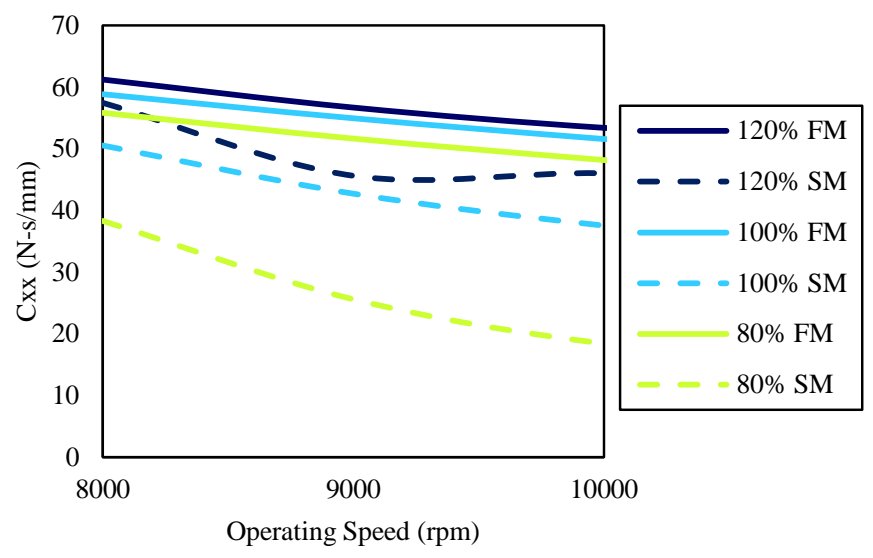

FIGURE C.5. HORIZONTAL DAMPING COEFFICIENTS VS OIL SUPPLY FLOW RATE, 124 KPA SPECIFIC LOAD.

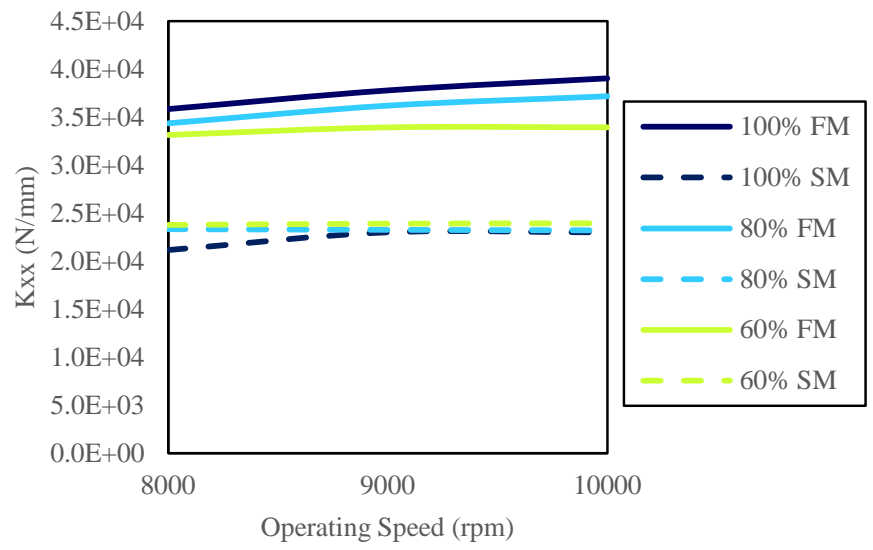

FIGURE C.6. HORIZONTAL STIFFNESS COEFFICIENTS VS OIL SUPPLY FLOW RATE, 365 KPA SPECIFIC LOAD.

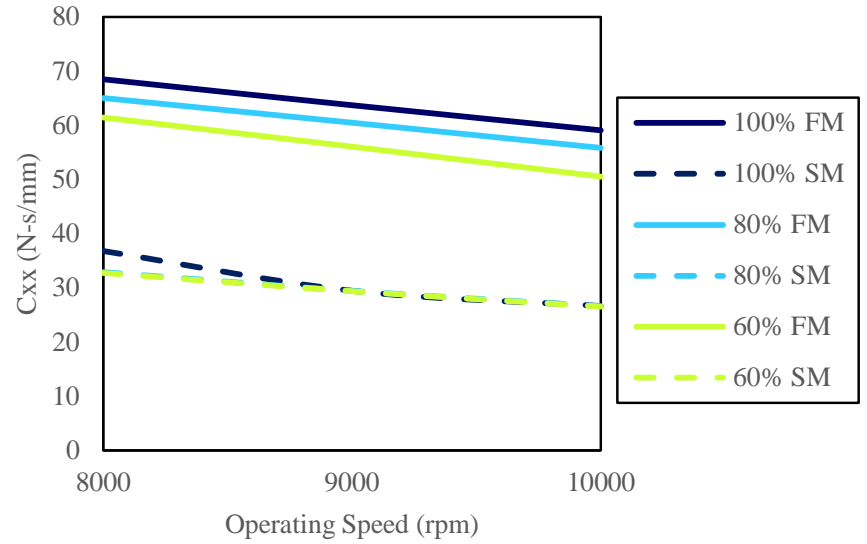

FIGURE C.7. HORIZONTAL DAMPING COEFFICIENTS VS OIL SUPPLY FLOW RATE, 365 KPA SPECIFIC LOAD.

\section{C.2. GRAPHICAL REPRESENTATION OF SYSTEM IDENTIFICATION PROCEDURE}

The system identification procedure used to obtain the experimentally identified damped natural frequencies and damping ratios presented in this work is described in detail in Section 4.4 of Chapter 4. The following provides a graphical representation of this procedure that is meant to more clearly illustrate these more abstract mathematical concepts. Time domain shaker forces in each direction and the shaft's response to those forces in both directions are first collected. Figures C. 8 and C.9 provide an example of the raw data for an electromagnetic shaker force in the $\mathrm{x}$-direction at a frequency of $60 \mathrm{~Hz}$ and the response of the shaft in the $\mathrm{x}$ - and $\mathrm{y}$ directions.

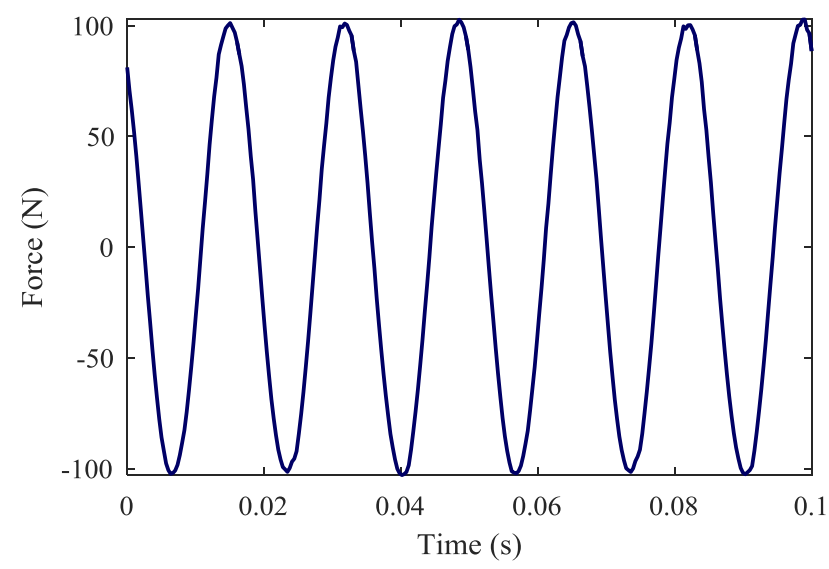

FIGURE C.8. TIME DOMAIN APPLIED FORCE RAW DATA, X-DIRECTION, $60 \mathrm{HZ}$. 


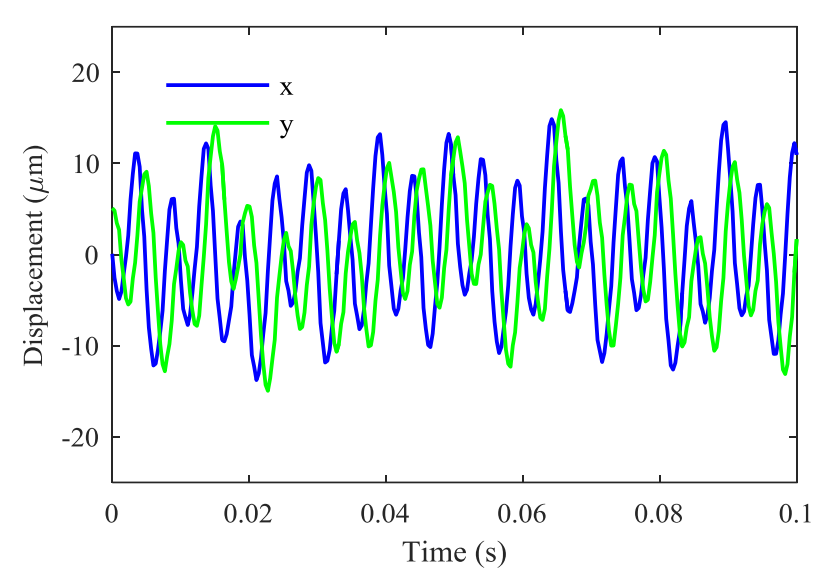

FIGURE C.9. TIME DOMAIN RESPONSE RAW DATA IN BOTH DIRECTIONS.

This raw data in then converted to the frequency domain via the Fast Fourier Transform (FFT). At a sampling frequency of 3,000 Hz, 3,000-point FFTs with a $1 \mathrm{~Hz}$ frequency resolution representing 1 second of data are calculated from the raw data. Seven FFTs at each perturbation frequency are averaged together in order to reduce the random error (i.e. noise floor) of the measurements. Figure C.10 and C.11 illustrate the averaged frequency domain spectra of the perturbation and response signals to a $60 \mathrm{~Hz}$ excitation at an operating speed of 12,000 rpm (i.e. $200 \mathrm{~Hz}$ ). Fig. C10 shows a clean forcing frequency spectrum with a sole $60 \mathrm{~Hz}$ contribution. Fig. C11 shows the response in the $\mathrm{x}-$ and $\mathrm{y}-$ directions which includes a $1 \mathrm{x}$ synchronous running speed contribution at $200 \mathrm{~Hz}$, a subsynchronous component at the first bending mode of the shaft around $80 \mathrm{~Hz}$, broadband subsynchronous hash between 0 and $75 \mathrm{~Hz}$, and the response to the shaker excitation at $60 \mathrm{~Hz}$.

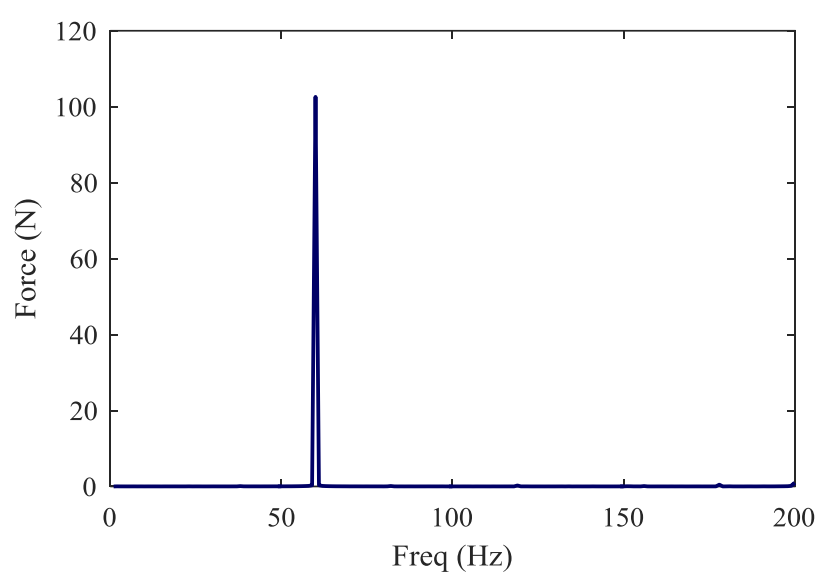

FIGURE C.10. AVERAGED FREQUENCY DOMAIN SPECTRUM OF APPLIED FORCE, X-DIRECTION, $60 \mathrm{HZ}$.

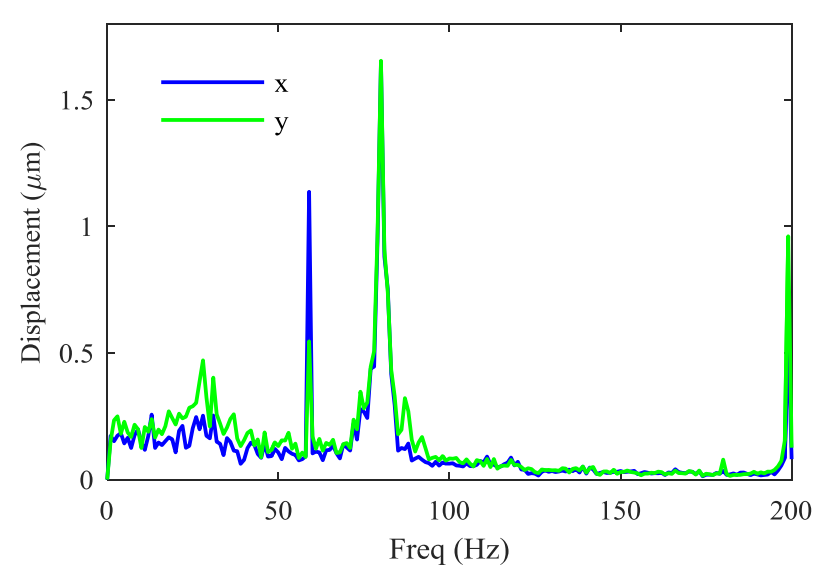

FIGURE C.11. AVERAGED FREQUENCY DOMAIN SPECTRA OF SHAFT RESPONSE.

From these spectra, cross power spectral density functions of the response and stimulus and auto power spectral density functions of the stimulus are calculated as described in Equation 4.1 in Chapter 4 with the value at each excitation frequency representing a single point of the frequency response function (FRF). For the case illustrated above with excitation in the $\mathrm{x}$-direction, this calculation yields discrete points in the $H_{x x}$ and $H_{y x}$ components of the 4x4 FRF matrix at $60 \mathrm{~Hz}$. The $H_{y y}$ and $H_{x y}$ components at this frequency are similarly found through excitation in the y-direction. After repeating this process across the frequency sweep range of interest, a complete FRF matrix is then assembled. Figure C.12 and C.13 illustrate the magnitudes and phases of the $H_{x x}$ and $H_{y y}$ components of the FRF matrix across the frequency 
sweep range. It should be noted that while these plots are presented here as continuous functions, they are in reality discrete points at each excitation frequency.

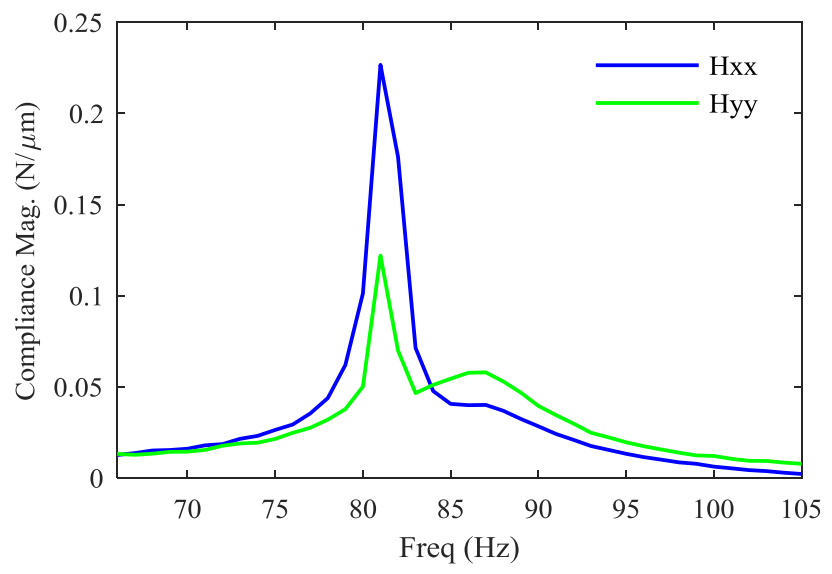

FIGURE C.12. EXPERIMENTALLY FREQUENCY RESPONSE FUNCTION COMPONENT MAGNITUDES (REAL NUMBER FIELD).

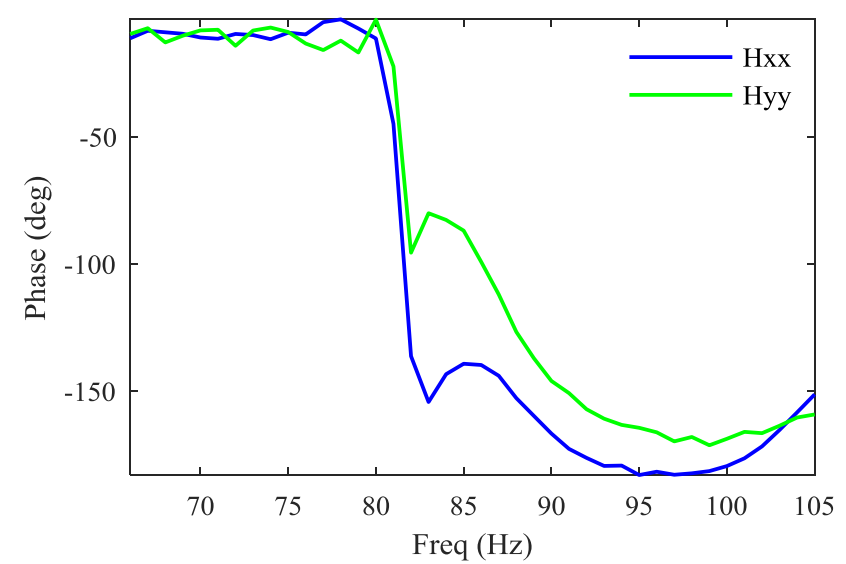

FIGURE C.13. EXPERIMENTALLY FREQUENCY RESPONSE FUNCTION COMPONENT PHASES (REAL NUMBER FIELD).

The power spectral density functions used to calculate these components can also be used to calculate associated coherence functions. The coherence function provides a quantitative measure of how much of the response is attributed to the applied stimulus. A value of 1.0 indicates that $100 \%$ of the response is attributed to the applied stimulus. The previously discussed averaging procedure applied to the force and response spectra is meant to reduce any contributions of the response to noise and to bring the coherence closer to unity. Figure C.14 illustrated the coherence functions of the FRF components presented in Figs. C.12 and C.13. Coherence values for all conditions tested in this work were generally greater than 0.95 indicating very good correlation of response to stimulus and low levels of noise. Slight dips in the coherence can be seen between 80 and $85 \mathrm{~Hz}$ and at $105 \mathrm{~Hz}$. These dips corresponded to the first bending mode of the shaft and a flexible support foundation mode, respectively.

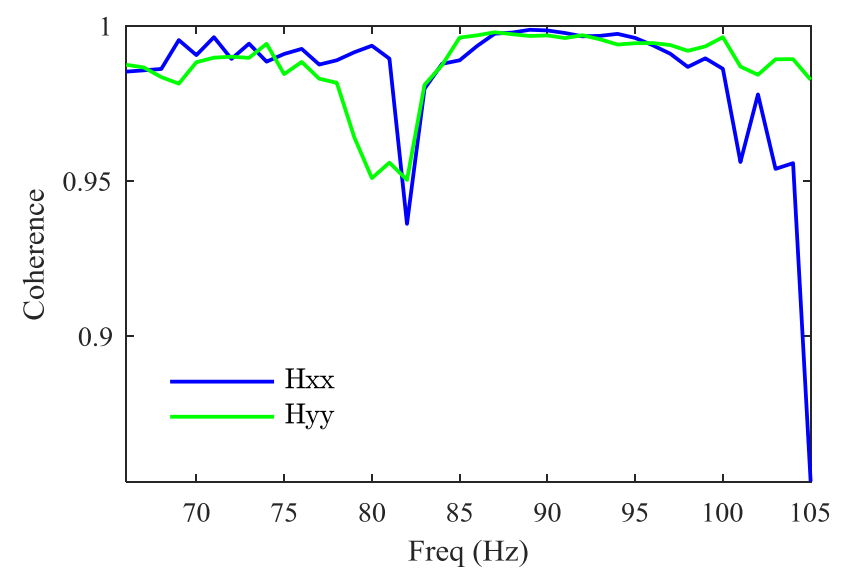

FIGURE C.14. COHERENCE FUNCTIONS FOR FREQUENCY RESPONSE FUNCTION COMPONENTS.

As clearly seen in Figs. C.12 and C.13, both of the primary FRF components contain contributions to both the forward and backward mode with one mode occurring around $82 \mathrm{~Hz}$ and the other occurring around $87 \mathrm{~Hz}$. The real number field FRF is transformed to the complex number field as described in detail in Chapter 4 in order to separate the contributions of these two modes. Figure C.15 illustrates the magnitude of the primary components of the complex number field FRF. As seen in this figure, the contribution of the $82 \mathrm{~Hz}$ mode is now much more isolated in the $G_{r r}$ component of the complex number field FRF. While this mode is still somewhat present is the $G_{\overline{r r}}$ component of the FRF due to cross-coupled response in the system, the contribution to the $87 \mathrm{~Hz}$ mode in more pronounced and isolated in this term. The complex number field FRF is better conditioned for more accurately capturing the modal properties of these two distinct modes through curve fitting procedures. 


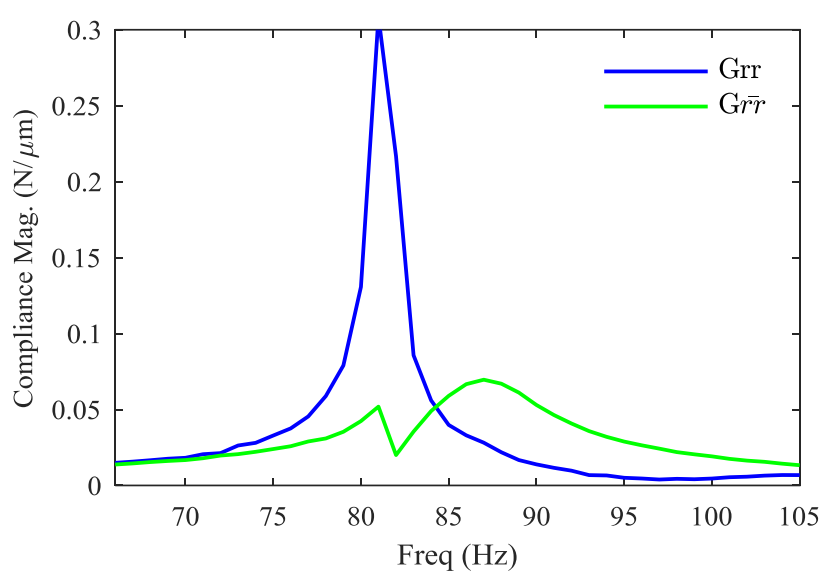

FIGURE C.15. EXPERIMENTALLY OBTAINED FREQUENCY RESPONSE FUNCTION COMPONENT MAGNTIUDES (COMPLEX NUMBER FIELD).

Finally, a fourth-order state-space model is fit to the full $4 \mathrm{x} 4$ complex number field FRF using a prediction-error minimization algorithm. This model provides the experimentally identified modal parameters of the system, specifically, damped natural frequency and damping ratio. Figure C.16 compares the magnitudes of the experimental FRF components presented in the above example to the fit models. As seen here, these models produce a very accurate fit of the experimental data with fit percentages above $90 \%$. The fit models for all identified systems under all operating conditions presented in this study were typically at or above this $90 \%$ mark.

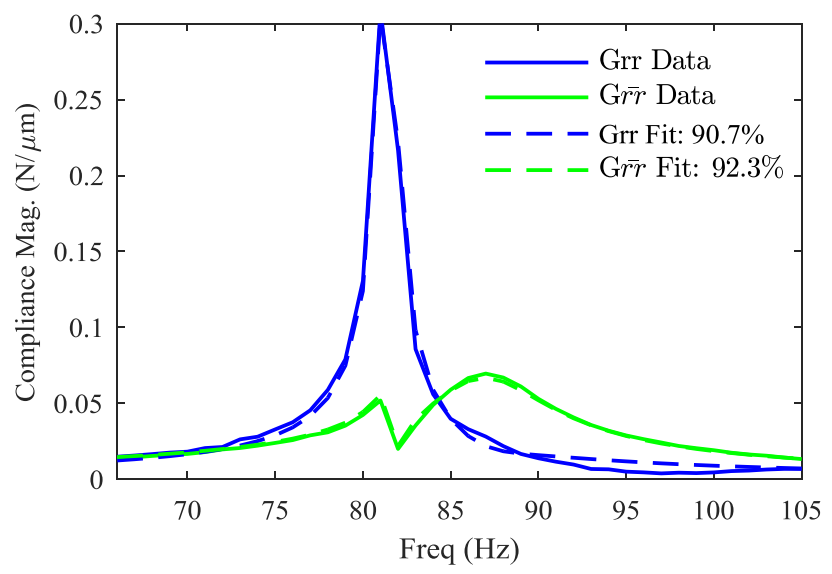

FIGURE C.16. DATA VS CURVE FIT OF FREQUENCY RESPONSE FUNCTION COMPONENT MAGNITUDES (COMPLEX NUMBER FIELD).

\section{C.3. IDENTIFIED DAMPING RATIOS VS OIL SUPPLY FLOW RATE, 124 KPA, HIGH SPEED}

The following graph provides a closer look at the experimental data presented in Figure 4.9 with a focus on the high speed data points that appear close together in the original figure due to the scale of the axes. As reinforced here, a clear decrease in system stability is seen with each decrease in oil supply flow rate. Uncertainties of $\pm 2 \%$ difference in these measured values are illustrated as error bars.

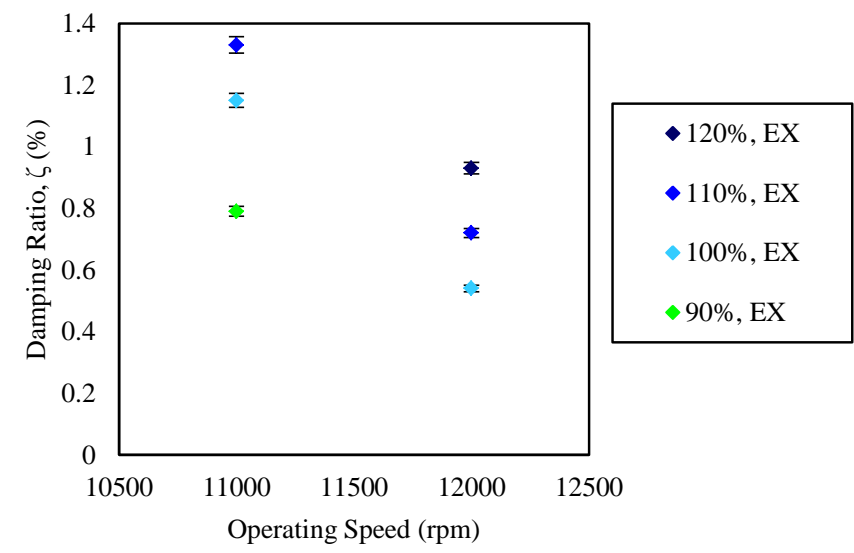

FIGURE C.17. MEASURED DAMPING RATIO VS OIL SUPPLY FLOW RATE WITH ERROR BARS, 124 KPA SPECIFIC LOAD, HIGH SPEEDS.

\section{C.4. REFERENCES}

[1] National Instruments, 2009. "The fundamentals of FFTbased signal analysis and measurement in LabVIEW and LabWindows/CVI." Available at: www.ni.com/white-paper/4278/en 